\title{
DEGRADATIVE STUDIES
}

IN THE

PICROTOXININ SERIES

RAMMOND MAURICE CARMAN

\begin{abstract}
Submitted for the degree
of doctor of philosophy at
\end{abstract}

- RAYMOND MAURTCE CARIAN

The Victoria University of Wellington. 
INTRODUCTION

$\underline{\text { Page }}$

The Carbon Skeleton $\quad \ldots . . \ldots \ldots \ldots \ldots \ldots \ldots . \ldots 3$

The Function Groups $\quad \ldots \ldots \ldots \ldots \ldots \ldots \ldots . \ldots . \ldots$

Recent Advances in Picrotoxinin Chemistry ... 29

DISCUSSION AND EXPRERTMDNTAL

Methyl $\beta$-Bromopicrotoxinate ........... 38

Experimental $\quad \ldots \ldots \ldots \ldots \ldots 696$

$\beta$-Bromopicrotoxinic acid $\ldots \ldots \ldots \ldots \ldots \ldots . \ldots 78$

Experimental $\quad \ldots \ldots \ldots \ldots \ldots \ldots . \ldots \ldots$

$\beta-$ Chloropicrotoxinin $\ldots \ldots \ldots \ldots \ldots \ldots \ldots . \ldots 6$

Experimental $\quad \ldots \ldots \ldots \ldots \ldots \ldots \ldots \ldots . . . .100$

$\beta$-Bromopicrotoxinin with $\mathrm{LiAlH}_{4} \ldots \ldots \ldots \ldots . . . \ldots 3$

Experimental $\quad \ldots \ldots \ldots \ldots 114$

B-Bromopicrotoxinin with MeMgI .......... 118

Experimental $\quad \ldots \ldots \ldots \ldots \ldots 122$

Picrotoxinin dicarboxylic acid $\ldots \ldots \ldots \ldots . . .124$

Experimental $\quad \ldots \ldots \ldots \ldots \ldots 131$

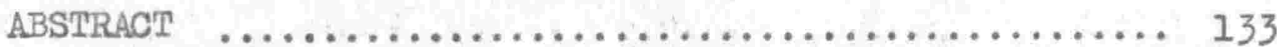

ACKNOWLEDGEMENTS $\ldots \ldots \ldots \ldots \ldots \ldots \ldots \ldots \ldots \ldots \ldots \ldots \ldots \ldots \ldots$ 
INTRODUCTION 
PICROTOXIN is a bitter principle of the berries of the species Mensiperum coculus and Anamirata coculus ${ }^{1}$, creepers which are indigenous to the East Indies. It was first isolated in $1812^{2}$, and subsequent elementary analysis showed that it contained only carbon, hydrogen, and oxygen. Because of its potent poisonous nature and its physiological action, together with its high oxygen content, picrotoxin has often been referred to as an "oxygen alkaloid". It is a central nervous system stimulant ${ }^{3,4}$ and a powerful convulsant drug. ${ }^{5}$ It is used in medicine as an antidote to barbiturate poisoning, 6,7 being still preferred for this purpose over many other drugs.,9 It has also been used in cases of alcoholic intoxication, and as a fish poison. 10

It was found in 1877 that picrotoxin could be split into two parts by bromination of an aqueous solution. 11 The resultant compounds, picrotoxinin and picrotin, were also obtained by fractional crystallization of picrotoxin fram benzene, 12 and considerable discussion ensued as to whether picrotoxin was a true compound or

1. Clark, J.A.C.S. 571111 (1935)

2. Boullay, Bull. Pharm. 4367 (1812)

3. Grumwala. Arch. Bxp. Path. Pharm. 60249 (1909)

4. Marshall et al. J. Pharmacol. 60 A $\frac{96}{42}$ (1937)

5. Kusumoto. Japan J. Med. Sci. $19 \overline{933} 89$

6. C.A. 296951 (1935)

6. Maloney \& Tatum. J Pharm. Bspo. Ther. 44299 (1932)

7. Kohn. J. Am. Med. Ass. 111387 (1938) 3301 (1932)

8. Sita-Lumsden. Lancet 256217 (1949)

9. Newman \& Feldman. Arch. Internal Med. 81690 (1948)

10. Spath 782 (1953)

10. Spath \& Kuffner. Monatsh. 6975 (1936) C.A. 31761 (1937)

11. Paterno \& Oglialoro. Gazz. I 193 (1877)

12. Barth \& Kretsky. Wien. Akad. Ber. 817 (1880) A. 40 (1881) 
an equimolecular mixture of picrotoxinin and picrotin. $13,15,16,17,18$.

It has now been shown to be an equimolecular mixture, $19,20,21$

The first reproducible separation of the constituents of picrotoxin was carried out in 1898. 22 Molecular weight and combustion determinations ${ }^{23}$ gave $\mathrm{C}_{15}{ }_{15}{ }^{\circ}{ }^{\circ}$ as the formula of picrotoxinin and $\mathrm{C}_{15} \mathrm{H}_{18} 8_{7}$ as that for picrotin.23a Both these compounds were found to be optically active, but only picrotoxinin was physiologically active. 24

Much research has gone into the elucidation of the structures of the picrotoxin family, and considerable advance has been made in the determination of the picrotoxinin structure. However, picrotoxin derivatives have been found to undergo complex and unusual rearrangements, and further work is necessary before many of these derivatives can be satisfactorily formulated.

13. Barth \& Kretsky. Monatsch Chem. 2796 (1881)

14. Barth \& Kretsky. Monatsch Chem 5 65 (1884)

15. Patemo \& Oglialoro. Gazz. $10 \frac{46}{36}$ (1880)

16. Paterno \& Nasini. Gazz. $16 \overline{262}$ (1886)

17. Schmidt \& Lowenhardt. Ber. $14 \quad 817$ (1881)

18. Schmidt. Annalem 222313 (1883)

19. Sielisch. Annalem 391 (1912)

20. Bakunin \& Giordani. Rend. Accod. Sci. Fis. Mat. Nepeli. 30 iii 166 (1924

\section{A. 128 i 691 (1925)}

21. Hansen \& Jerslev. Dansk. Tidsskr. Farm. 28 (1954)

22. Meyer \& Bruger. Ber. 31 2958 (1898)

23. Horrmam Ber. 45 2090 (1912)

23a. Oglialoro and Forte. Gazz. 2lii 213 (1891)

24. Kohn.J. Am. Pharm. Assoc. 2728 (1938) 
THE CARBON SKELETON

A Iarge number of degradative reactions have been carried out upon picrotoxinin and picrotin and their derivatives in an attempt to elucidate the carbon skeleton. Three main types of degradation have been used. (a) "Classical" degradations which produced chiefly aromatic substances, and which involved reactions such as reduction with hydriodic acid and red phosphorus, oxidation with permanganate, and fusion with potassium hydroxide. These reactions were carried out between 1900 and 1939 by the following workers:

Angelico $25-31$
Hormann $23,32-43$
Hansen 44
Tettweilex \& Drishaus 45
Robertson $46-49$

25. Angelico. Gazz. $36 i j$ 645 (1906)

26. Angelico, Gazz, 39i 296 (1909)

27. Angelico. Gazz. 40i 391 (1910)

28. Angelico. Atti. ‥ Acad. Lincei. 19 vi 473 (1910) A. $28 i$ 577 (1910)

29. Angelico. Gazz. 4l ii 377 (1911)

30. Angelico. Gazz. 42 ii 540 (1912)

31. Angelico \& Monforte. Gazz, 53800 (1923)

32. Horrmann. Ber. 431903 (1910)

33. Hormann \& Seydel. Ber. 453080 (1912)

34.4 Hormann. Ber. 45 3434 (1912)

35. Hormann. Ber. 1662793 (1913)

36. Hormam. Ann. 411 273 (1916)

37. Horrmann \& Wachter. Ber. 49 1554 (1916)

38. Horrmann. Ber. 492107 (1916)

39. Horrmann \& Prillwitz. Arch Pharm, 258 200 (1920)

40. Hormann \& Hagendorn. Arch. Pharm. 259 7 (1921) 
(b) Alkaline degradations resulting in the production of aliphatic compounds by...

Sutter \& Schlittler $50-54$

$$
\text { Slater } 55-59 \text {. }
$$

(c) The thermal degradation to picrotoxadiene by Conroy $60-62$.

41. Horrmann \& Behschnidt. Arch. Pharm. 259 69 (1921)

42. Horrmann \& Bischoff. Arch. Pharm. 259 165 (1921)

43. Horrmann \& Thilo. Arch. Pharm, 273433 (1935)

44. Hansen. Ber. $66 \quad 849$ (1933)

45. Tettweiler \& Drishaus. Ann. $520 \quad 163$ (1935)

46. Mercer, Robertoon \& Cahn. J.C.S. 1935997

47. Mercer \& Robertson.J.C.S. 1936288

48. Harland \& Robertson. I.C.S. 1939937

49. O'Donnell, Robertson \& Harland. I.C.S. 19391261

50. Sutter \& Schlittler. Helv, Chim. Acta. 30403 (1947)

51. Sutter \& Schlittler. Helv. Chim. Acta. 302102 (1947)

52. Sutter \& Schlittler. Helv. Chim. Acta. 321855 (1949)

53. Sutter \& Schlittler. Helv. Ghim. Acta. 221860 (1949)

54. Sutter \& Schlittler. Helv. Chim. Acta. 33902 (1950)

55. Slater. J.C.S. 1949806

56. Slater \& Wilson. Nature $167 \quad 324 \quad$ (1951)

57. Slater et a.. J.C.S. 19521042

58. Slater \& Wilson. J.C.S. 19521597

59. Slater et 21. J.C.S. 19522292

60. Conroy. J.A.C.S. $73 \quad 1889$ (1951)

61. Conroy. J.A.C.S. 14491 (1952)

62. Comroy. J.A.C.S. $743046 \quad$ (1952) 
Aromatic Degradations

Many of the degradative attempts of earlier workers failed due to either the employment of picrotoxin as a starting material or to the use of too violent a degradative route. Schmidt ${ }^{18}$ obtained no definite results from either zine dust or soda lime distillation, and the first real Indic ation of the nature of the carbon skeleton was not ob tained until Angelico ${ }^{29}$ treated both picrotoxinin and picrotin with boiling hydriodic acid and red phosphorus. In both cases the same products, an acid named picrotic acid, $\mathrm{C}_{15} \mathrm{H}_{18} \mathrm{O}_{4}$, and a ketone known as picrotone, $\mathrm{C}_{14} \mathrm{H}_{1} 6_{3}$, were formed. It was assumed that migrati on of carbon atons had not occurred during the rather fierce reduction, and thus it followed that both picrotoxinin and picrotin possessed the same carbon skeleton. This view was supported by the formation of the same chloroketone, $\mathrm{C}_{14} \mathrm{H}_{1} 3_{3} \mathrm{O}_{3} \mathrm{Cl}$, from either picrotoxinin or picrotin on treatment with hydrochloric acid at $180^{\circ} \mathrm{C}^{28}$

Oxidation of picrotic acid with alkaline permanganate gave a dibasic acid $\mathrm{C}_{12} \mathrm{H}_{10} \mathrm{O}^{2}{ }^{29,30}$ named Angelico's acid. The same acid was also obtained by oxidation of picrotoxinin and picrotin with manganese dioxide and sulphuric acid. 44 The structure of picrotic acid, eventually formulated as I by Robertson, 46 was elucidated as follows:
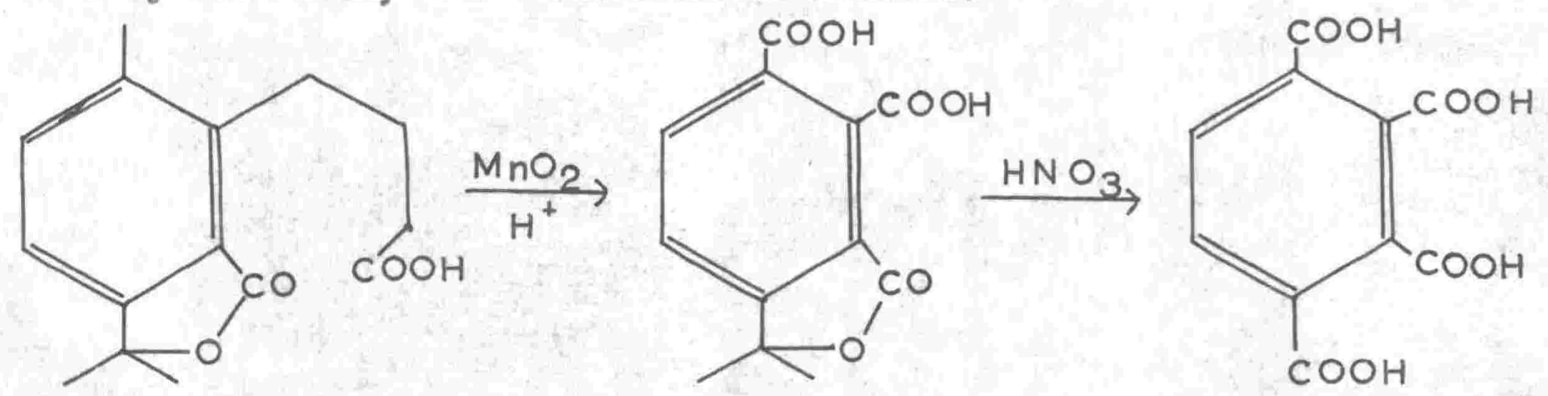

I. Picrotic acid

$$
\begin{gathered}
\text { Angelico's acid } \\
\text { via imide }
\end{gathered}
$$$$
1: 2: 3: 4 \text { - Benzene }
$$$$
\text { tetracarboxylic acid. }
$$

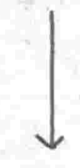




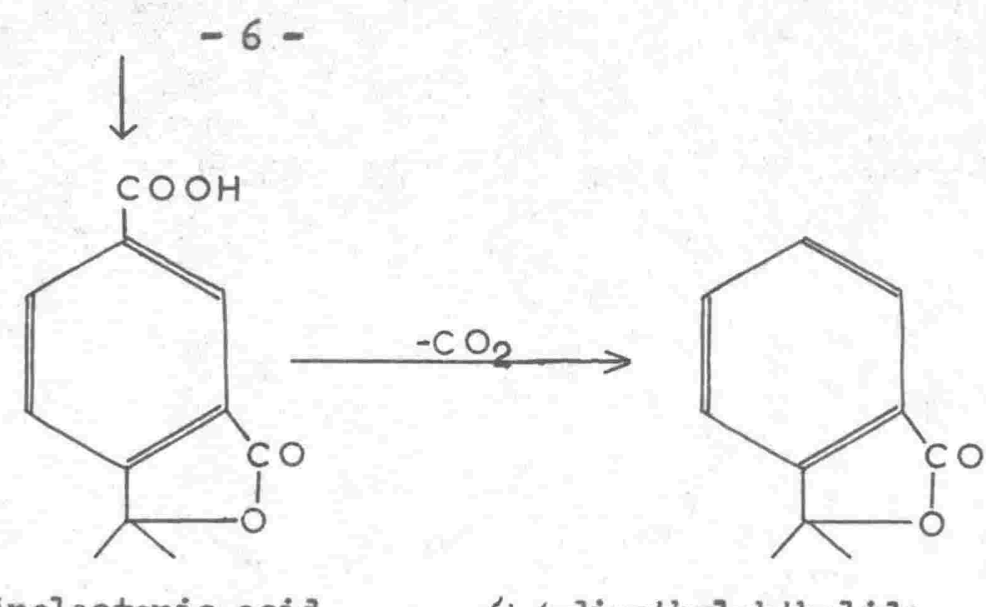

Cannabinolactonic acid

$\alpha: \alpha$-dimethylphthalide

Further evidence as to the structure and orientation of picrotic acid was given by the following series of reactions. 31,46

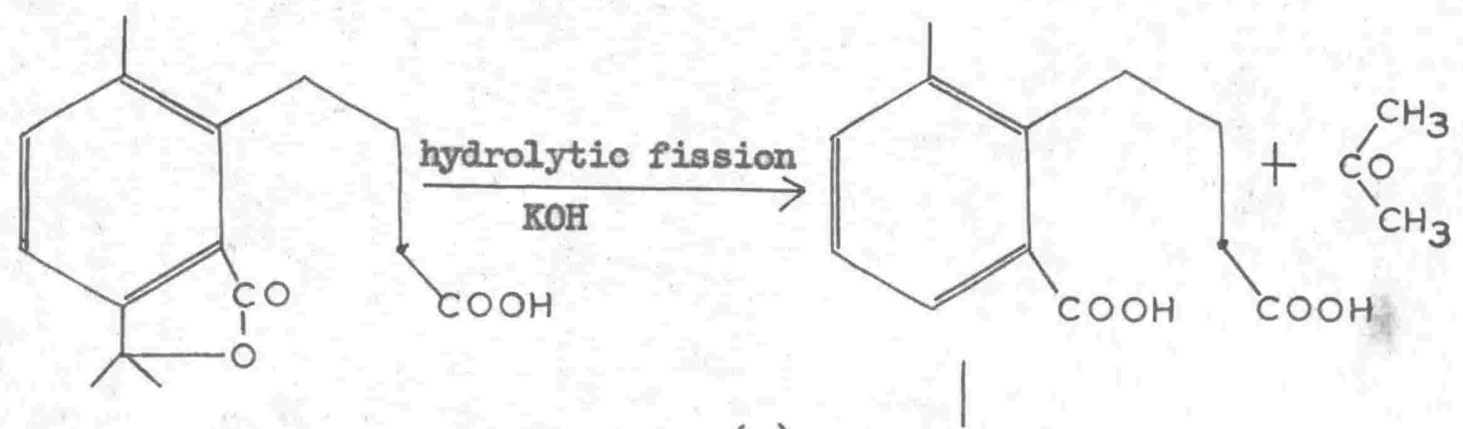

picrotic acid

(a) esterification

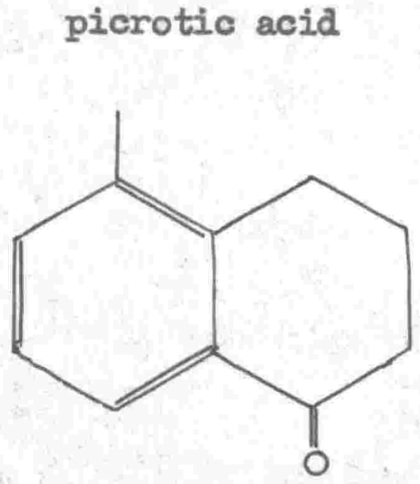

(a) hydrolyse

(b) Diekmamn cyclisation

(b) decarboxylate

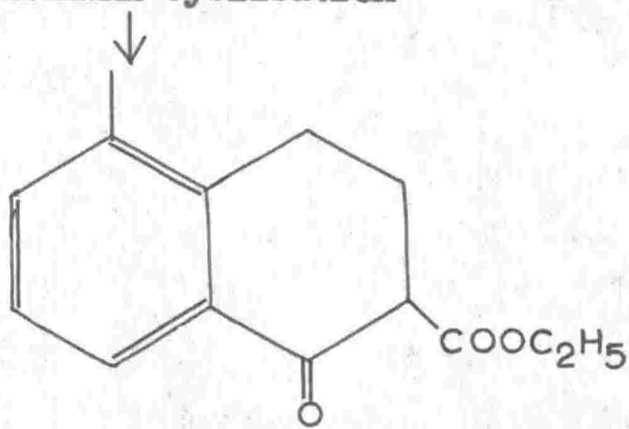

5-methyl tetral-1-one

The product from these reactions was identical to 5-methyl tetral1-one synthesised from $\gamma$-o-tolylbutyric acid.

The structure of the aromatic methyl ketone, picrotone, formed in conjunction with picrotic acid, was established as follows: 


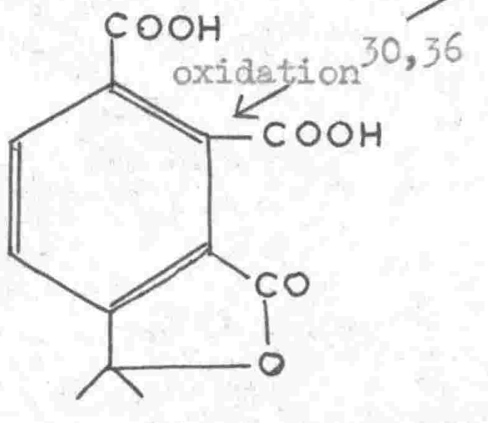

Angelico's acid
Picrotone $\mathrm{C}_{14} \mathrm{H}^{\mathrm{H}} 6^{\mathrm{O}} 3$

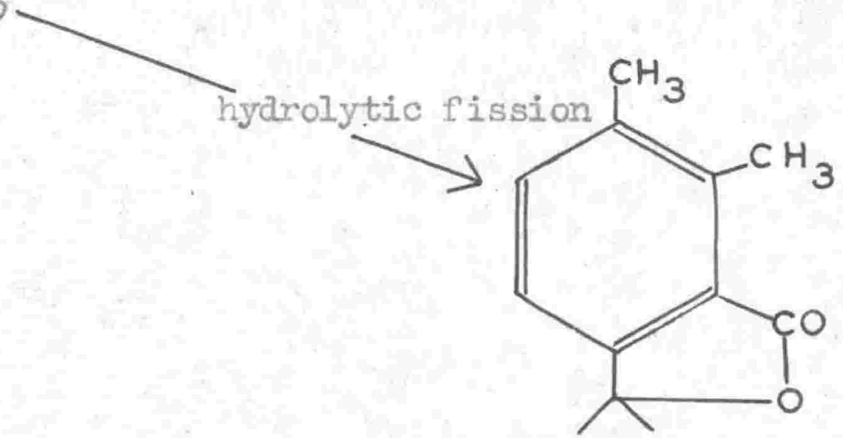

$\alpha: \alpha: 3: 4$-tetrame thylphthalide.

Hormann ${ }^{42}$ suggested the structure of picrotone to be therefore either II or III, and Robertson 47 reported that it followed as a corollary to the structure of picrotic acid that picrotone must have the latter structure.
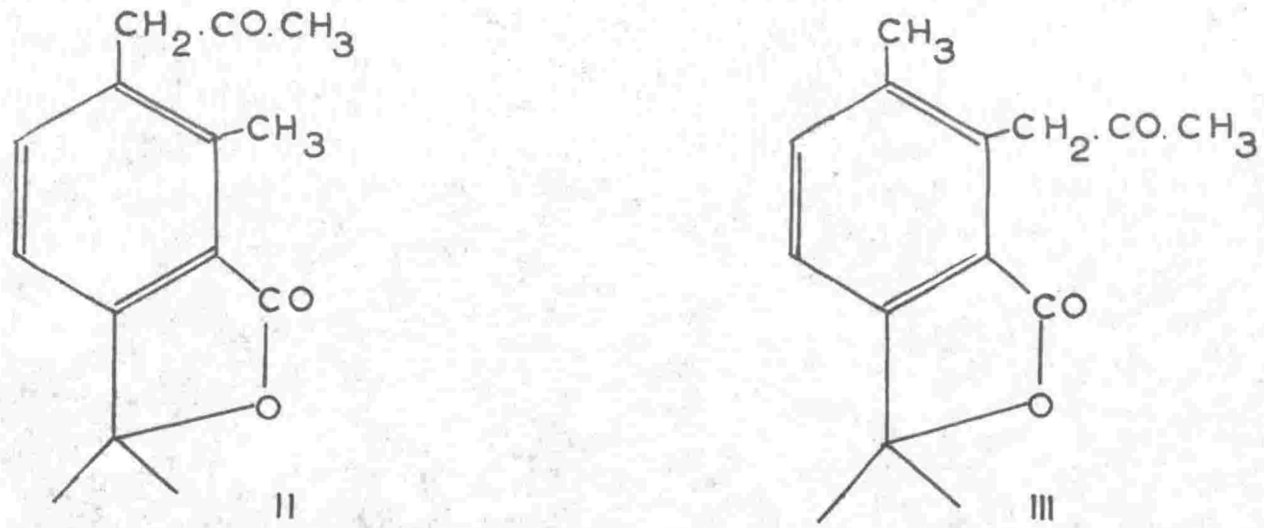

The action of dilute potassium hydroxide or methoxide upon picrotin jielded a monobasic acid, $\alpha$-picrotinic acid $\mathrm{C}_{15} \mathrm{H}_{20} \mathrm{O}_{8}$. Hydrolysis of this acid with $25 \%$ sulphuric acid led to the formation on an $\alpha$-hydaroxy ketone named picrotonol, $47 \mathrm{C}_{14} \mathrm{H}_{16} 6^{\circ}$. Oxidation of this ketone gave an acid $\mathrm{C}_{13} \mathrm{H}_{14} \mathrm{O}_{4}$, which had no ketanic properties. Decarboxylation of this acid yielded a tetra-methyl phthalide which was found to be identical to the phthalide formed from picrotone. Hydrolytic fission of the monobasic acid with aqueous alkali gave a dibasic acid, $\mathrm{C}_{10} \mathrm{~F}_{10} \mathrm{O}_{4}$, together with acedone. Symthesis showed this 
dibasic acid to be 6-methyl homophthalic acid, and the series of reactions was formulated as follows:

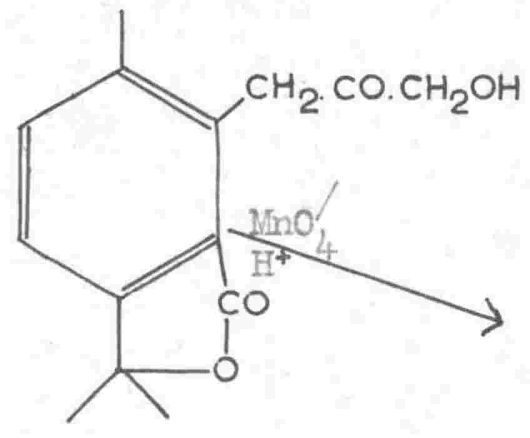

$-\mathrm{CO}_{2}$ $\longrightarrow \mathrm{CH}_{2} \mathrm{COOH}$

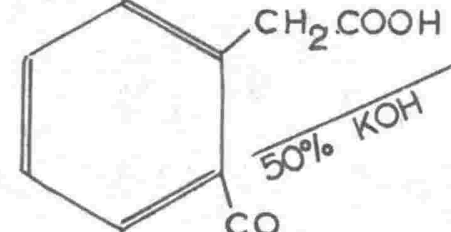

6-methyl homophthalic acid acetone

L: $\{: 3: 4$-tetramethy 1 phthalize.

Thus the carbon skeleton of picrotin, previously suggested as IV from the structure of the rather brutally formed picrotic acid, was confirmed by the structure of picrotonol, a compound formed from picrotin by mild hydrolyses.

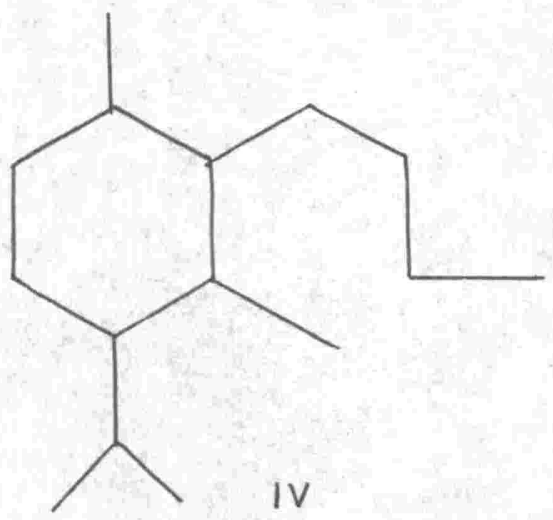

\section{Alkaline Degradations}

The action of alkali upan the picrotoxinin series of compounds gave chiefly aliphatic and hyuroaromatic products. These 
products were often found to be indefinitely related to the degradative compounds obtained by classical methods.

Reaction with cold dilute alkali generally produced hydroaromatic substances with no loss to the carbon skeleton, and usually took effect through lactone opening Occasionally these reactions were reversible.

Degradation with hot alkali normally produced acetone together with a mixture of resins. Sytter and Schlittler ${ }^{52}$, using $10 \%$ sodium carbonate solution at $80^{\circ} \mathrm{C}$ successfully degraded dihydropicrotoxinin to a mixture of dihydropicrotoxinic acid, $C_{1}{ }_{520}{ }^{\circ}$, and acids $\mathrm{V}$ and VI. The degradation of dihydro- $\alpha-$ picrotoxinic acid was also investigated by Schlittler, and the same two compounds $V$ and VI were again obtained from the resulting resin.

The reaction of picrotoxinin with barium hydroxide yielded, besides the known $\alpha$-picrotoxinic acid and compound VI, a new acid VII. Dihydropicrotoxinin also yielded compounds VI and VII an treatment with barium hydroxide.

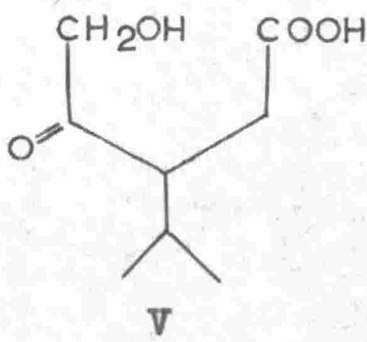

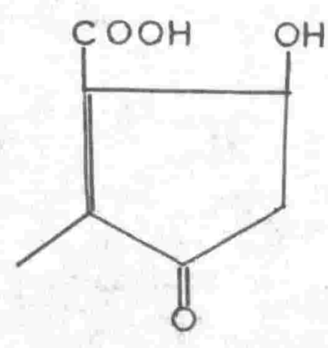

VI

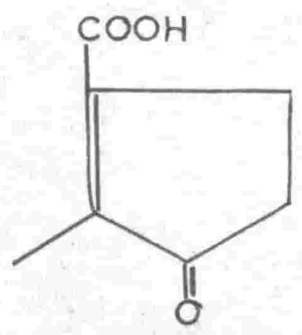

VII

\footnotetext{
Slater and Wilson 56,58

studied the degradation of picrotin with hot alkali. They isolated compound VI and an acid which lactonised readily and which has been formulated as VIII.
} 


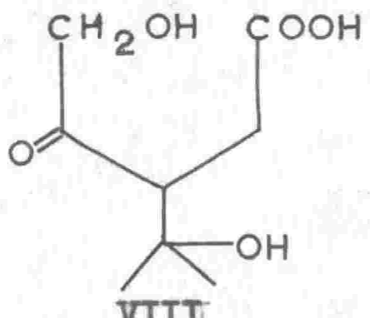

Campounds V and VI appeared to be too dissimilar to be derived from the same section of the picrotoxinin molecule, and, as they together included fifteen carbon atoms, it was thought probable that they resul ted from a complete cleavage of the parent compound. Schlittler postulated that this cleavage was caused by a reversed aldol condensation such as...

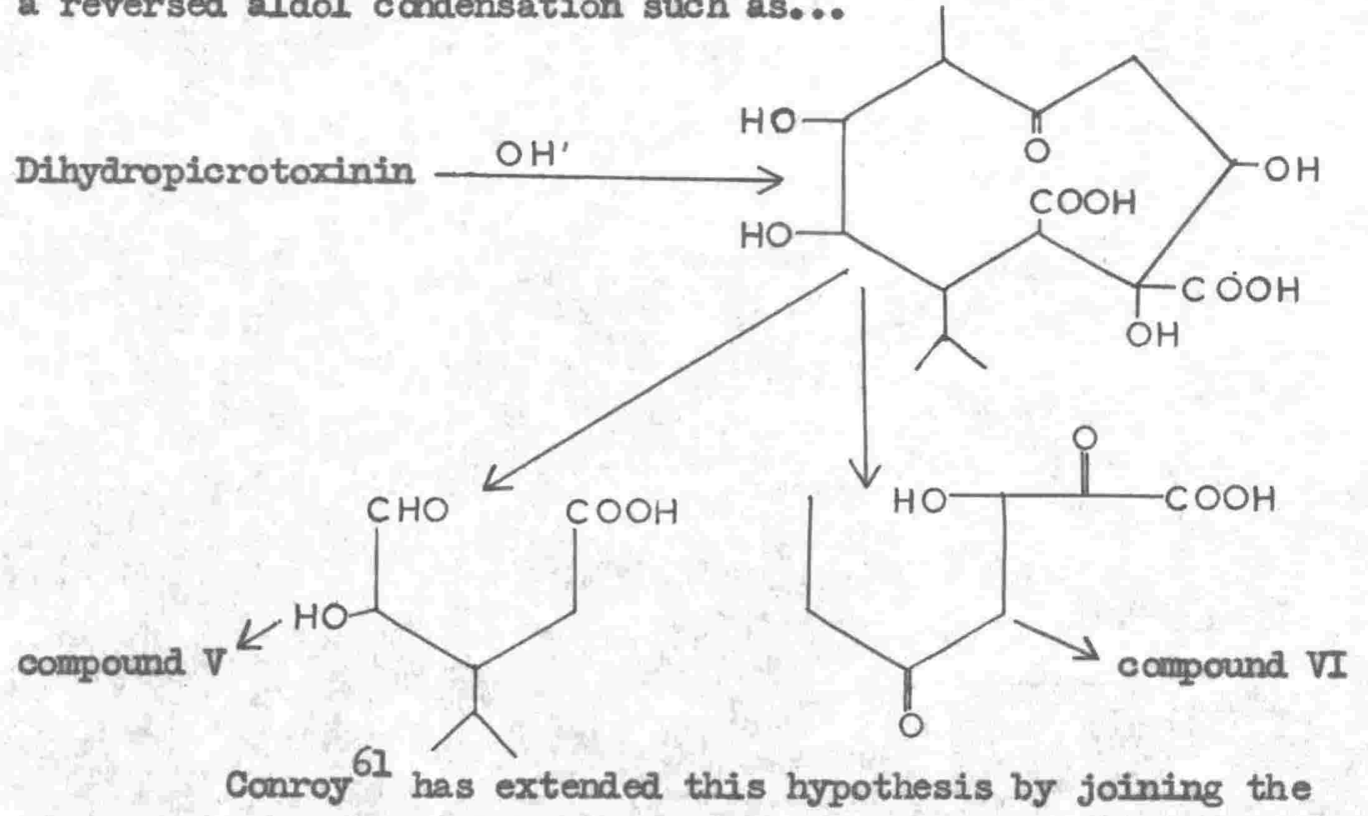
end of the carbon chain of Robertson's structure (page 8) to the six membered ring to obtain the skeleton IX, which he then pictured as degfading in the presence of alkali thus: 


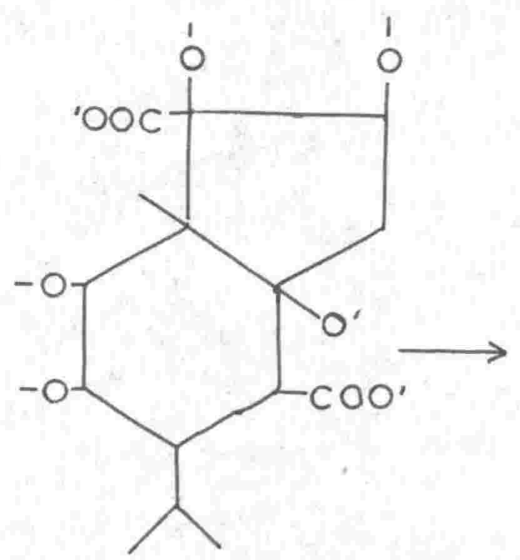

IX
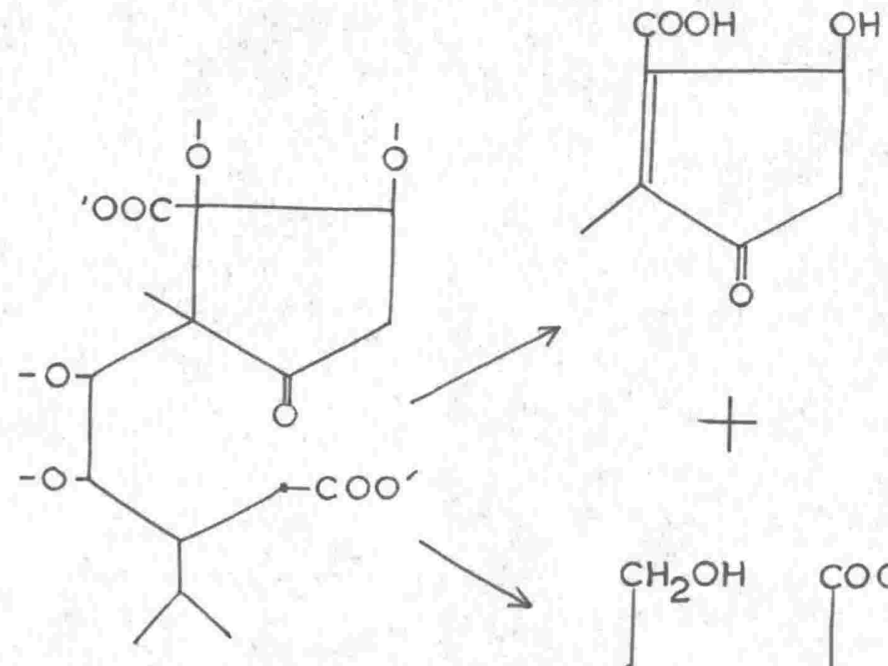

$+$

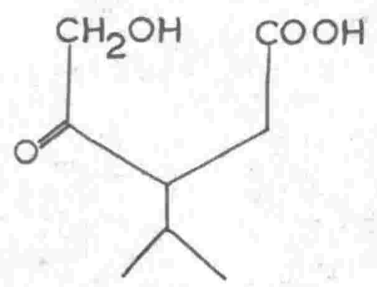

Thermal Degradation

Conroy $^{60}$ reported in 1950 the formation of a compound.

$\mathrm{C}_{14} \mathrm{H}_{18} \mathrm{O}_{4}$ which he obtained by pyrolysis of dihydro- $\alpha$ - picrotoxinio acid with the loss of carbon dioxide. The exact relationship between picrotoxinin and dihydro- $(-$ picrotoxinic acid was not clear, but since this acid was obtained from the parent compound by a series of mild reactions, it was thought that the carbon skeletons should not materially differ.

The compound $\mathrm{C}_{14} \mathrm{H}_{18} \mathrm{O}_{4}$ was named picrotoxinide, and was assigned the structure $\mathrm{X}$ by Conroy on the following evidence.

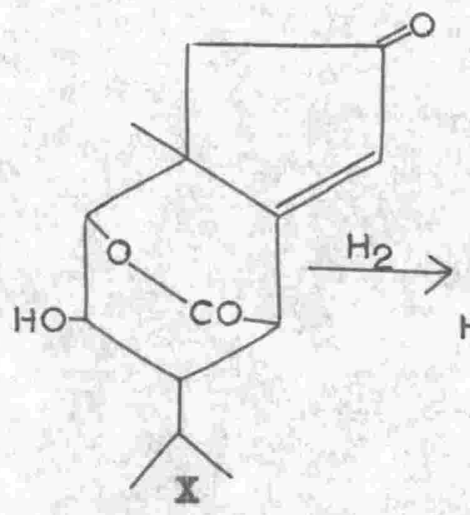

picrotoxinide

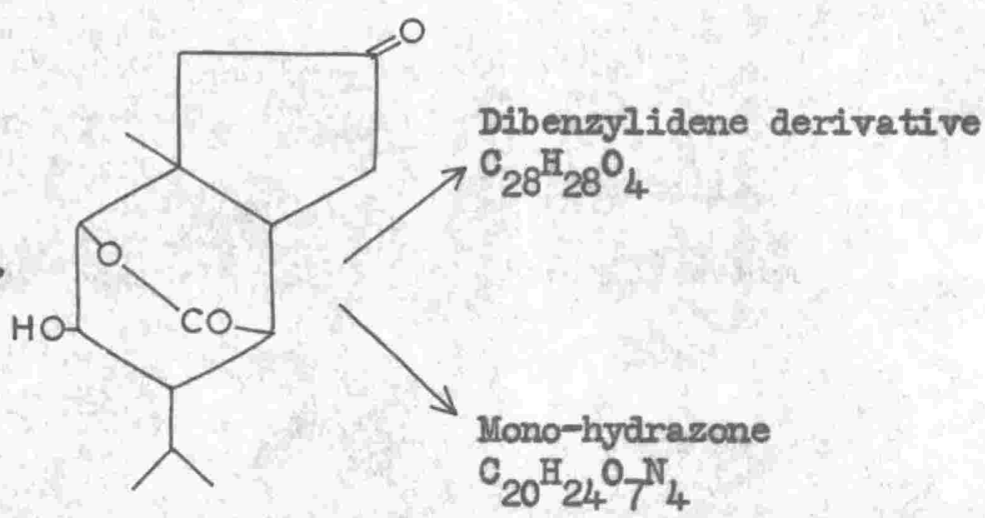

dihydropicrotoxinide 
The dibenzylidene compound was found to be strikingly similar in both its infra-red and ultra-violet absorption spectra to the dibenzylidene derivative of oyclopentanone. The dihydroxy keto-acid formed frcm dihydropicrotoxinide on lactane opening reacted with one mole of periodate, and could be relactonised in quantitative yieldo Dihydropicrotoxinide was converted into its ethylene mercaptal, $\mathrm{C}_{16} \mathrm{H}_{24} \mathrm{O}_{3} \mathrm{~S}_{2}$, with ethane 1:2-dithiol. Raney nickel desulphurisation of this compound produced the lactone tetrahydrodesoxypicrotoxinide, $\mathrm{C}_{14} \mathrm{H}_{22} \mathrm{O}_{3}$, which on treatment with alkali produced a diol which again reacted with periodate.

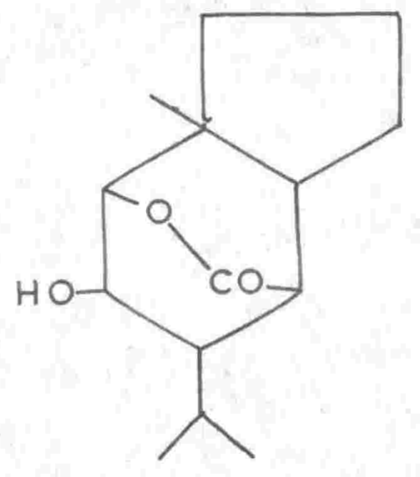

XI

The desoxy compound was converted to its benzoate which underwent pyrolysis with the formation of carbon dioxide, benzoic acid, and a liquid hydrocarbon designated picrotoxadiene.

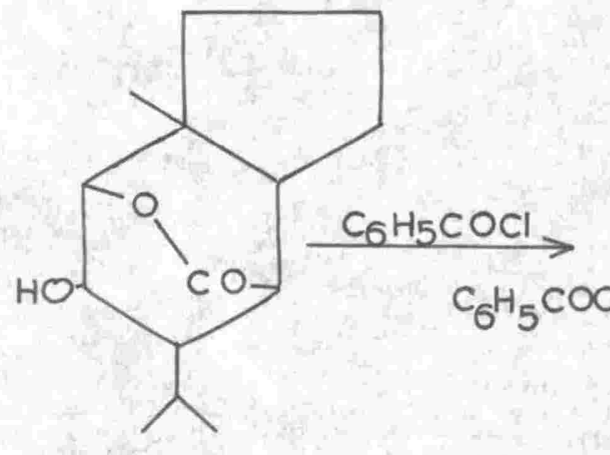

Tetrahydrodesoxypicrotoxinide

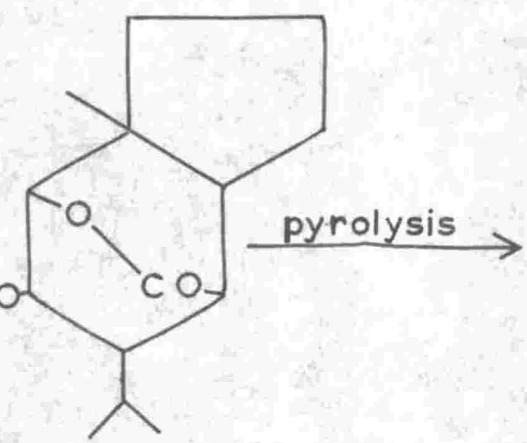

benzoate

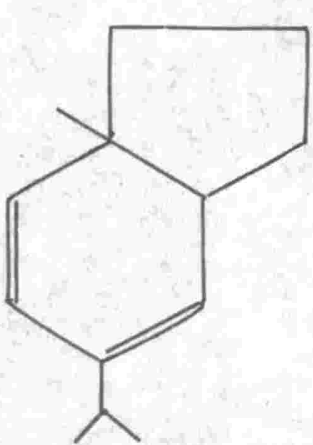

picrotoxadiene 
This latter compound was characterised through its maleic anhydride addition product, the corresponding imide, and the $\mathrm{N}$-phenyl imide, and further confirmation was attempted by the total synthesis of these derivatives. ${ }^{62}$ Synthetic picrotomiene did not produce a crystalline maleic anhydride adduct, but gave an infra-red spectrum identical to that of the natural product. Both the synthetic amides gave melting points differing from the natural derivatives, but as in both cases the infra-red spectra were identical, Conroy considered that picrotoxadiene was an optically active form of the synthetic product. An optically active isomer of picrotoxadiene has recently been prepared ${ }^{63}$ and this compound was found to be the mirror image of the natural product.

The structure of picrotoxinide could be deduced after picrotoxadiene had been satisfactorily formulated, and, using the former compound as a basis, Conroy postulated structure XII as the complete carbon skeleton for picrotoxinin.

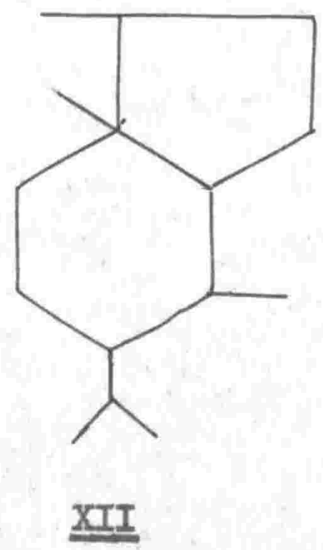

63. Cohen. Ph.D. Thesis, Calumbia University, (1956) 
No fresh evidence has been advanced to contradict the validity of this skeleton, and a study of the functional groups is necessary before a more complete formulation can be made.

\section{THE FUNCTIONAL GROUPS}

Picrotoxinin is an unsaturated compound which can be catalytical ly hydrogenated to give a dihydro-derivative. This, together with ozonolysis experiments, has indicated that picrotoxinin contains one double bond. Picrotin is stable to brommation, hydrogenation, and ozonolysis, and has therefore been regarded as saturated.

Acetylation and benzoylation reactions give mono-acyl derivatives in the case of picrotin but have no effect on picrotoxinin, indicating that picrotin, unlike picrotoxinin, has a primary or secondary hydroxyl group. Zerewitinoff active hydrogen determinations have, while often giving fractional numbers, indicated the presence of at least two hydroxyl groups in picrotin and one in picrotoxinin, and it thus appears that both these compounds have an unacylable tertiary hydroxyl group. This view is supported by infra-red data.

Picrotoxinin and picrotin have been converted by excess alkall into picrotoxinin dicarboxylic acid, $\mathrm{C}_{15^{\mathrm{H}}}{ }_{20}{ }^{\circ}$, and picrotin dicarboxylic acid, $\mathrm{C}_{15} \mathrm{H}_{22} \mathrm{O}_{9}$, respectively. 36 Picrotin, but not picrotoxinin, may be reprecipitated from a cold alkaline solution on acidifitation. Dihydropicrotoxinin is also reprecipitated under the same conditions. This evidence, together with conductomeric and infrared results, indicated that both picrotoxinin and picrotin were dilactones.

The presence of two lactone systems accounts for four 
oxygen atoms in both picrotin and picrotoxinin. If a further two oxygen atoms in picrotin and one in picrotoxinin are involved in hydroxyl groups, there remains one oxygen atom in each molecule to be assigned a function. It has been suggested that this oxygen is present as an ether link, but no recognizable degradation products containing such a link have been obtained. No reducing groups are present in either picrotin or picrotoxinin, despite the fact that both these compounds apparentily show marked reducing properties. Slater 57 suggested that these compounds reduce only after they have been degraded by the alkaline reagents used in the conventional tests. The functional groups can be summarized as follows: Picrotoxinin Picrotin
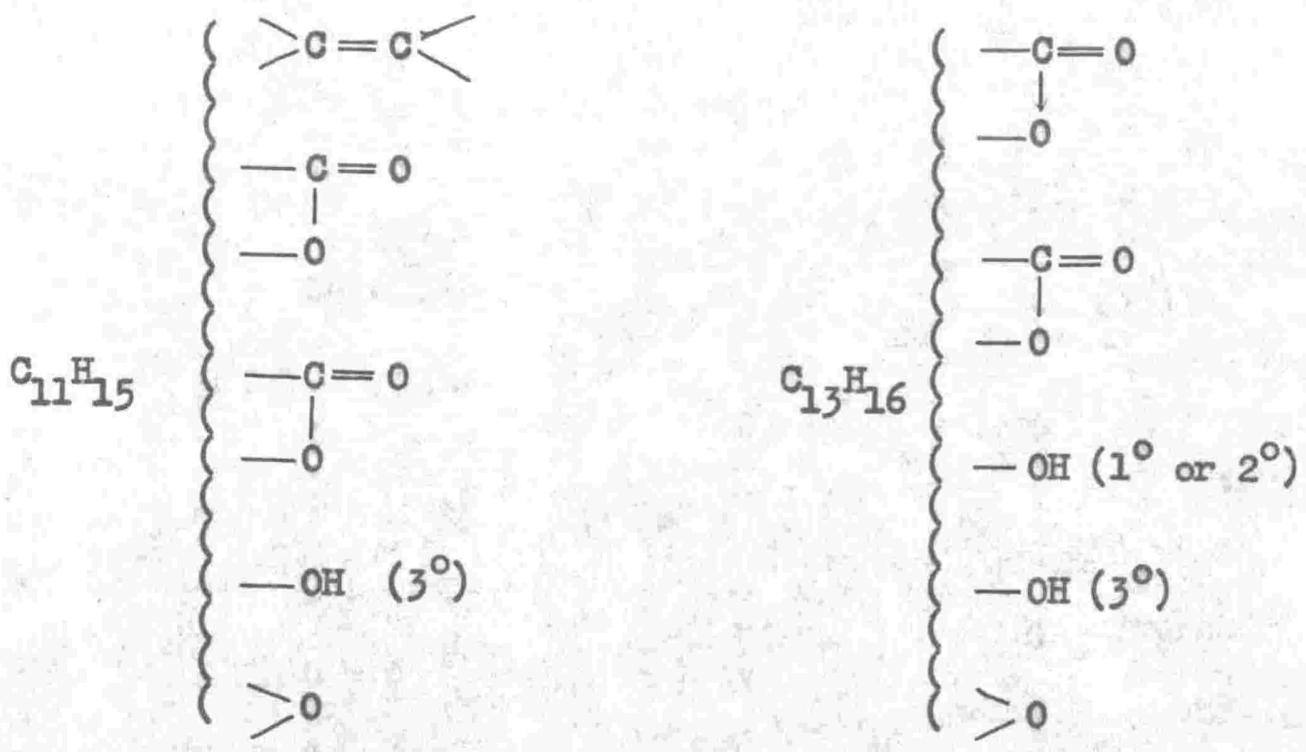

The residues $\mathrm{C}_{11} \mathrm{H}_{15}$ and $\mathrm{C}_{13} \mathrm{H}_{16}$ will give saturated hydrocarbons of formula $\mathrm{C}_{11} \mathrm{H}_{20}$ or $\mathrm{C}_{13} \mathrm{H}_{24}$ respectively, and the compounds must therefore possess two carbocyclic rings. This fact is consistent with the proposed Conroy skeleton, XII. 
The Double Bond

Ozonolysis:

Ozonolysis of picrotoxinin, $\mathrm{C}_{15}{ }_{16}^{\mathrm{H}} 6_{6}$, and picrotoxic acid,

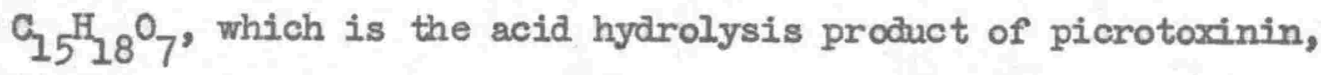
jielded the ketones picrotoxinone, $\mathrm{C}_{14} \mathrm{H}_{14}{ }^{\mathrm{O}} 7$, and picrotoxinonic acid, $\mathrm{C}_{14} \mathrm{H} 16^{\circ}$, respectively. As only one carbon atom was lost, and as formaldehyde was produced, 48 the double bond in the parent compounds could only be present in a vinyl group.

On heating picrotoxinone or picrotoxinonic acid with hydriodic acid and red phosphorus, a mixture was obtained frcm which a ketonic phenol, $\mathrm{C}_{13} \mathrm{H}_{16} \mathrm{O}_{2}$, was isolated. This compound on Clemmensen reduction, yielded a saturated phenol $\mathrm{C}_{13} \mathrm{H}_{18} \mathrm{O} \cdot$ Robertson ${ }^{48}$ concluded that this phenol was a tetrahydronaphthol, and showed by synthesis that it was 1 -methyl, 4-ethyl, 5:6:7:8-tetrahydro, $\beta$-naphthol XIII.

A comparis on between this structure and the structure of picrotic acid I, a compound also formed by hydriodic acid and red phosphorus reduction, showed clearly that the carbon $C^{*}$ was missing from the former. It was thus apparent that ozonolysis had split an isopropenyl residue in piorotoxinin to form an acetyl group, which was then reduced to give an ethyl group in the naphthol.
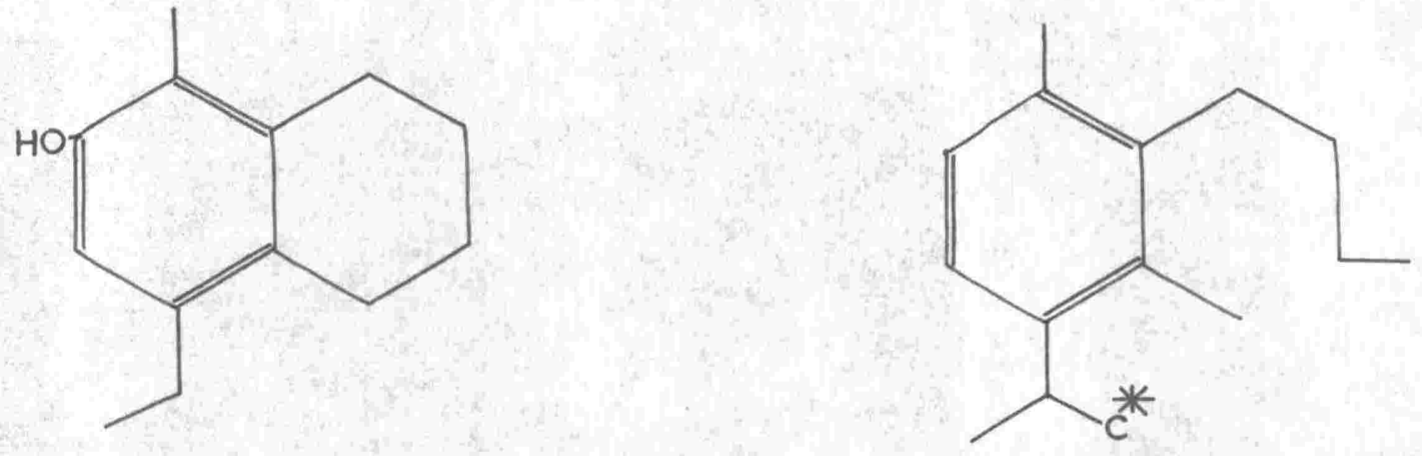
The double bond of picrotoxinin is therefore in a position represented by formula XIV.

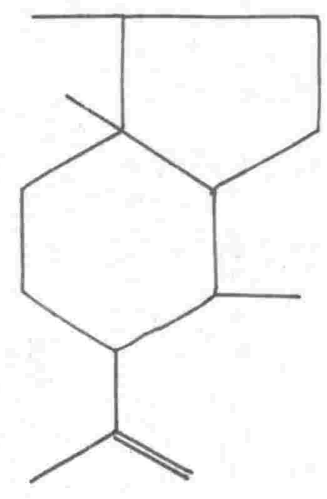

\section{$\underline{\underline{X I V}}$}

The isolation of two acids, norpicrotic acid, XV, and hydroxy norpicrotic acid, XVI, from hydriodic acid and red phosphorus reduction of picrotoxinone also served to verify the position of the double bond, as the terminal methyl group $C^{*}$ was again missing in both these compounds.
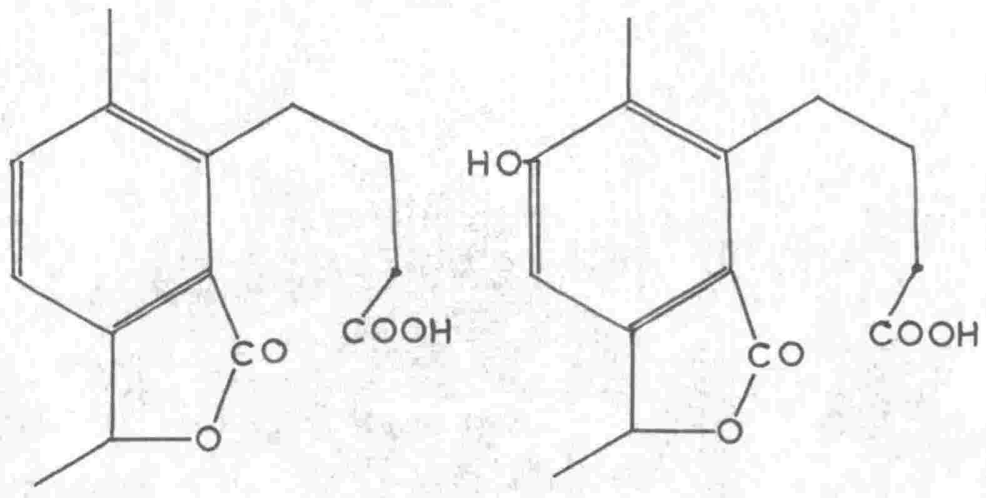

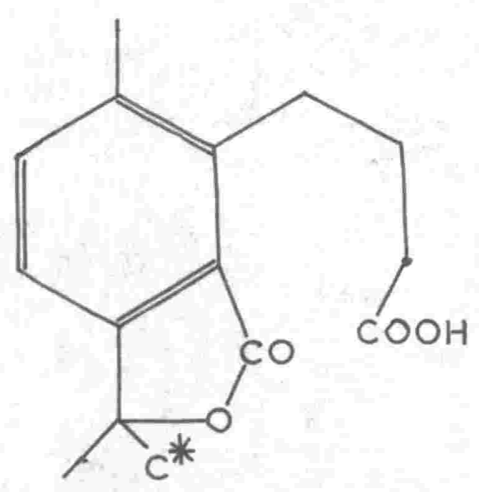


Bromination:

Bromination of picrotoxinin in either aqueous or methanolic solution gave rise to a mixture of two insaluble iscmeric bromopicrotoxinins. 23 This mixture could be separated. by fracticnal crystallization into $\alpha$ - and $\beta$-bromopicrotoxinin, both of which regenerated picrotoxinin on treatment with zinc and ammonium chloride. This fact has been used in the normal method. of separating picrotoxinin fram picrotin, as picrotin remains in solution during the bramination reaction.

Both the bromopicrotoxinins are saturated and contain only one bromine atom. It has been suggested that a dibromide does initially form, but that this compound readily loses hydrobromic acid and undergoes ring closure to give a saturated monobromo derivative. As the bromopicrotoxinins show no hydroxyl absorption in the infra-red a possible bramination mechanism has been proposed $\operatorname{ass}^{49}$

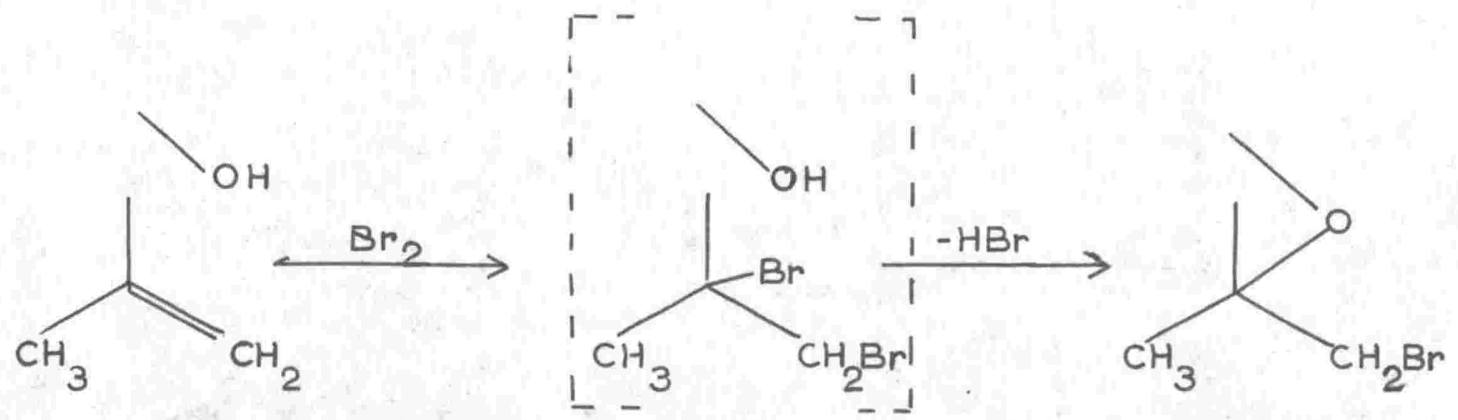

which produces one additional asymmetric carbon atom and hence two iscmers. Conroy 64 has suggested that one of the two isomers may however have the structure XVII.

64. Conroy.J.A.C.S. 791726 (1957) 


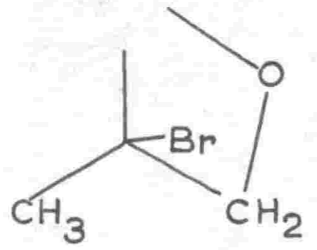

\section{XVII.}

\section{Hydrogenation:}

Hydrogenation of the double band with a platinum catalyst gave a straight-forward reaction and $\alpha$-dihydropicrotoxinin was obtained as the sole product. This compound on hydrolysis gave dihydropicrotoxic acid, an acid also obtained by hydrogenation of picrotoxic acid,

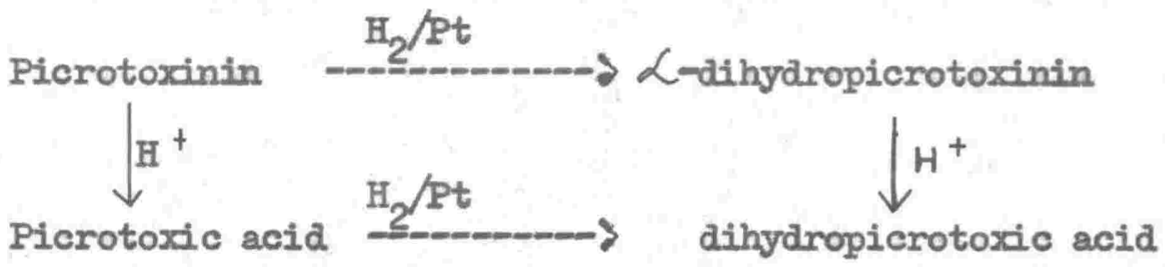

A more complex reaction occurred when picrotoxinin was hydrogenated with a palladium catalyst under weakly acidic conditions. Acid hydrolysis of the hydrogenation product yetlded three compounds ... picrotonol, dihydropicrotoxic acid, and $\beta$ - dihydropicrotoxinin - an isomer of the $\alpha$ - form. As $\beta$-dihydropicrotoxinin was stable to acid hydrolysis and $\alpha$-dihydropicrotoxinin was converted under such conditions to dihydropicrotoxic acid, and since neither compound yielded picrotonol, the hydrogenation mixture before acid hydrolysis was postulated to contain both $\alpha$ - and $\beta$ - dihydropicrotoxinin and a "picrotonol precursor"t $7,49,55$. 
(1) $\alpha$-dihydropicrotoxinin dihydropicrotoxic acid picrotoxinin $\frac{\mathrm{Pa} / \mathrm{H}_{-}^{+}}{\mathrm{H}_{2}}$

(2) $\beta$-dihydropicrotoxinin -H.':

(3) picrotanol precursor $\beta$-dihydropicrotoxinin picrotonol

The picrotonol precursor was first izolated by Robertson 49 as the acetate, and then by Slater ${ }^{55}$ who obtained it by bromination of the reduction mixture. An insoluble bromo-derivative was formed which on debromination gave the picrotonol precursor, an isomer of picrotoxinin, which was named neopicrotoxinin.

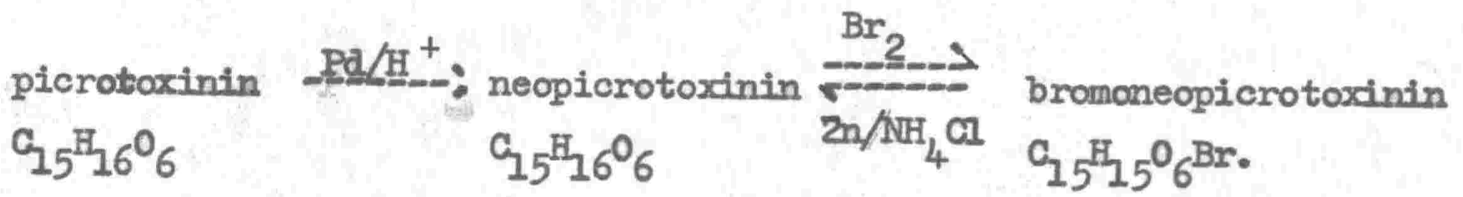
The mechanism of the formation of neopicrotoxinin has not been determined, but it has been show that hydrogen, hydrogen ions, and palladium,are all essential to the reaction.

Neopicrotoxinin differed in a number of ways from picrotoxinin. These differences are enumerated below:

(a) Neopicrotoxinin could readily be transformed under mild conditions into the aromatic compound picrotonol whilst picrotoxinin gave hydroaromatic derivatives.

(b) Neopicrotoxinin, unlike picrotoxinin, formed a monoacetate, suggesting that the tertiary group in picrotoxinin had rearranged into a primary or secondary position. 49

(c) Picrotoxinin could be hydrogenatid readily, while neopicrotoxinin reacted only slowly and with difficulty. The product formed was identical with $\beta$-dihydropicrotoxinin, which was therefore renamed dihydroneopicrotoxinin. This resistance to hydrogenation 
has been suggested to indicate that the double bond of picrotoxinin has changed its position to a tetra-substituted environment in neopicrotoxinin.

(d) Dihydropicrotoxinin was hydrolysed by dilute acid to dihydropicrotáxic acid, whereas dihydroneopicrotoxinin was stable.

(e) Bromination of picrotoxinin gave rise to two bramo derivatives, both of which had their lactone systems opened irreversibly with alkali. Neopicrotoxinin however formed only one bromo-derivative and this compound was reversibly affected by alkali.

No attempt has yet been made to formulate neopicrotoxinin, but a basic similarity to picrotoxinin is known to be present as dihydroneopicrotoxinin has been degraded under alkaline conditions to the same compounds V and VI which are obtained under similar conditions from dinydropicrotoxinin. 56

Dehydration of picrotin:

Picrotin gave alkaline degradation products closely related to those obtained from picrotoxinin, 56,58 and attempts have been made to formulate picrotin as the chemical hydrate of picrotoxinin. These attempts were only partially successful. Dehydration of picrotin with phosphorus pentachloride yielded a substance different from, but isomeric to, picrotoxinin, which was named anhydropicrotin. 32 Dehydration with oxalic acid gave rise to a compound which was identified through its bromo-derivative as neopicrotoxinin, together with a possible further isomer of picrotoxinin which was isolated as the acetate. 

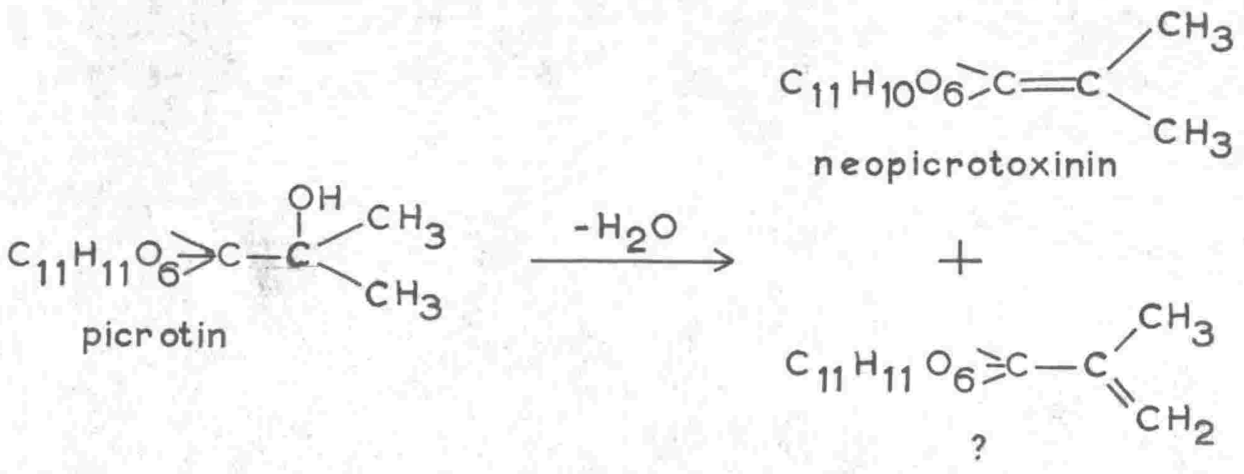

A further dehydration was obtained when $\alpha$-picrotinic acid, formed by the action of alkali on picrotin, 33 was heated above its melting point. 36 The compound isolated, picrotoxic acid, could also be readily produced by either acid or alkaline hydrolysis of picrotoxinin, and this reaction thus afforded an addition interrelationship between the picrotoxinin and picrotin series. The Lactones.

Infra-red spectroscopic examination of picrotoxinin and of $\beta$-bromopicrotoxinin indicated the presence of two $\gamma$-lactones in each compound $\left(1794,1777 \mathrm{~cm}^{-160,65}\right.$, and $1777 \mathrm{~cm}^{-1}$ double peak, respectively).

Picrotoxic acid, formed by the action of one mole of alkali upon picrotoxinin, produced infra-red ab sorption at $1794 \mathrm{~cm}^{-1}$ and $1730 \mathrm{~cm}^{-1}$, showing that only the lactone responsible for the $1777 \mathrm{~cm}^{-1}$ band of picrotoxinin had been opened in this acid. The isomeric $\alpha$-picrotoxinic acid, obtained by debromination of $\beta$-bromopicrotoxinic acid, ${ }^{35}$ gave two peaks at $1735 \mathrm{~cm}^{-1}$ and $1730 \mathrm{~cm}^{-1}$. $\quad \beta$-Bromopicrotoxinic acid itself absorbed in a broad band at $1725 \mathrm{~cm}^{-1}$, and neither of these compounds absorbed in the $\gamma$-lactone region. This inf ra-red data has made it necessary to formul ate both $\alpha$ picrotoxinic acid and $\beta$-bromopicrotoxinic acid 
as compounds containing a $\delta$-lactone, and it was thus essential to postulate a rearrangement during the formation of $\beta$-bromopicrotoxinic acid.

Picrotoxic acid could not be brominated and hence it was also necessary to postulate a change other than simple lactone opening during the formation of this compound. Both these reactions were found to be irreversible.

The infra-red absorption of the lactones can be summartzed as in Table A.

\begin{tabular}{|c|c|c|c|c|c|}
\hline & $\gamma$-lactone & $\delta$-lactone & $-\mathrm{COOH}$ & $-\mathrm{OH}$ & $: c=c:$ \\
\hline Piorotoxinin & 1794,1777 & & & 3464,1163 & 1649 \\
\hline Bromopicrotoxinin & 1777 & & & - & - \\
\hline Picrotoxic acid & 1794 & & 1730 & 3390 & 1650 \\
\hline $\begin{array}{l}\beta \text {-Bromopicrotoxinic } \\
\text { acid (sodium salt) }\end{array}$ & & 1739 & 1725 & 3400 & - \\
\hline$\alpha$-Picrotoxinic acid & & 1755 & 1730 & 3490,3450 & 1649 \\
\hline Heopicrotoxinin & 1798,1763 & & & 3497 & $\begin{array}{l}\text { tetra- } \\
\text { substituted }\end{array}$ \\
\hline Picrotin & 1803,1773 & & & 3333,1158 & - \\
\hline
\end{tabular}

TABLE A

The Hydroxyl Group

Active hydrogen determinations have indicated the presence of two hydroxyl groups in picrotoxinin ${ }^{65}$. Similar determinations have shown that $\beta$-bromopicrotoxinin contains an active hydrogen while 
infra-red data have shown that no hydroxyl group can be present in this compound. Zerevitenov determinations on dihydropicrotoxinin have given the very unexpected result of four active hydrogens, and for these reasons the value and use of active hydrogen determinations have been questioned. 66

Infra-red absorption showed the presence of a tertiary hydroxyl group in picrotoxinin $\left(3464,1163 \mathrm{~cm}^{-1}\right)$ : Bromination removed this hydroxyl group and the bromopicrotoxinins had no hydroxyl contento Picrotoxinin is now therefore formulated with only one hydroxyl group.

$\beta$-Bromopicrotoxinin was stable to alkali fission whilst picrotoxinin was not, and it was suggested ${ }^{59}$ that the tertiary hydroxyl must be free before the reversed aldol reaction, and hence degradation could occur. Thus $\beta$-bromopicrotoxinin, bromoneopicrotoxinin, and $\beta$-bromopicrotoxinic acid were found to be alkali stable, whereas picrotoxinin, neopicrotoxinin, and $\alpha$-picrotoxinic acid underwent al kaline fission. Picrotoxic acid was also stable to alkaline degradation, hnd has been formulated ${ }^{59}$ as having no tertiary hydroxyl group in the same position as picrotoxinin. This structure was supported by the fact that picrotoxic acid could not be brominated.

Picrotoxinin was stable to acetylation. 65 Dihydropicrotoxinin however gave an acetate which was originally thought to be a di-acyl compound, 57 but which has now been shown to be a monoderivative. 66 Picrotin formed both a mono- and a diacetate $11,22,65,67$.

65. Slater et al. J.C.S. 19564715

66. Conroy. J.A.C.S. in print

67. Paterno and Oglialoro. Gazz. 257 (1879) 
Partial formulations for some picrotoxinin derivatives have been given by Conroy 60,61 as follows:

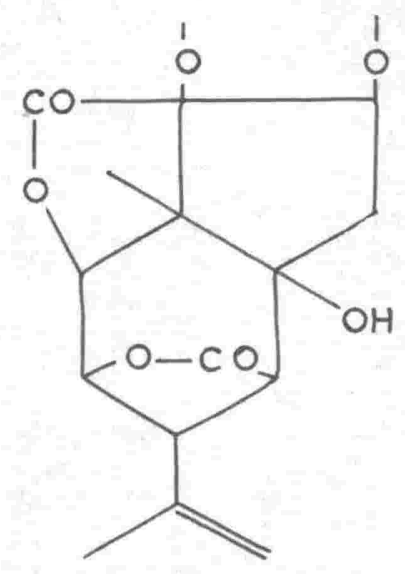

Picrotoxinin

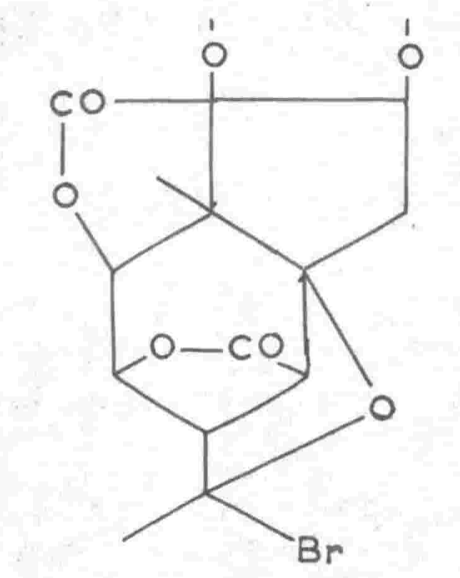

${ }_{B}^{\alpha}=$ Bromopicrotoxinin

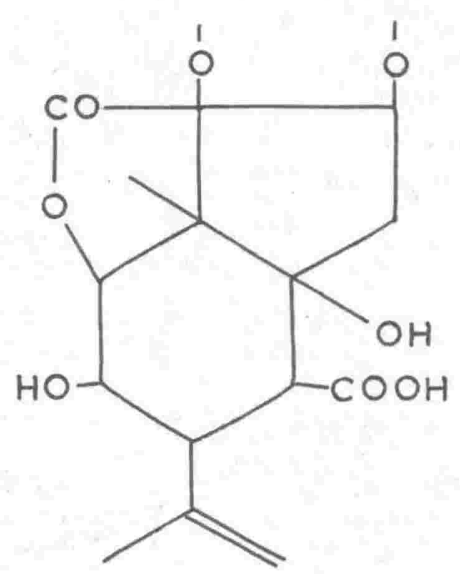

Picrotoxic acid
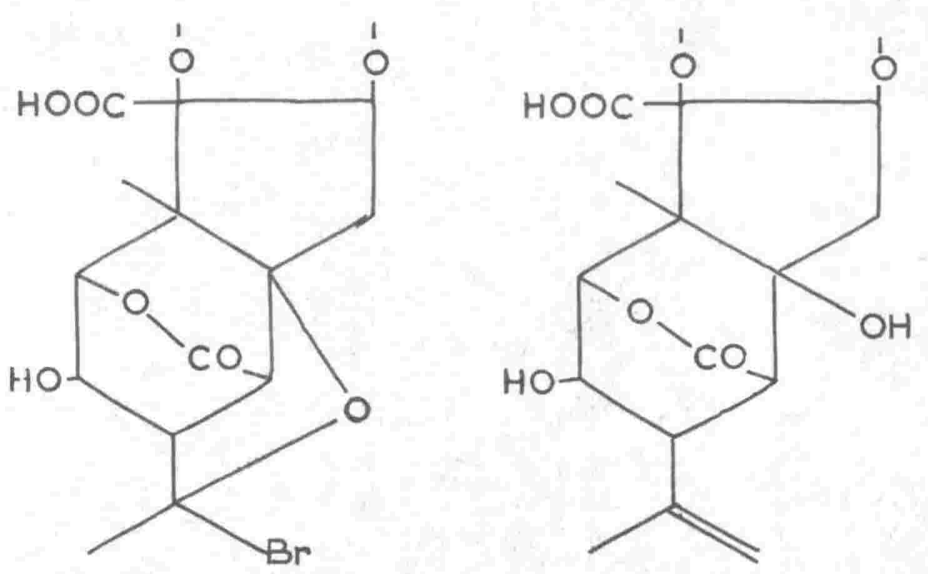

$\alpha=$ Bromopicrotoxinic acid d-Picrotoxinic acid.

His reasons are given briefly in the following arguments.

Degradation products of picrotoxinin indicated that axygen atoms were present in the positions shown in structure XVIII. 


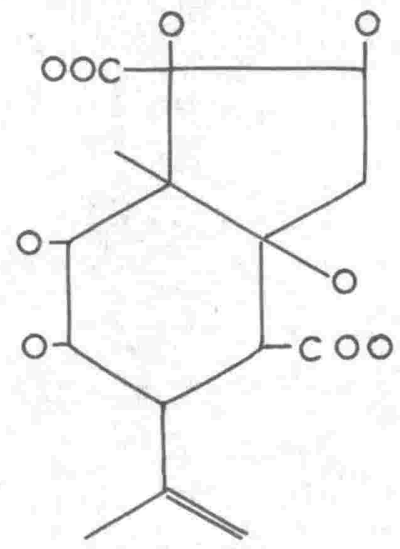

\section{XVIII}

Neither picrotoxic acid nor $\alpha$-picrotoxinic acid reacted with sodium periodate, whereas picrotoxinin dicarboxylic acid, formed from picrotoxinin by hydrolysis with two moles of alkali, did react. Thus picrotoxinin must contain the unit:

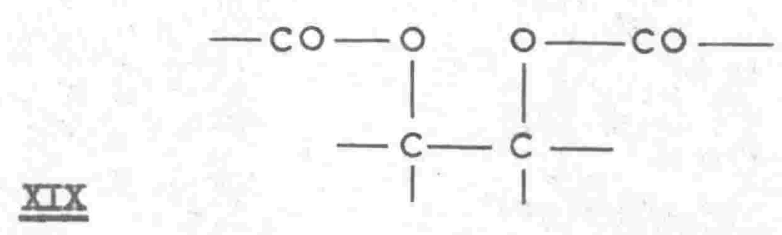

and, as it is known to contain two $\gamma$-lactones, it must be formulated as above. The structures of $\beta$-bromopicrotoxinin, $\beta$-bromopicrotoxinic acid, and thus $\alpha$-picrotoxinic acid, follow fairly readily fram this formulation and will be discussed more fully later. The formula for picrotoxic acid is however unsatisfactory, and has been questioned ${ }^{59}$ on the grounds that picrotoxic acid cannot be brcminated and is alkali stable. An amended partial formulation for picrotoxic acid was suggested as $x x^{59}$ 


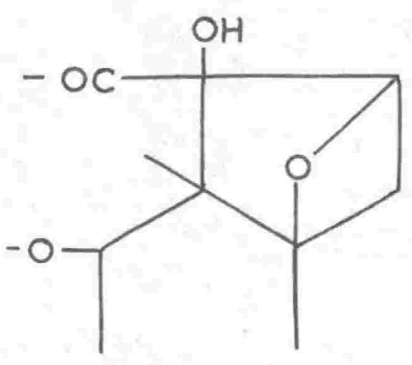

\section{$\underline{\mathrm{xx}}$}

\section{The Ether Link}

In order to account for the functions of all the picrotoxinin oxygen atoms, Conroy ${ }^{60}$ suggested that an epoxide link should be drawn between the two adjacent carbons of the five membered ring to give structure XXI.

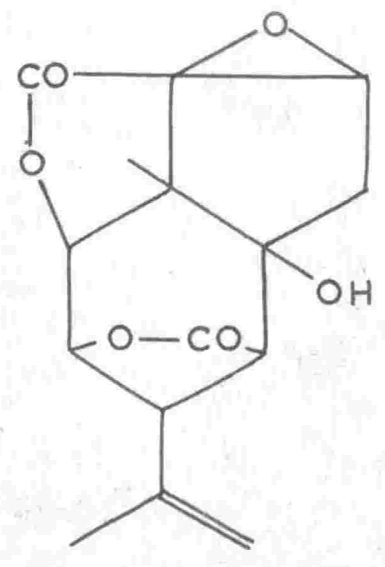

\section{$\underline{\mathrm{XXI}}$}

However, no recognizable degradation products containing the epoxide link have been isolated, and attempts to prove the presence of an ethylene oxide system chemically have failed. It was found that...

(a) Picrotoxinin and picrotin were stable to superheated steam, 
a reagent which normally reacts with epoxide links. 57

(b) Picrotoxinin did not give the expected - $\alpha$-hydroxy chloro- derivative with gaseous hydrogen chloride.

(c) No glycol diacetate could be isolated from the ferric chloride catalised reaction between picrotoxinin and acetic anhydride. 57

.... and it was therefore concluded ${ }^{65}$ that no epoxide link was present, and that a better formulation would include a hemiacetal-lactone system of the type:

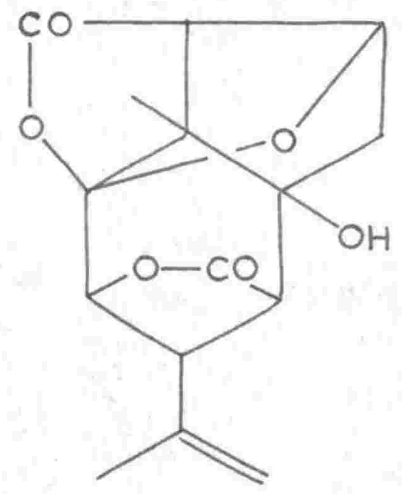

$\underline{\operatorname{XXII}}$

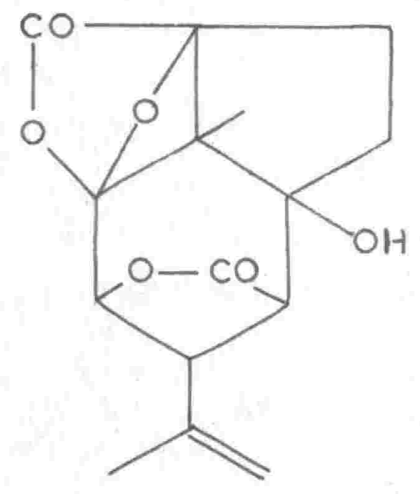

XXIII

Conroy has since justified his original formulation

xXI by explaining ${ }^{64}$ that the apparent unreactivity of the epoxide resubted from the highly caged structure of the molecule. He demonstrated that rearward attack, which is considered essential for epoxide reaction, was practically impossible in many picrotoxinin compounds due to the close proximity of the lactone rings. 
RECENT ADVANCES IN PICROTOXININ CHEMISTRY

Reduction studies.

The reduction of $\beta$-bromopicrotoxinic acid or its methyl ester with lithium aluminium hydride gave a compound analysing as $\mathrm{C}_{15} \mathrm{H}_{21} \mathrm{O}_{6} \mathrm{Br} \cdot 65$ This campound could be treated with periodic acid to give, together with some formaldehyde, a product, $\mathrm{C}_{14} \mathrm{H}_{1} 7^{\mathrm{O}} \mathrm{Br}$, which was formulated as a five membered cyclic ketone. (Ultra-violet absorption maximum 3020 - 50 \&, infra-red maximum $1768 \mathrm{~cm}^{-1}$ ). The same ketone was obtained by oxidising the sodium borohydride reduction product of $\beta$-bromopicrotoxinic acid wi th 1 ead dioxide. 64

Slater 65 formulated these reactions as follows:

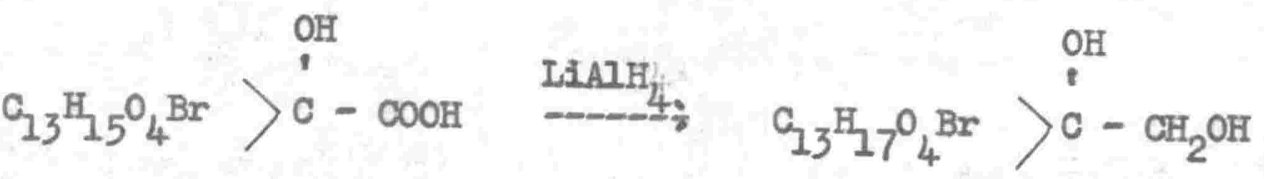
$\mathrm{HIO}_{4}$

$$
\mathrm{C}_{1} 3_{17} \mathrm{H}_{4} \mathrm{Br}>\mathrm{C}=0
$$

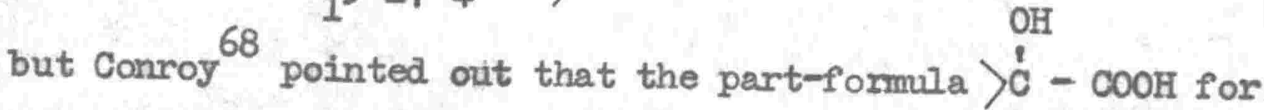
$\beta$-bromopicrotoxinic acid was inconsistent with the fact that this acid did not react with lead tetraacetate or lead dioxide. He formulated the borohydride reduction series as XXIV - - XXVI and suggested that the structure of the lithium aluminium hydride product was therefore XXVII. 

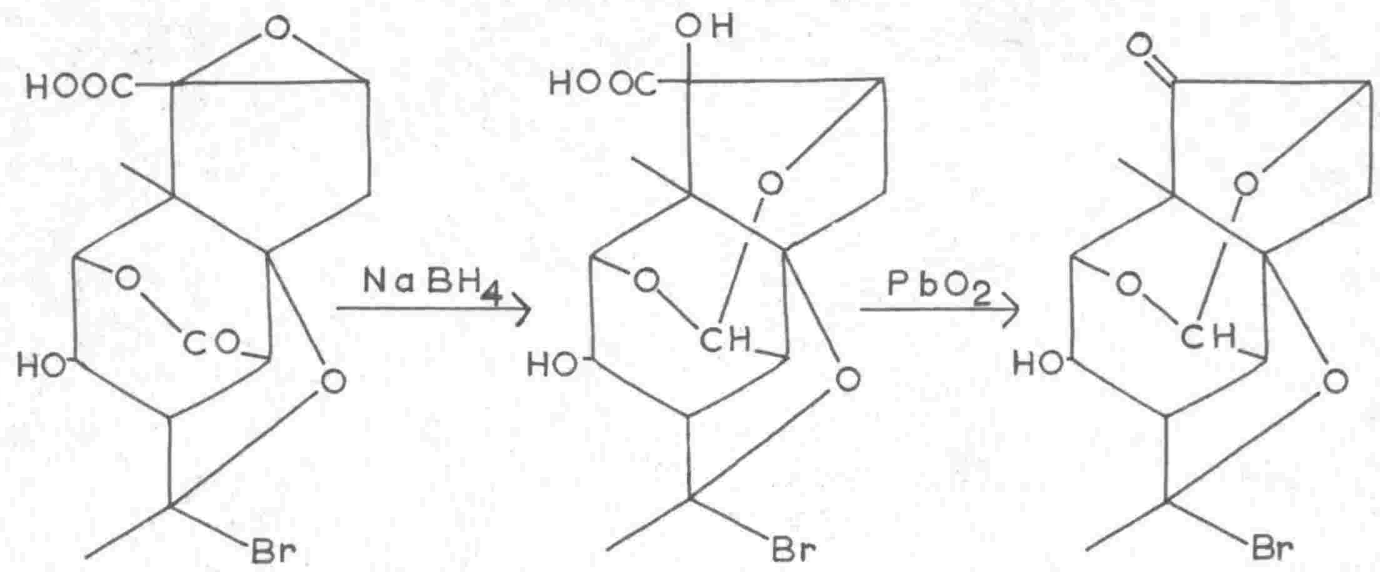

XXIV

$\beta$-bromopicrotoxinic acid
$X X V$

$\mathrm{C}_{15} \mathrm{H}_{19^{\mathrm{O}}} \mathrm{Br}$

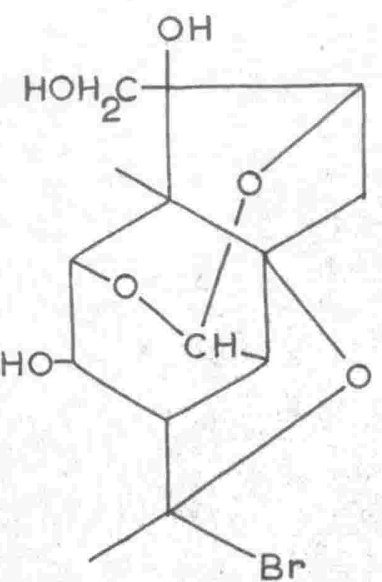

\section{XXVII}

XXVI

$\mathrm{C}_{14} \mathrm{H}_{17} \mathrm{O}_{5}^{\mathrm{Br}}$

The rearrangement of the epoxide linkage of

$\beta$-bromopicrotoxinic acid to give the ketal formation on reduction has been demonstrated to be geometrically possible, 64 and was postulated to occur when the carbonyl accepted a hydride 
ion while the excess charge on the carbonyl oxygen caused simultaneous rearward displacement of the oxirane link.

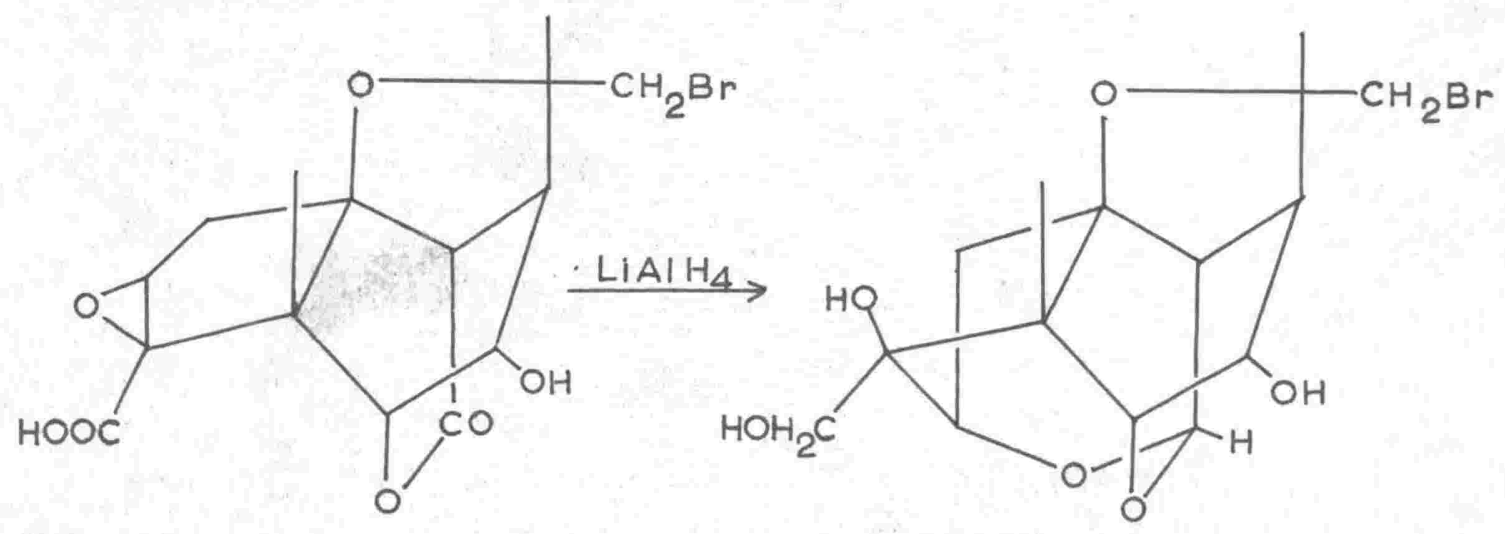

XXIVa

$\beta$-bromopicrotoxinic acid
XXVa

$\mathrm{C}_{15^{\mathrm{H}}}{ }_{21} \mathrm{O}_{6}^{\mathrm{Br}}$

Lithium aluminium hydride reduction of $\beta$-bromopicrotoxinin gave a compound $\mathrm{C}_{15} \mathrm{H}_{23} \mathrm{O}_{6} \mathrm{Br}$, which was postulated as being formed by complete reduction of both lactones. 65 0xidation of this compound with periodic acid led to a complex reaction in which three moles of periodate were consumed and bromine was expelled. Two bromine-free end products were obtained which analysed as $\mathrm{C}_{15} \mathrm{H}_{22} \mathrm{O}_{7}$ and $\mathrm{C}_{15} \mathrm{H}_{24} \mathrm{O}_{7}$ respectively. Conductomeric titration of the first of these preducts indicated the presence of a lactone group and this was verified by infra-red absorption at $1759 \mathrm{~cm}^{-1}$. The compound gave no other infra-red carbonyl absorption, and so any possible ketonic or aldehyde function must have been present in a combined form as an acetal or ketal.

In order to explain the lactone formation on oxidation, partial formulations for $\beta$-bromopicrotoxinin, reduced $\beta$-bromopicrotoxinin, and the compound $\mathrm{C}_{15}{ }_{22} \mathrm{H}_{7}$ have been 
suggested. 65

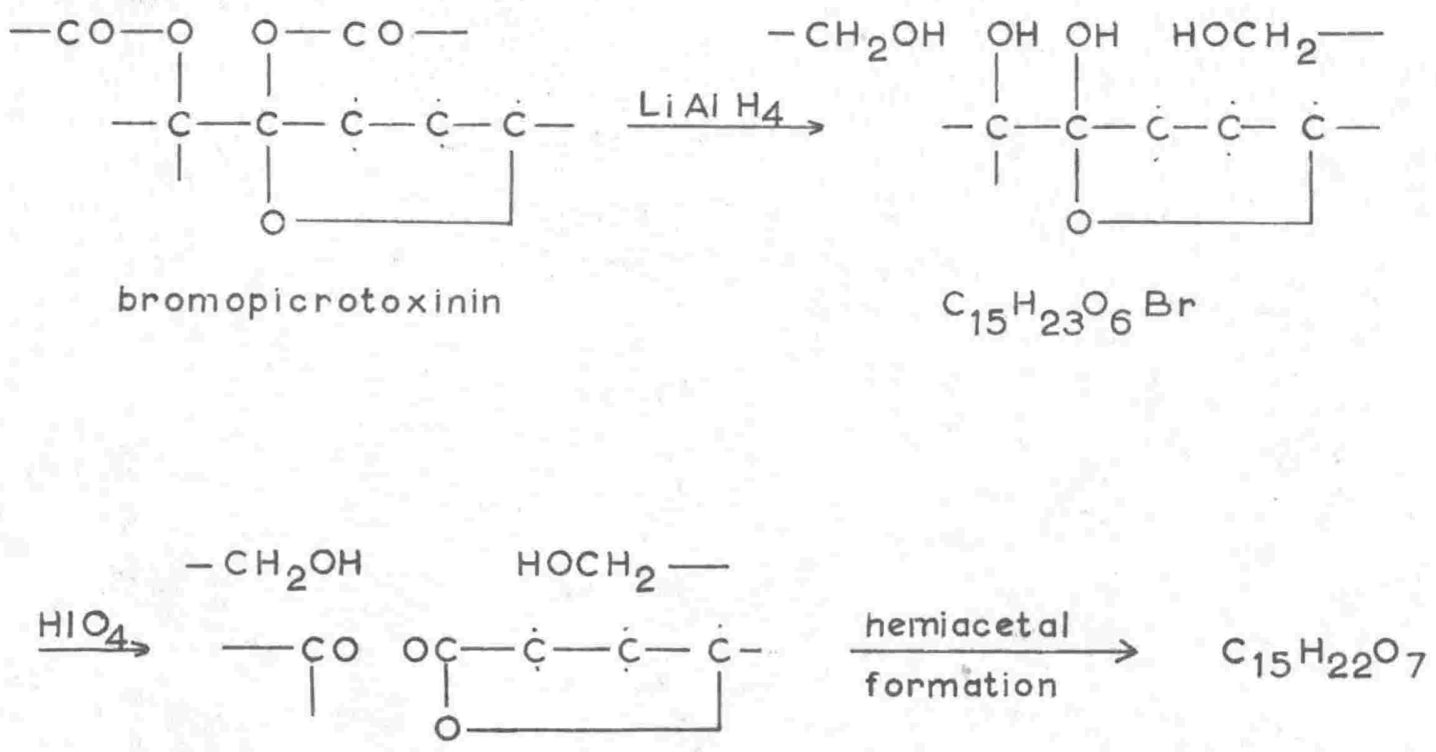

These reactions imply the presence of a hemiacetal-lactone group in $\beta$-bromopicrotoxinin and thus in picrotoxinin, and are one reason for the formulation of picrotoxinin as XXII or XXIII. conroy $^{68}$ considered that lactone fomation on oxidation of reduced $\beta$-bromopicrotcoinin did not necessarily indicate the presence of a hemiacetal-lactone system in $\beta$-bromopicrotoxinin, and he suggested that the lactone was simply a dehydration product of an acid formed during the oxidation. He postulated that reduction had proceeded through a pinacolic ring expansion and that subsequent periodate oxidation gave a product from which bromine could be readily eliminated. 


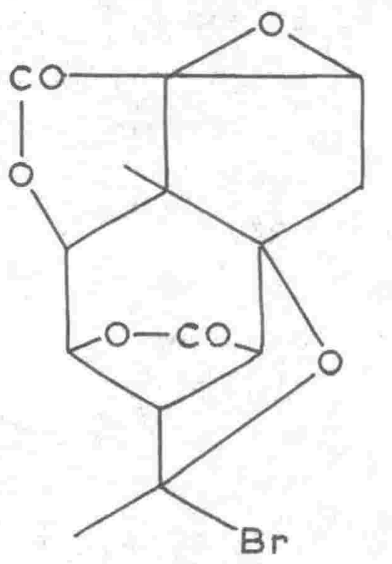

$\stackrel{\mathrm{Li} \mathrm{AIH}_{4}}{\longrightarrow}$

bromopicrotoxinin

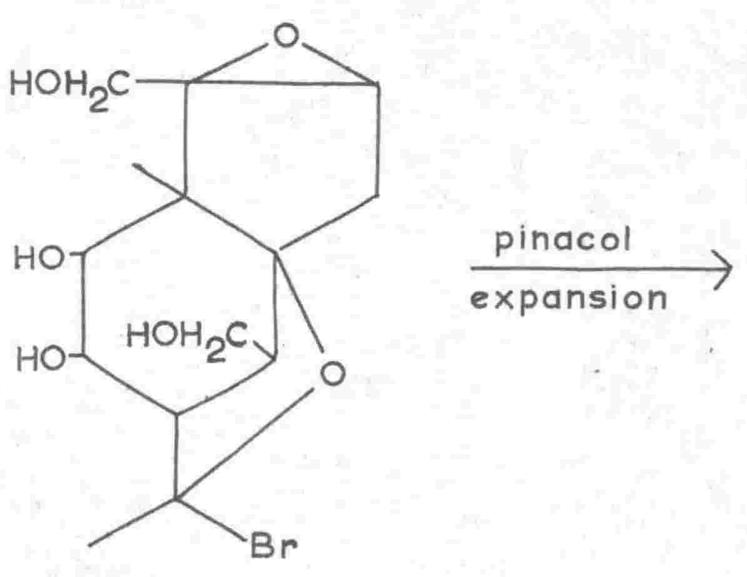

$$
x \times 111
$$
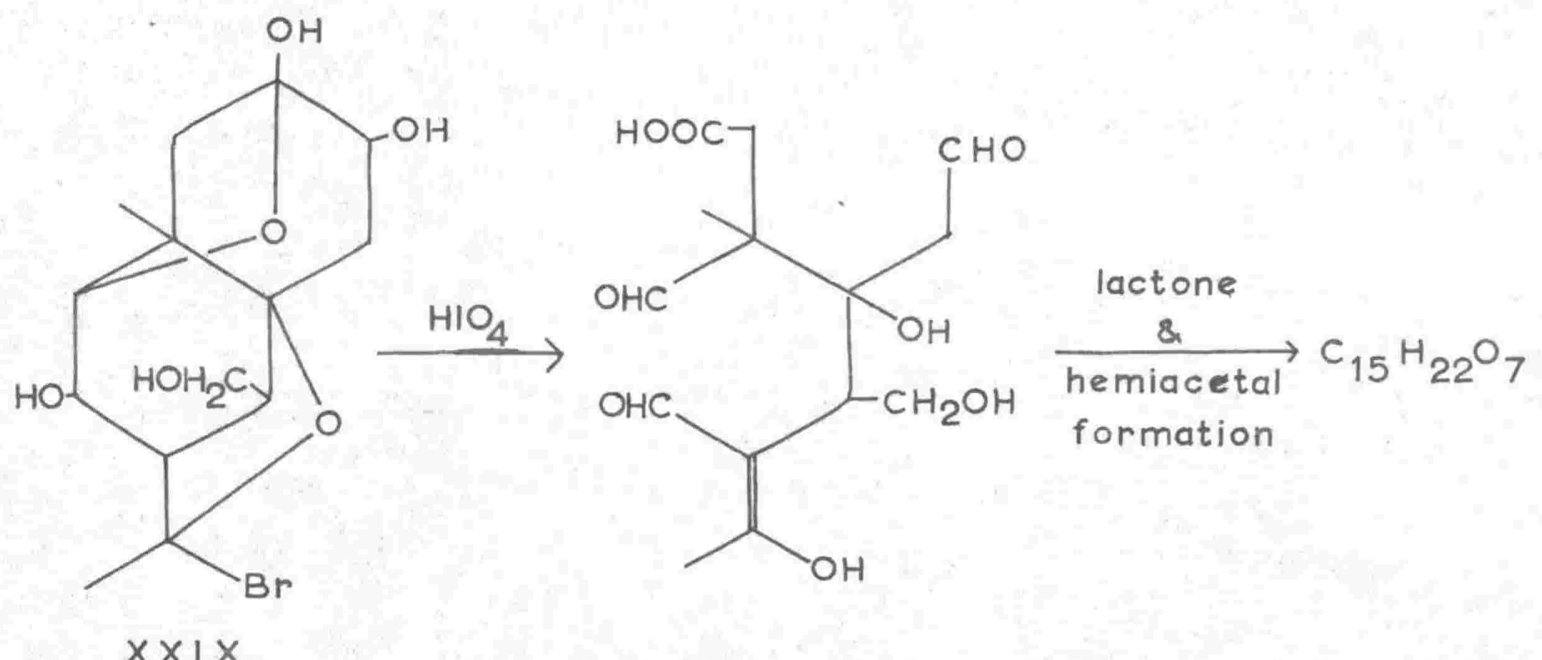

$x \times 1 \times$

Reduction of picrotoxinin with lithium aluminium hydride gave a compound the formula of which, $\mathrm{C}_{15} \mathrm{H}_{20} \mathrm{O}_{6}$, indicated that four hydrogen atoms had been added. No characteristic infra-red carbonyl absorption was present in the carbonyl region, and so the compound was sugges ted to have been formed by partial reduction of both lactone groups. 65 More recently Robertson ${ }^{69}$ obtained two products from the lithium aluminium hydride reduction of picrotaxinin. 
One of these, $\mathrm{C}_{15} \mathrm{H}_{20} \mathrm{O}_{6}-\mathrm{xxx}$, was faund to be identical to the compound mentioned above, while the other, $\mathrm{C}_{15} \mathrm{H}_{22} \mathrm{O}_{6}-\mathrm{XXXI}$, was obtained in only $3 \%$ yield. The compound $\mathrm{C}_{15} \mathrm{H}_{20} \mathrm{O}_{6}$ reacted with periodate to give a product $\mathrm{C}_{15} \mathrm{H}_{18} \mathrm{O}_{6}-\mathrm{XXXII}$, which, when hydrolysed with either acid or alkali, gave formic acid together with a compound $\mathrm{C}_{14} \mathrm{H}_{15} \mathrm{O}_{5}-\mathrm{XXXIII}$. The same compound, together with some formaldehyde, was obtained when the secand product, $\mathrm{C}_{15^{\mathrm{H}}} \mathrm{O}^{\mathrm{O}} 6^{\text {}}$, was treated with periodate.

Robertson postulated that these reactions followed the scheme indicated below, and that reduction of picrotoxinin had therefore caused a rearrangement of the ether link similar to that which was suggested to occur ${ }^{64}$ during the reduction of $\beta$-bromopicrotoxinic acid.

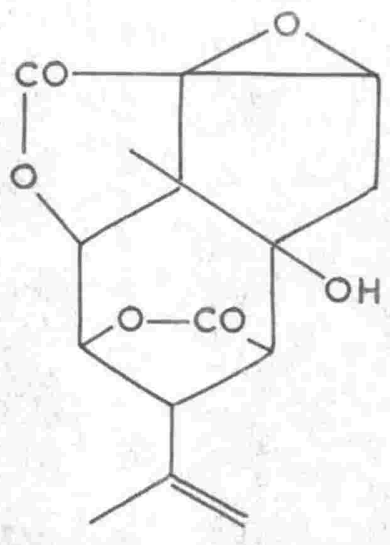

Piorotoxinin XXI
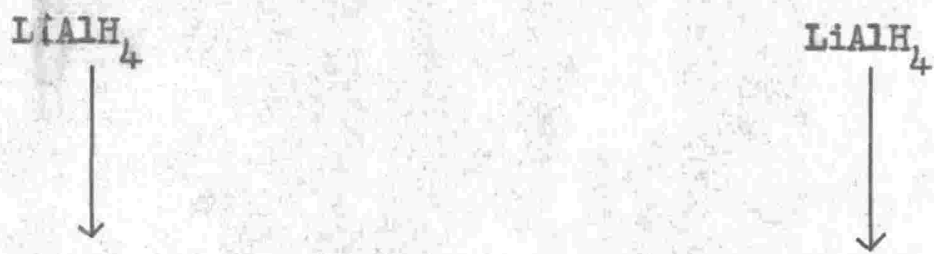


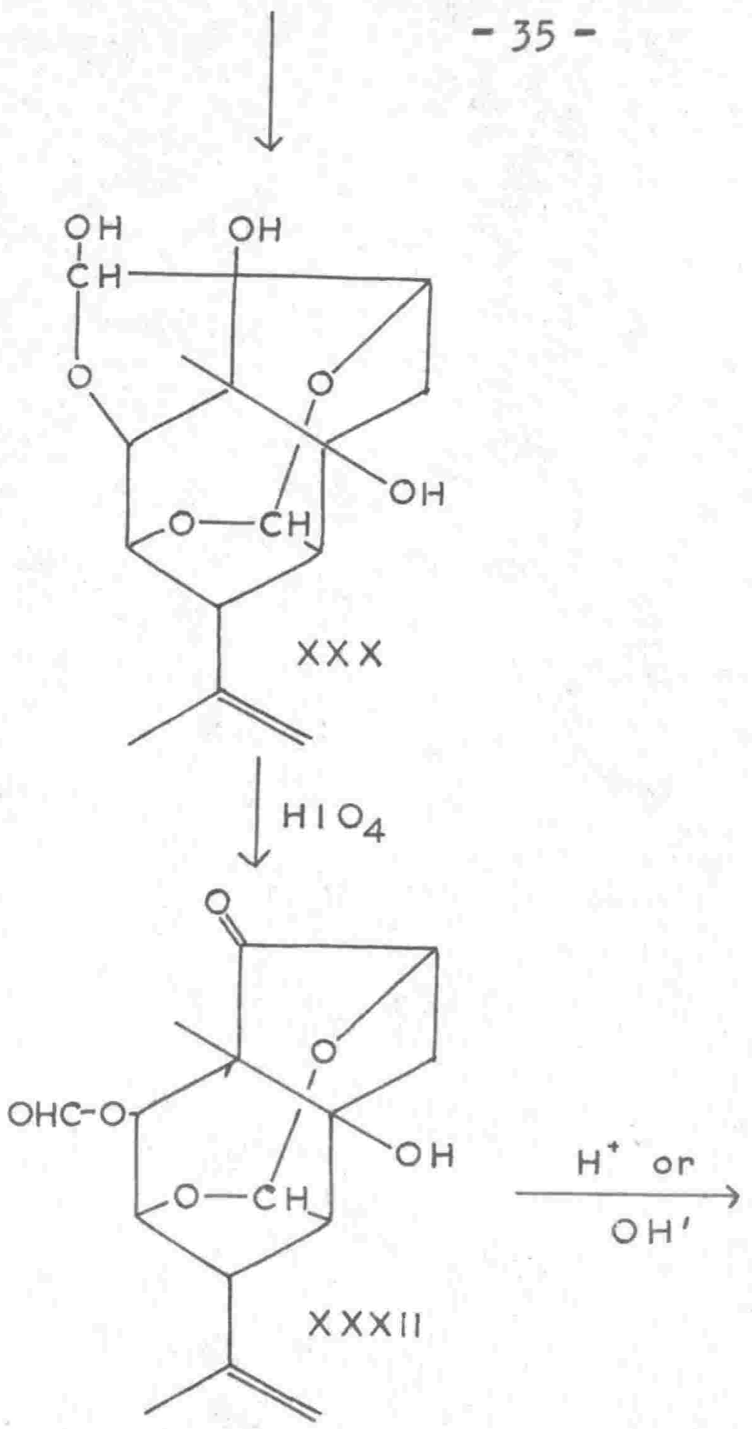<smiles>C=CC</smiles>
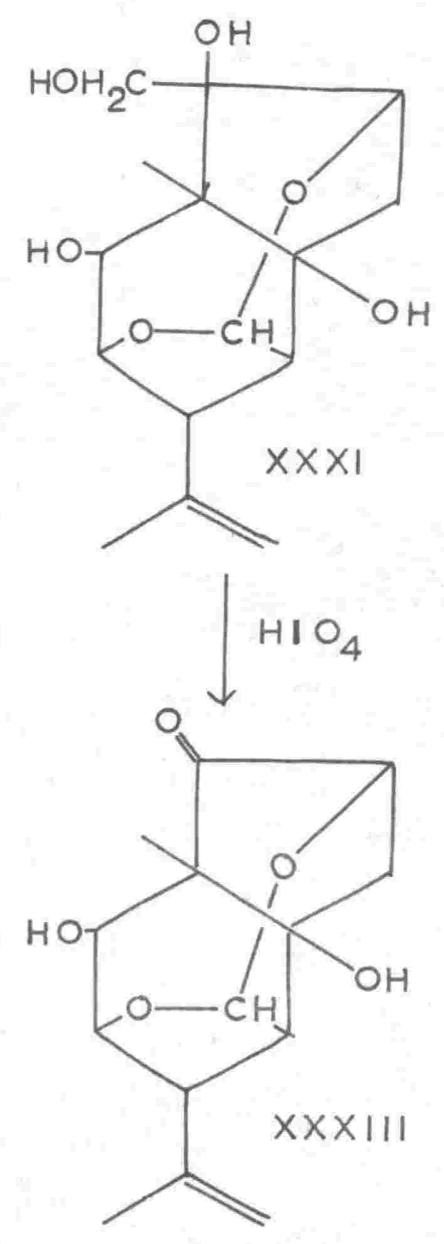

Reduction of picrotin, $\mathrm{C}_{15}{ }_{18} \mathrm{H}_{7}$, with lithium aluminium hydride gave a compound, $\mathrm{C}_{15^{\mathrm{H}}} \mathrm{O}_{7}$, which was formulated asXXXIV ${ }^{69}$. This compound, on treatment with periodate and subs equent hydrolysis, gave a product $\mathrm{C}_{14} \mathrm{H}_{20} \mathrm{O}_{6}$ formulated as XXXV. Lithium aluminium hydride reduction of this compound gave the alcohol XXXVI, which was found to be identical to the compound formed by treating compound XXXIII of the picrotoxinin series with perbenzoic acid and reducing the resultant epoxide with hydride. Thus another direct relationship between ${ }_{\Lambda}^{\text {phe }}$ icrotoxinin and picrotin series was established. 


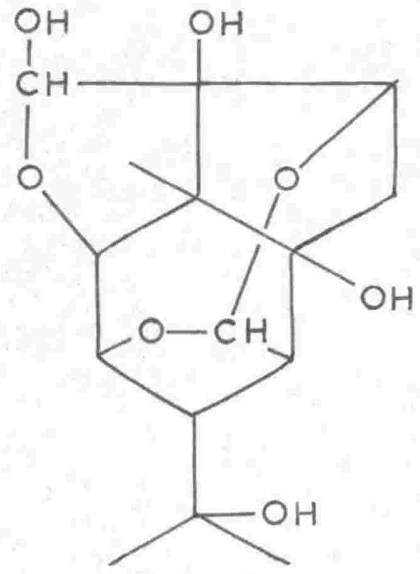

$X \times X I V$

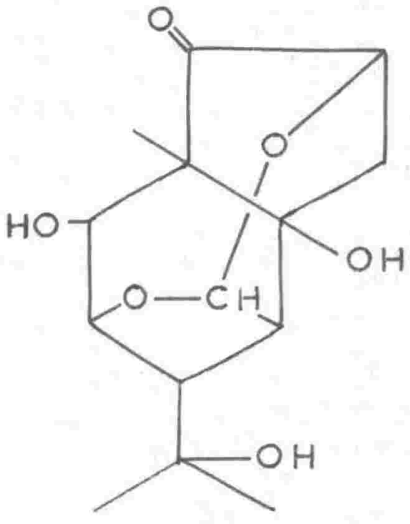

$X \times X V$<smiles>CC(C)(O)C1CC2(O)CC3OC(C2O)C1(C)C3O</smiles>

$X \times X \vee I$

\section{Apopicrotoxinic dilactone:}

A further example of a reaction in which a picrotoxinin derivative was postulated to undergo fission of the epoxide link together with formation of a new bridge between carbon atoms 12 and 15 has been discussed by Conroy. ${ }^{64}$ Whilst $B$-bramopicrotoxinic acid itself did not react with periodate, Conroy found that this acid could be rearranged by hot alkaline treatment to give a syrup which then consumed three moles of periodate. When this syrup was 
debrominated with zinc and ammonium chloride, a compound $\mathrm{C}_{15} \mathrm{H}_{18}{ }_{7}$, isomeric with $\alpha$-picrotoxinic acid, was formed. This compound, which had infra-red absorption at $1792 \mathrm{~cm}^{-1}$ and $1724 \mathrm{~cm}^{-1}$, was found to be non-acidic, and was named apopicrotoxininic dilactone. (To be consistent with the nomenclature used throughout this thesis, this compound will be renamed apopicrotoxinic dilactone). The dilactone was formulated by Conroy as XXXVII.

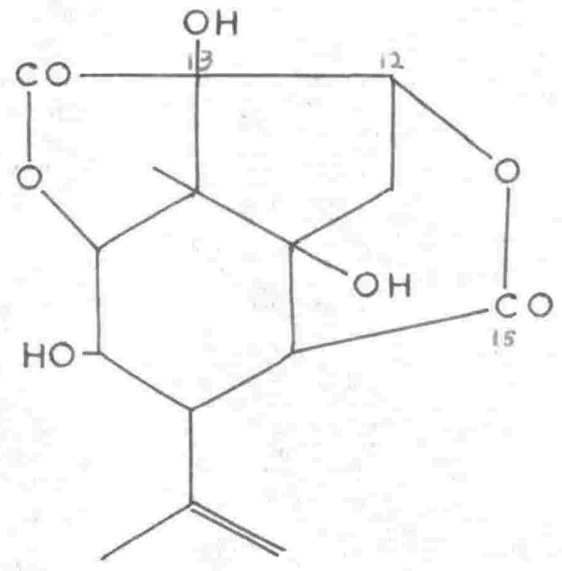

\section{XXXVIII}

It can be seen from the foregoing introduction that some picrotoxinin derivates may have an epoxide link between carbons 12 and 13, while other derivatives appear to have rearranged so that the function of oxygen atoms, if any, which are attached to these two positions, is more obscure. The work described in this thesis was an attempt to elucidate the structure of the picrotoxinin five-membered ring, and in particular to investigate the functions of the oxygen substituents attached to this ring. 
Methyl B-bromopicrotoxinate 


\section{Discussion}

Many of the problems associated with the determination of the structure of picrotoxinin have been due to the instability of the molecule. Thus, while it has been necessary to postulate the presence of an ether link in picrotoxinin, no simple derivative contrining such an ether function has been obtained. This molecular instability has been assigned, at least in part, to the presence of two lactane systems, and it was considered that removal of these groupings should give more amenable compounds.

Picrotoxinin undergoes rearrangements under both acid and alkaline conditions, and hence any attempted stepwise degradation must involve an initial neutral step. Iithium aluminium hydride and sodium borohydride reductions have given useful results in the case of $\quad \beta$-bromopicrotoxinin and $\quad \beta$-bromopicrotoxinic acid, but some unusual and unexpected reactions have been encountered, and it was felt that additional results might be advailable if these compounds were also reduced with a grignard reagent. Picrotoxinin has been formulated as $x I^{60}$.

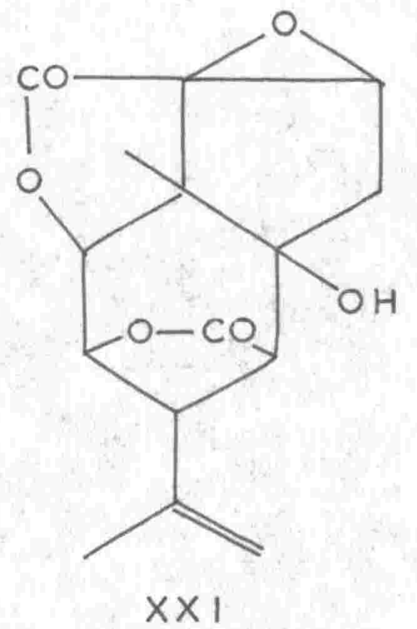


Other structures have been proposed in which the ether link occupies a different position (XXII and XXIII) ${ }^{65}$, but for the sake of convenience in this discussion formula XXI will be tentatively assumed to be correct. Infra-red absorption shows two $\gamma$-lactones, a double bond, and a tertiary hydroxyl group. Bromination of picrotoxinin gives two mono-bromo products, heither of which contain a double bond or an hydroxyl group. The two $\gamma$-lactones are still present in the bromo-compounds and, as there is no reason to suspect a rearrangement of the epoxide ring, the bromopicrotoxinins have been formulated as steroisomers of XXVIII. 60 Debromination of bromopicrotoxinin yields, as would be expected, picrotoxinin. Treatment of $\beta$-bromopicrotoxinin with alkali gives $\beta$-bromopicrotoxinic acid. The reaction occurs in the cold and involves the addition of one water molecule, and it is unlikely that serious rearrangement has occumed during the hydrolysis. However the reaction is irreversible, and infra-red absorption indicates that, besides a carboxyl function, $\beta$-bromopicrotoxinic acid contains a $\delta$-lactane. An explanation of these facts has been put forward by Conroy ${ }^{60,61}$ who suggested that both the $\beta$-bromopicrotoxinin lactones have been opened and that one has reclosed in a different position. 


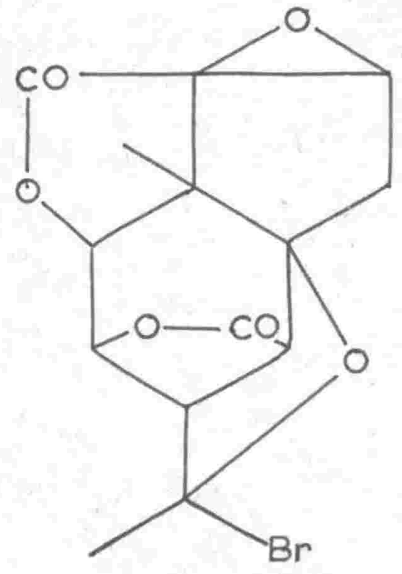

XXVIII

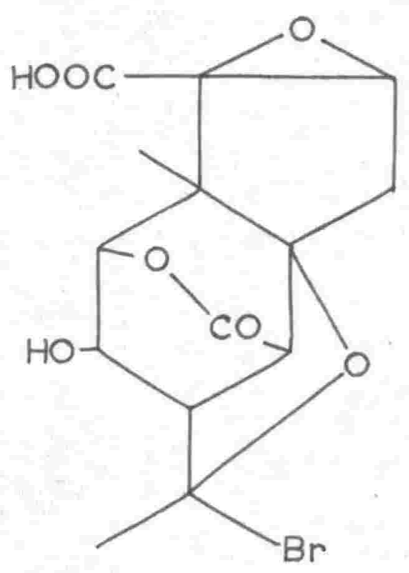

XXIV

A secondary hydroxyl group is present in the bromoacid. Acetylation of this hydroxyl gives a mono-acetate which shows no hydroxyl absorption in the infra-red. $\quad \beta$-Bromopicrotoxinic acid will not react with lead tetraacetate and has thus been formulated as XXIV.

Formaldehyde was obtained in $9 \%$ yield when $\beta$-bromopicrotoxinic acid reduced with lithium aluminium hydride was treated with periodate. 65 This indicated that the grouping XXXVIII was present in the reduced compound despite the fact that $\beta$-bromopicrotoxinic acid did not contain the grouping $x \times x+x$. The reduction of methyl $\quad \beta$-bromopicrotoxinic ester with methyl magnesium iodide was therefore carried out in an attempt to determine whether the grouping $X C$ was formed in the product in a manner analogous to the formation of XXXVIII in the hydride series. 
$\begin{aligned} & \mathrm{OH} \\ - & \mathrm{c}-\mathrm{CH}_{2} \mathrm{OH}\end{aligned}$

XXXVIII
$\mathrm{OH}$
$-\stackrel{c}{c}-\mathrm{COOH}$

$\underline{\operatorname{XXXIX}}$

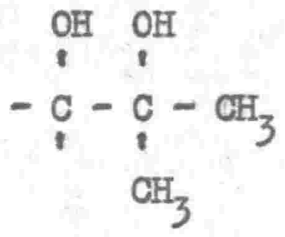

XI

Methyl $\beta$-bromopicrotoxinate was prepared by direct methylation of $\beta$-bromopicrotoxinin using sodium methoxide as a catalyst. The suspension of $\quad B$-bromopicrotoxinin in methanol gave a clear solution after four hours stirring and then rapidly precipitated the ester, indicating that the esterification reaction proceeded through a soluble intermediate. The ester melted at $225^{\circ} \mathrm{C}$. and showed infra-red absorption at $3548 \mathrm{~cm}^{-1}$ (hydroxyl) and $1744 \mathrm{~cm}^{-1}$ (ester and $\delta$-lactone). Methyl porcmopicrotoxinate was found to be relatively insoluble in dry ether and initially a grignard reaction was carried out using methyl magnesium iodide and methyl bbromopicrotoxinate in a solvent mixture of ether and toluene. The reaction mixture was worked up in the normal manner to give a brown oil which was chromatographed on alumina to produce, after recrystallization from ethyl acetate, a colourless crystalline compound melting at $227-228^{\circ} \mathrm{C}$. This same compound was obtained when the reaction was repeated using dioxan as a solvent, and it was also obtained if either neutral or acidic reagents were used during hydrolysis of the grignard complex. Subsequently it was found that a slightly cleaner product was obtained if the methyl - $\beta$-bromopicrotoxinate was ether extracted directly into an ethereal 
solution of the grignard reagent, and this method was used in all further preparations. The yield was approximately $80 \%$.

The compound m. $\mathrm{m}_{0} \cdot 227-228^{\circ} \mathrm{C}$ analysed as $\mathrm{C}_{18} \mathrm{H}_{27} 7_{6} \mathrm{Br}$, indicating the addition of three methyl groups to the molecule, with the loss of the ester methyl group and one oxygen associated with it. Infra-red absorption showed the presence of hydroxyl groups $\left(3543,3327 \mathrm{~cm}^{-1}\right)$, and the absence of absorption in the carbonyl region suggested that both the ester and lactane groupings had been reacted upon. A maximum at $2220 \AA, \varepsilon=275$, (Graph I), in the ultra violet was of unknown origin.

The grignard product did not react with bromine in cabbon tetrachloride or with neutral permanganate and was thus considered to be saturated. It was non-reducing, and was soluble to the same extent in alkali as in water. It did not give an iodoform reaction, but formed a mono-acetate, $\mathrm{C}_{20} \mathrm{H}_{29^{\circ}} \mathrm{O} \mathrm{Br}, \mathrm{m} . \mathrm{p} .82^{\circ} \mathrm{C}$, when treated with acetic anhydride in pyridine. This acetate was purified by repeated sublimation, as recrystallization gave material of variable melting point. It showed the same ultraviolet absorption ( $2200 \AA, \varepsilon=260$ ) as the parent compound, and gave acetate bands at 1740 and $1236 \mathrm{~cm}^{-1}$ and hydroxyl absorption at $3438 \mathrm{~cm}^{-1}$ in the infra-red.

Methylation of the grignard product with methyl iodide and silver oxide gave a compound with a melting point which varied from $200-236^{\circ} \mathrm{C}$, and which could not be further purified by either sublimation or recrystallization. It gave a definite mixedmelting point depression with the starting material, and 


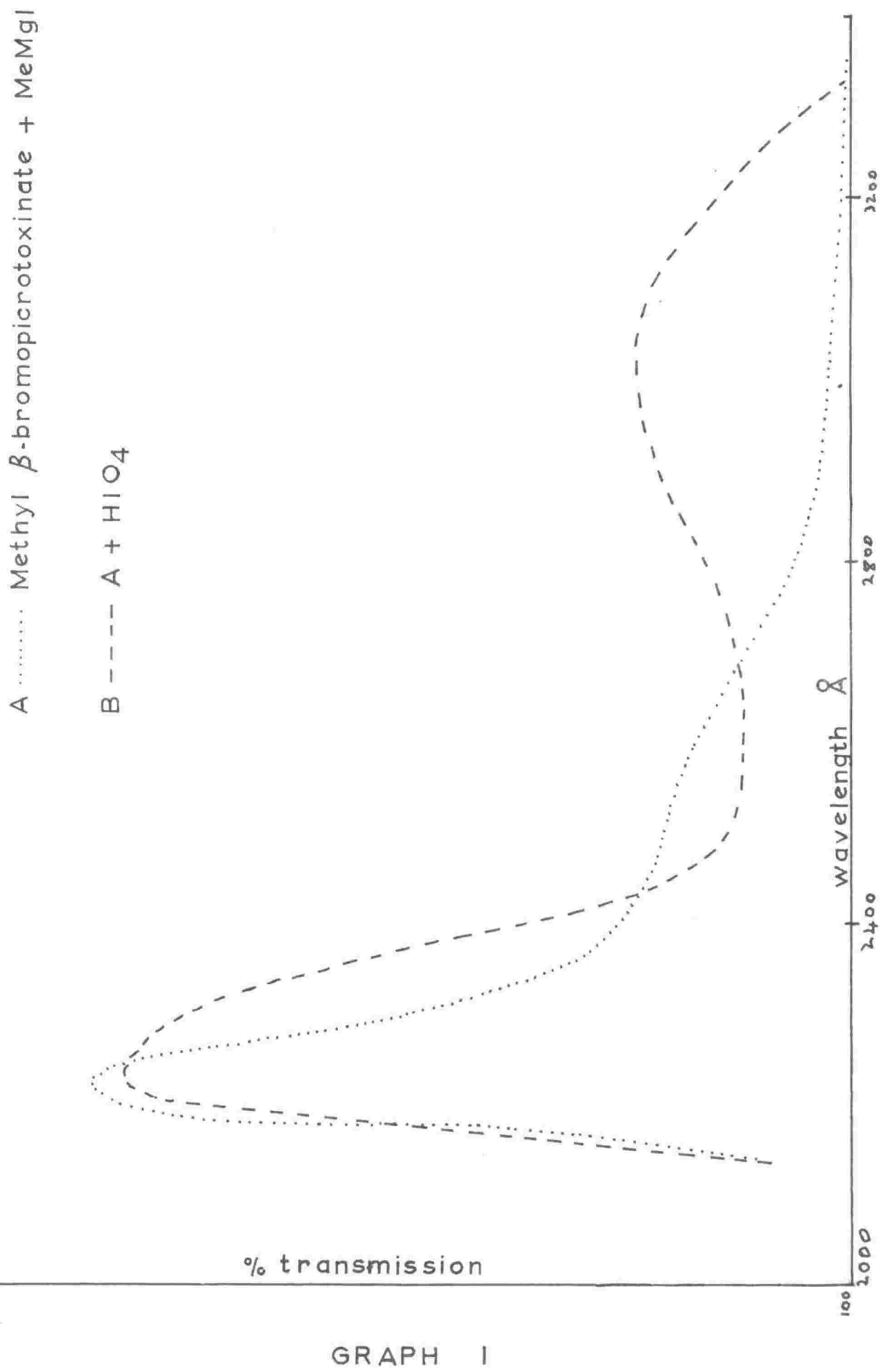


ultra-violet absorption showed a peak at $2180 \AA$. This compound was probably a mixture resulting from methylating the grignard product to various degrees, as was probably a similar impure compound obtained by methylation with dimethyl sulphate, m.p. circa $192^{\circ} \mathrm{C}$.

Oxidation of the grignard product with periodic acid was carried out at room temperature, and the amount of periodate consumed was measured by back titration of aliquots as the reaction proceeded. (Table II).

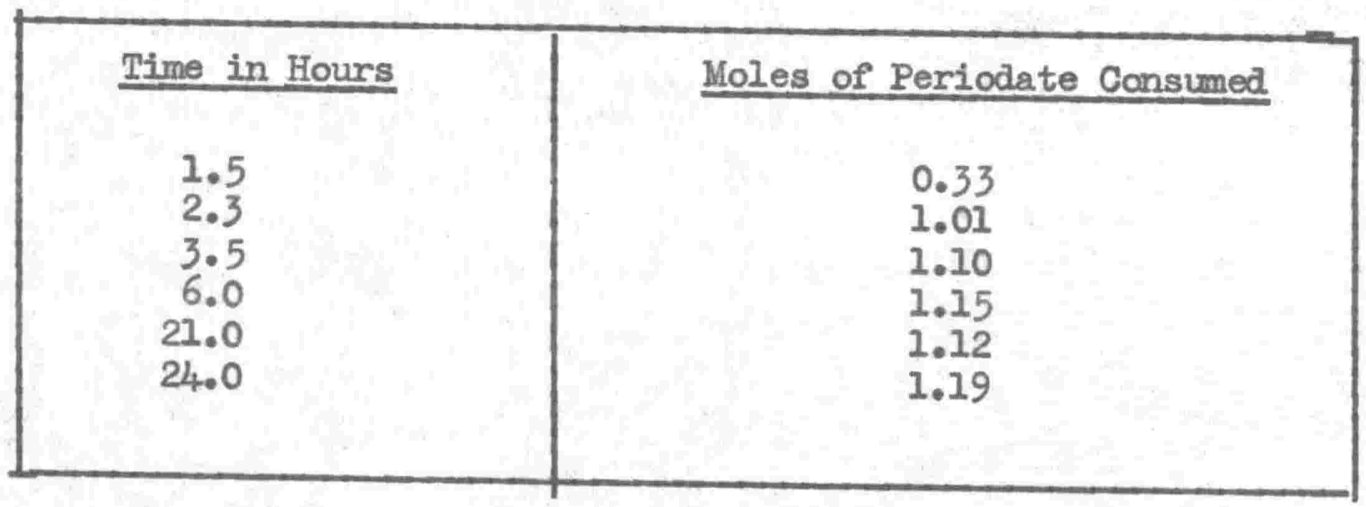

Table II

A white solid precipitated out after about three hours, the actual time varying inversely in each reaction with the concentration of the grignard product in solution.

In a separate experiment the reaction mixture was stirred by bubbling air through the solution, the air was then passed into a 2:4 - dinitrophenylhydrazine solution, and after three hours the precipitated 2:4 - dinitrophenylhydrazone was filtered off and weighed. The derivative melted at $125^{\circ} \mathrm{C}$ and gave no mixed melting point depression with acetone $2: 4$ - 
dinitrophenylhydrazone, m.p. $125^{\circ} \mathrm{C}$. It al so had an ultraviolet spectrum identical to that of acetone 2:4-dinitrophenylhydrazone with a maximum at 3650 \&. A $65 \%$ yield of acetone was ob tained by this method, and this yield was further increased to $81 \%$ by ether extraction of the remaining reaction mixture and distillation of the ethereal solution. This yield compares very favourably with the maximum $\%$ yield of formaldehyde obtained when hydride reduced $\quad \beta$-bromopicrotoxinic ester was treated with periodate $^{65}$ Periodate oxidation of the acetate of the grignard product also gave acetone, identified by chromatography of the 2:4-dinitrophenylhydrazone.

The white solid material was collected by filtration and by ether extraction of the periodate solution, mp. $214-216^{\circ} \mathrm{C}$. Recrystallization of this compound from ethyl acetate raised the melting point to $223^{\circ} \mathrm{C}$, with a mixed melting point of $204^{\circ} \mathrm{C}$ with the starting material. The melting point was very dependent upon the rate of heating, and it was difficult to determine when the material was absolutely pure. UI tra-violet absorption maxima were present at $2230 \AA$ and $3010 \AA$ (Graph I). In the crude material the peak at the lower wave length was approximately ten times as strong as the peak at $3010 \AA$, but on repeated recrystallization this ratio was reduced to a constant value of 6.88 times. The same terial, m.p. and mixed m.p. $223^{\circ} \mathrm{C}$, ultraviol et maximum $3010 \AA$, was also ob tained when the grignard compound was oxidised with either neutral sodium periodate solution or with l ead tetraacetate in neutral solution. The grignard product 
was only difficultly soluble in water or dilute acid, and thus it was essential to stir the reaction mixture during periodate oxidation. On occasions when stirring was not carried out, unchanged material could be isolated 48 hours after the commencement of the reaction.

The periodate product analysed as $\mathrm{C}_{15} 5_{1}^{\mathrm{H}}+9^{\mathrm{O}} 5^{\mathrm{Br}}$, and this residue, together with the $\mathrm{C}_{3} \mathrm{H}_{6} \mathrm{O}$ split off as acetone, accounts for all the atoms of the grignard molecule. The infra-red absorption of the compound indicated the presence of at least one hydroxyl group $\left(3488 \mathrm{~cm}^{-1}\right)$ and of a carbohyl group $\left(1767 \mathrm{~cm}^{-1}\right)$. Acetylation of the product with acetic anhydride in pyridine yielded a monoacetate, $\mathrm{C}_{17} \mathrm{H}_{21} \mathrm{O}_{6} \mathrm{Br}, \mathrm{m} \cdot \mathrm{p} \cdot 144^{\circ} \mathrm{C}$. This compound exhibited the same ultra-violet spectrum as the parent compound, $(2230 \AA$ and $3000 \AA)$, but gave no hydroxyl absorption in the infrared (carbonyl absorption at $1762 \mathrm{~cm}^{-1}$ and acetate at $1729 \mathrm{~cm}^{-1}$ and $1245 \mathrm{~cm}^{-1}$ only).

The periodate oxidation product appeared to form a 2:4-dinitrophenylhydrazone after heating for four hours with phenylhydrazine reagent. This derivative was chromatographed on a bentonite-kieselguhr column ${ }^{70}$ to give an intractable oir together with a small quantity of pale orange powder, mp. 230$40^{\circ} \mathrm{C}$. The ultra-violet spectrum of this powder gave a maximum at 3600 \&. An attempt was also made to purify the oxime which could be formed from the carbonyl function, m.p. $245-51^{\circ} \mathrm{C}$, but this compound yellowed and decomposed on exposure to the atmosphere. 
The absence of an activated $\alpha$-methylene group in the periodate product was shown by the reactions of this compound with both selenium dioxide and benzaldehyde. The reaction with selenium dioxide was carried out at $79^{\circ} \mathrm{C}$ for two hours, but as no red selenium had precipitated in this time, the temperature was raised to $100^{\circ} \mathrm{C}$ for a further six hours. The resulting solution contained a small amount of sticky red $g$ um, indicating that some oxidation had occurred, but the product isolated in very small yield. had an ultra-violet spectrum (2050 $\AA$ maximum, 2500 and $2850 \AA$ inflections) entirely different from that expected for an $\alpha-$ diketone (camphorquinone - maximum $4660 \AA$, other 1:2-diones maxima at $3370-800 \AA$ and at $2950 \AA^{71,72}$ ).

No product other than benzoic acid and starting material could be obtained by prolonged treatment of the periodate product with benzaldehyde in the presence of catalytic amounts of sodium ethoxide.

The product of the reaction between methyl magnesium iodide and methyl bromopicrotoxinate is not easy to formulate. Three methyl groups have been added to the molecule, and two of these must have been added to the methyl bromopicrotoxinate ester group in order that :

(a) No earbonyl activity due to a ketone or ester grouping remained in the molecule.

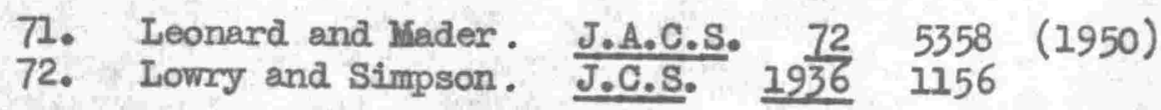


(b) Acetone could be evolved on oxidation with periodic acid.

$$
\mathrm{CH}_{3}-\mathrm{OOC}-\stackrel{2 \mathrm{MeMgI}}{\longrightarrow} \quad \underset{\mathrm{CH}_{3}}{\mathrm{CH}_{3}} \stackrel{\mathrm{OH}}{\mathrm{C}}-
$$

For this latter reaction (b) to occur the group XII must be present in the grignard product. The oxygen on $C_{1}$ may be present as a free hydroxyl or combined in a hemiketal, a hemiacetal, or an epoxide link, as these latter groups would be expected to generate a hydroxy group under acid conditions. The glycol oxidation could also be carried out, however, with neutral sodium periodate and with neutral lead tetraacetate, conditions under which the hemiketal, hemiacetal, or epoxide group should not react, and it is thus necessary that the group $\mathrm{XI}$ be present in the grignard product.

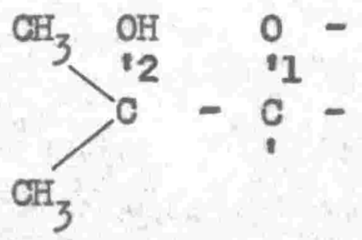

XII

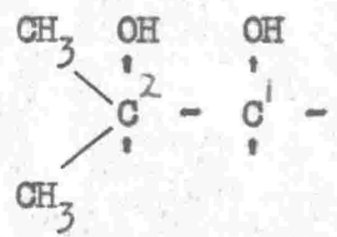

XI

No other glycol system is present as only one mole of neutral or acidic periodate is consumed.

Periodate oxidation gave a ketone which absorbed in the infra-red at $1767 \mathrm{~cm}^{-1}$. The position of this absorption, 
together with the presence of an ultra-violet maximum at $3010 \AA$, led to the formulation of the periodate product as a substituted cyclopentanone. (cyclopentanone itself absorbs at $2990 \AA$ in the ultra-violet ${ }^{73,74}$ and at $1740^{75}-1772^{76} \mathrm{~cm}^{-1}$ in the infrasred.)

The ketone obtained by oxidation of either the lithium aluminium hydride or sodium borohydride reduction products of $\beta$-bromopicrotoxinic acid also absorbed in the same regions in the ultraviolet and infra-red, (Table III), and this compound has also been formulated as a five-membered cyclic ketone. ${ }^{64,65}$ The grignard product is therefore partially formulated as XIII.

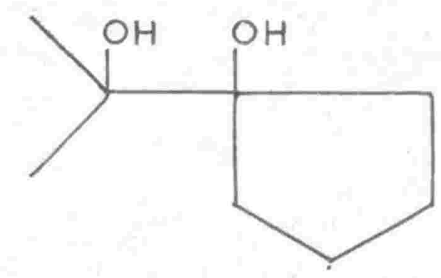

$X$ XII

\begin{tabular}{|c|c|c|}
\hline Compound & Infra-red & UItra-violet \\
\hline $\begin{array}{c}\beta \text {-bromopicrotoxinic ester } \\
+ \text { MeligI }+\mathrm{HIO}_{4}\end{array}$ & $1767 \mathrm{~cm}^{-1}$ & $3010 \AA$ \\
& \\
$+\left\{\begin{array}{l}\mathrm{NaBH}_{4}+\mathrm{FbO}_{2} \\
\mathrm{IiAlH}_{4}+\mathrm{HIO}_{4}\end{array}\right.$ & $1768 \mathrm{~cm}^{-1}$ & $3020 \AA$ \\
\hline
\end{tabular}

73. Dorfman. Chem, Rev. 5351 (1953)

74. Mariella \& Raube. J.A.C.S. 74519 (1952)

75. Whitten \& Thompson. J.C.S. 19461005

76. Hartwell, Richards, Thompson. J.C.S. 19481436 
The above evidence gives definite proof as to which of the two $\beta$-bromopicrotoxinin lactone functions has opened to form the ester grouping in methyl $\beta$-bromopicrotoxinate, and Conroy's formula for $\beta$-bromopicrotoxinic acid, XXIV, is verified at least in so far as the positioning of the acid function is concerned.

The product of reaction of a lactone with methyl magnesium iodide is difficult to predict, and many anomalous products have been formed. 77,80 However three chief types of end-products are possible $e^{81}$.

(a) No addition to the lactone may have occurred due to steric hindrance.

(b) Complete reaction may have occurred. 82,83

(c) Partial addition may have occurred ${ }^{84}$

(b)

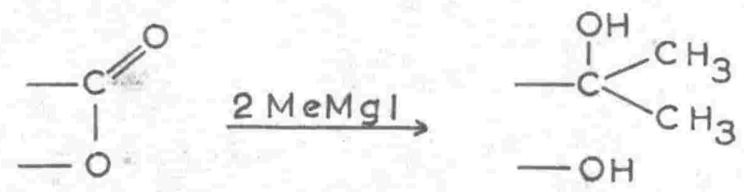

(c)

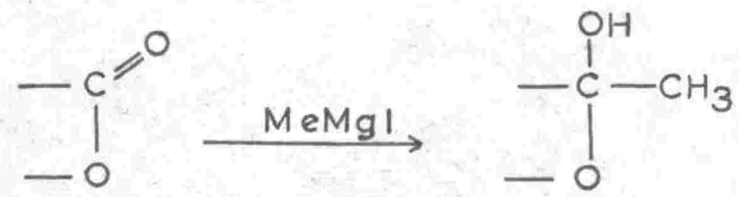

77. Smith \& Ruoff. J.A.C.S. 62145 (1940)

78. Cox. J.A.C.S. 66865 (1944)

79. Greshain et al. J.A.C.S. 712807 (1949)

80. Easton et al. J.A.C.S. 754731 (1953)

81. Kharasch \& Reinmuth. Grignard Reactions of Nonmetallic Substances. p. 574. Prentice-Hall, N.Y. (1954)

82. Henry. Compt, Rend. 1,3 1221 (1906)

83. Kohn. Monatsh $\frac{34}{1729}$ (1913)

$$
\text { A } 106175 \text { (1914) }
$$

84. Thompsan, Yates, Odell. J.A.C.S. 761195 (1954) 
In the case of methyl $\beta$-bromopicrotoxinate (a) above cauld not have occurred as the product showed no infrared lactone absorption. Option (b) could also not have occurred as this reaction requires the addition of two methyl groups and hence the formation of a $\mathrm{C}_{19}$ product. Option (c) is a possibility, and the hemiketal system XIIII or the ketal system XIIV may be present in the product.

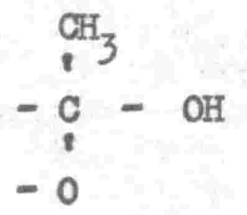

XIIII

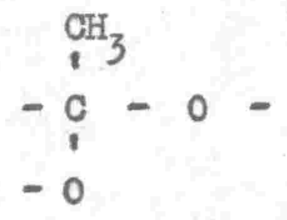

XIIV

Consider now the ether link. $\quad \beta$-Bromopicrotoxinic acid will not react with either lead dioxide or lead tetraacetate and hence does not contain an hydroxyl group in a position $\mathcal{\alpha}$ to the acid function. However, the pro duction of acetone upon neutral periodate oxidation of the grignard product indicates that this compound now contains an hydroxyl group on the $\alpha$-carbon, and this must have arisen from cleavage of an ether link. 
Two problems remain to be solved :

(a) To what carbon atom was the second end of the ether link attached in $\beta$-bromopicrotoxinic ester.

(b) What happened to this ether link during grignard reaction. Conroy's formulation for methyl $\beta$-bromopicrotoxinate gives an epoxide link between carbon atoms 12 and 13. The normal reaction of a grignard reagent with an epoxide involves ring opening followred by alkyl substitution $85,86,87$, butsome anomolous reactions are known $85-89$.
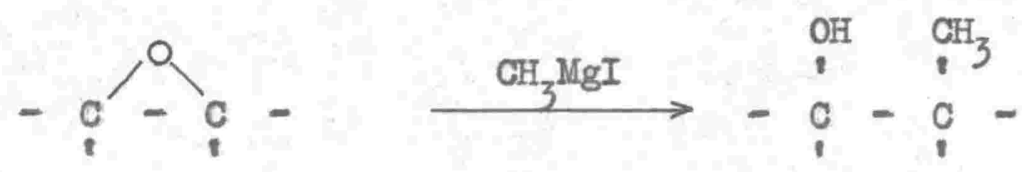

\section{XIV}

The grignard product after periodate treatment did not react with either selenium dioxide or benzaldehyde, and therefore must have a substituent on both carbon atoms adjacent to the keto-group (XIVI). However no addition of an alkyl group to an epoxide in $\beta$-bromopicrotoxinic ester could

85. Miderfield. "Heterocyclic Compounds" Part I p.55 Wiley \& Sons, N.Y. (1950)

86. Gaylord \& Becker. Ghem. Rev. 49413 (1950)

87. As reference 81 . p. 961

88. Fuson et al. J. Org. Chem. $10 \quad 69$ (1945)

89. Kauer et al. Helv. Ghim. Acta. 29233 (1946) 


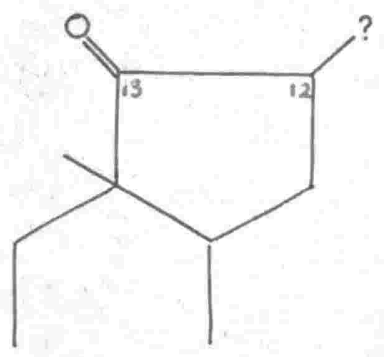

$\underline{\text { XIVI }}$

have occurred during the grignard reaction as this would again require the farmation of a $\mathrm{C}_{19}$ compound. Therefore the carbon $\sigma_{12}$ must be substituted by an oxygen, - either in hydroxyl or ethereal form (XIVII). This evidence shows that the ether link in methyl $\beta$-bromopicrotoxinate may have been present as an epoxide which has then reacted in an unusual fashion with methyl magnesium iodide.

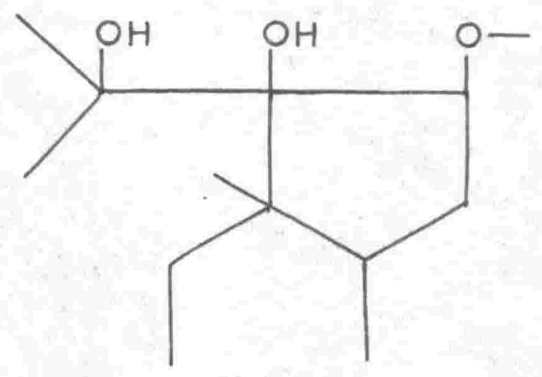

$\underline{\text { XIVII }}$

Methyl $\beta$-bromopicrotoxinate, the grignard product, and the periodate product, all show infra-red hydroxyl absorption, and will all form mono-acetates. The acetates of methyl $\beta$-bromopicrotoxinate and the periodate product do not show hydroxyl absorption, and therefore their parent compounds contain 
only one hydroxyl group. Since two hydroxyl groups are involved in periodate splitting, the grignard product will thus contain three hydroxyl groups.

The hydroxyl group of methyl $\beta$-bromopicrotoxinate, which has been shown by oxidation experiments to be present at $\mathrm{C}_{5}{ }^{98}$, should not be affected by the grignard or periodate reactions, and should therefore exist at $C_{5}$ in all three compounds. The hydraxyl groups can thus be placed as follows
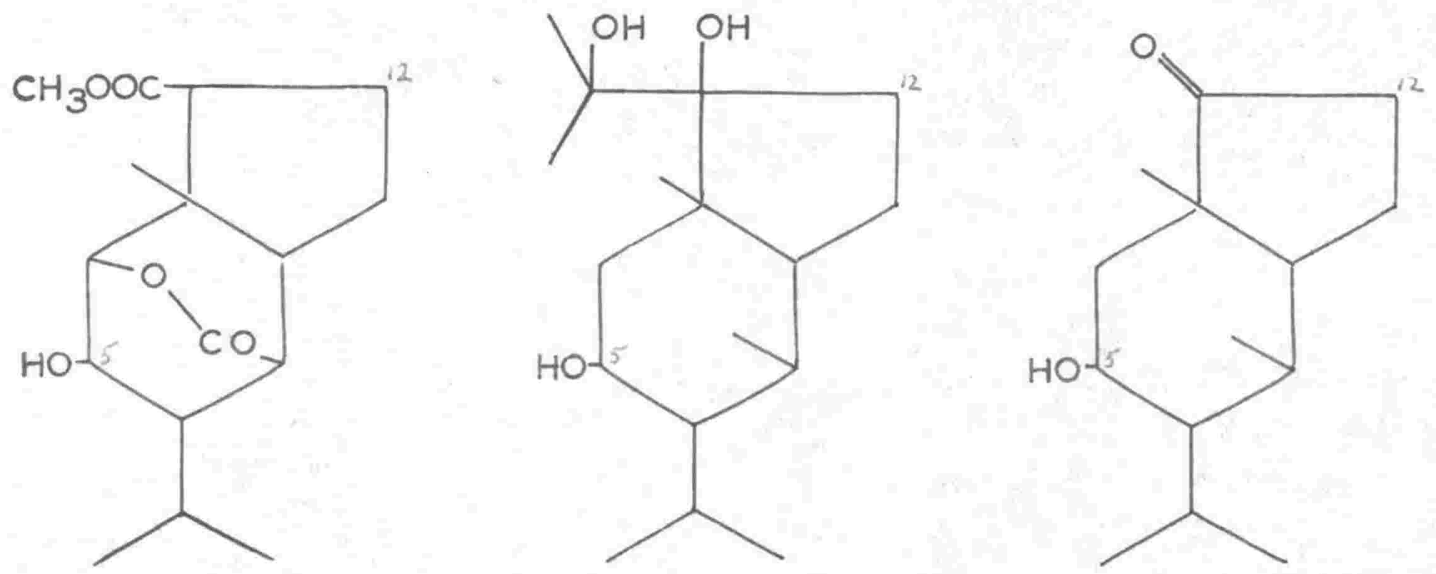

Methyl B-bromopicrotoxinate Grignard product Periodate product

The proposed ketal/hemiketal function, XIIII/XIIV, cannot contain a free hydroxyl group, and thus must be present as the ketal XIIV. The oxygen function previously shown to be positioned at $\mathrm{C}_{12}$ in the periodate product can also not be present as an hydroxyl group, and must hence involve an ether link.

The grignard and periodate products are formulated completely a.s XLVIII and XIIX. 


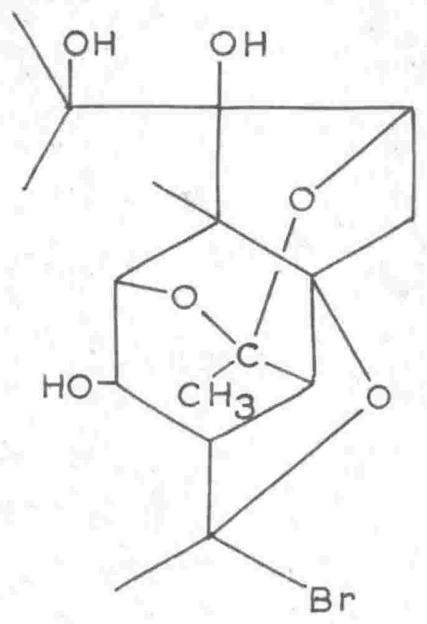

XIVIII

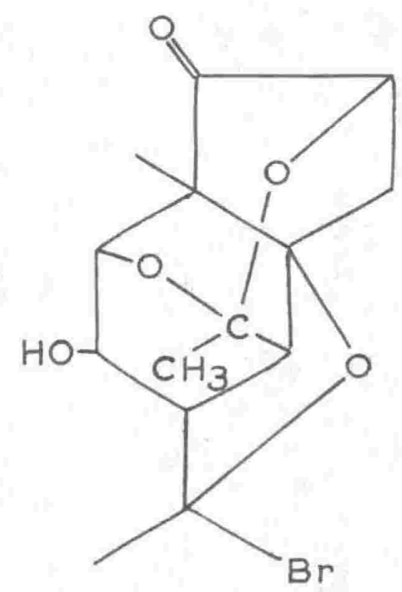

$\underline{X I X}$

These compounds formed by grignard reaction are thus campletely analagous to those formed by hydride reduction of $\beta$-bromopicrotoxinic acid, which have been postulated to have the structures XXV, XXVI, and XXVII. The mechanism of formation of the grignard product probably proceeds along lines similar to those postulated for the sodium borohydride compound, i.e. a methyl radicle attacks the lactone carbonyl group and excess electronic charge builds up on the carbonyl oxygen. This accumulated charge causes rearward displacement of the nearby epoxide linkage, and results in the formation of the ketal system. Simultaneous addition of two methyl groups to the ester function gives the compound XIVIIIa. 

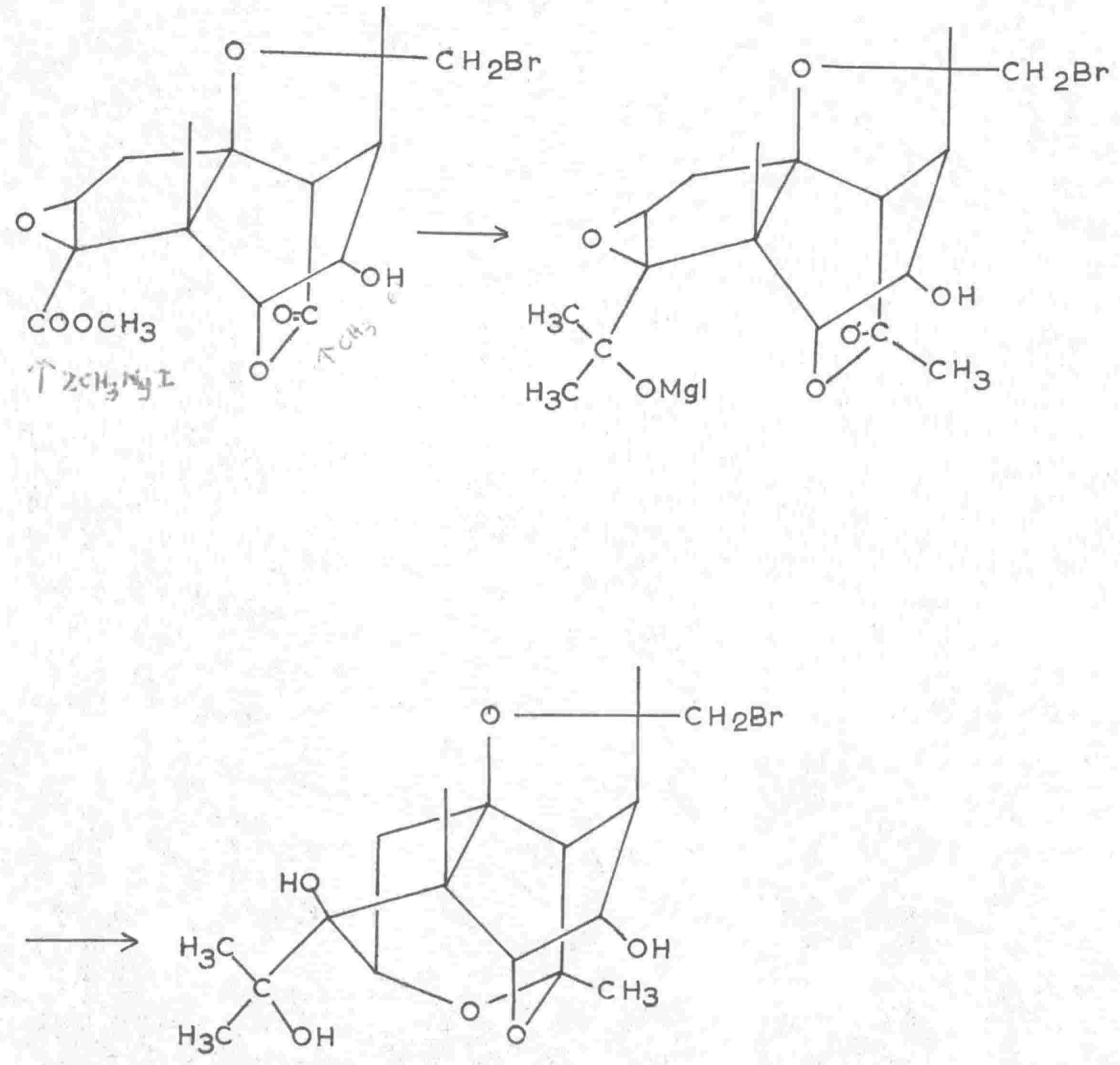

\section{XIVIII a}

A compound formulated as XIVIII and containing a ketal function should react with warm dilute acid to give a methyl ketcone which should then react with three moles of periodate. 

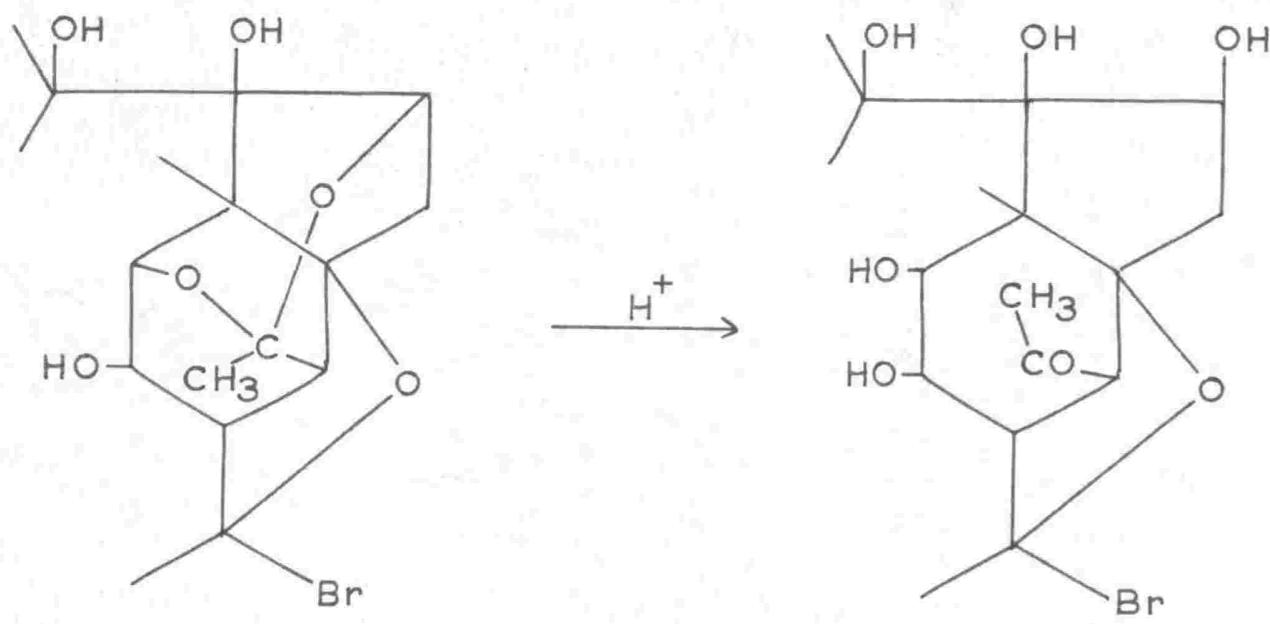

\section{XIVIII}

When the grignard product was refluxed for two hours with 2N sulphuric acid a brown intractable gum was formed together with same unchanged material. Milder treatment with $2 \mathrm{~N}$ and with 0. 2N acid on a water bath produced, besides starting material, only a brown gum. This gum showed no absorption in the ultraviolet other than bel ow $2150 \AA$.

The reaction was repeated in the presence of a small amount of hydrogen peroxide in the hope that mild acid oxidation might give a cleaner hydrolysis product. Again no solid product could be obtained, but formic acid, detected by its smell and its reactions with litmus, ammoniacal silver nitrate, and with barium hydroxide/bromine water 90,91 , was liberated in considerable quantity. No great emphasis can be placed upon this result

90. Frehden \& Furst. Mikrochemie $25 \quad 256$ (1938)

C.A. $\frac{23}{33} 1877$ (1939)

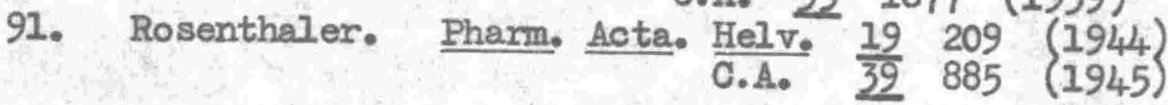


however, as a large number of organic compounds have been found to give formic acid on peroxide treatment. $92,93,94$.

The periodate product was stable to $0.2 \mathrm{~N}$ acid treatment for eight hours at $100^{\circ} \mathrm{C}$. However, both this compound and the grignard compound were more soluble in warm $2 \mathrm{~N}$ acid than in water, thus suggesting the presence of a acid-unstable group. The fact that only relatively harsh acid treatment will degrade the compounds is probably due to the highly caged structure of the molecule. This caging is partly due to the oxide ring associated with the bromine atom, and a debrominated compound should prove to be very much more reactive towards acid treatment. Unfortunately debromination of both the grignard and periodate products has led only to the production of intractable oils.

Compound XIVIII should react with chromic acid in acetone to yield a mono-ketone. $95,96,97$. The oxidation of the grignard compound with this reagent however was complex, and a mixture of at least three products was obtained. The major product was not

92. Kuchlin. Biochem 2. 261 411 (1933)

93. Payne \& Lemon, J.A.C.S. 63226 (1941)

94. Gilman. "Organic Chemistry" Vol IV. p.1153

95. Bowden et al. J.C.S. 194640

96. Bladon et al. J.C.S. $\frac{1951}{19502}$

97. Bowers et al. J.C.S. 19532548 
the compound $\mathrm{C}_{18} \mathrm{H}_{25^{\circ}} 6^{\mathrm{Br}}$ which had been expected, but rather a

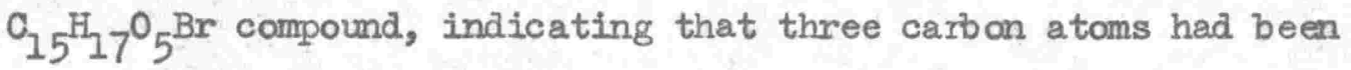
lost during oxidation. This material melted at $191^{\circ} \mathrm{C}$. The ultra-violet spectrum showed ketonic abserption at $3160 \AA$ ( $\varepsilon=79)$, Graph II. This peak is at a longer wave length than that normally associated with simple ketones, but is possible if the compound is a strained cyclohexanone containing an $\alpha$-carbon atom substituted with either an oxygen or a halogen atom. 73 (The oxidation product of $\beta$-bromopicrotoxinic acid, which is postulated to contain an $\alpha$-substituted cyclohexanone system, absorbs at $3150 \AA^{98}$ ). The $\varepsilon$ value is also abnormally high for a simple ketone but may be due to the additive effect of a diketone. Infra-red absorption showed the presence of two keto-groups, (1769 $\mathrm{cm}^{-1}$ - five-membered cyclic ketcne, 1749 - six-membered cyclic ketone), and no hydroxyl groups. The compound was stable to further chromic acid treatment and to periodic acid oxidation, and was formulated as L. It is formed from the grignard compound by oxidation of the secondary hydroxyl together with fission of the glycol system.

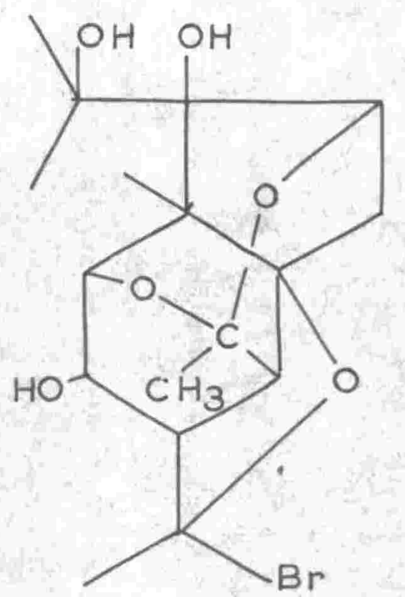

$\underline{\text { XIVIII }}$

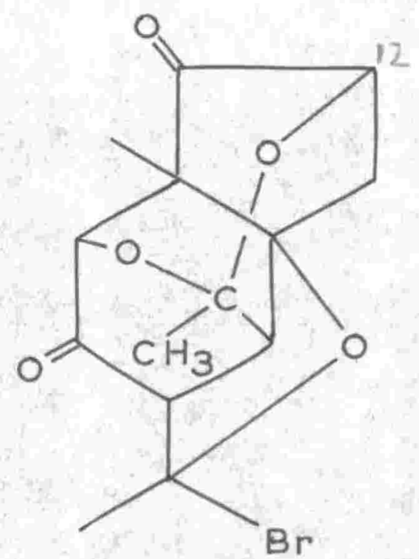

$\underline{I}$ 
Verification of the structure of this compound was obtained when the periodate product XIIX was oxidized with chromic acid to give a compound identical to I.

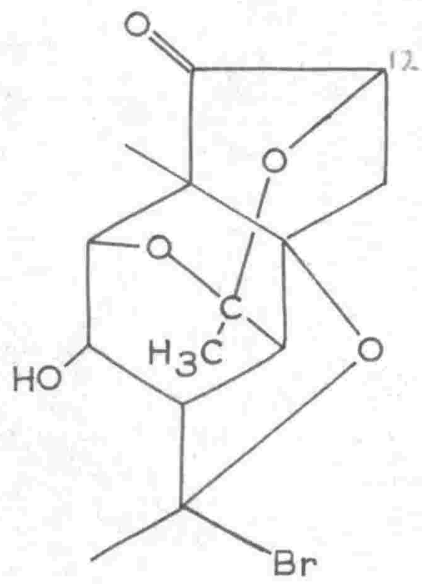

$\underline{\text { XIIX }}$

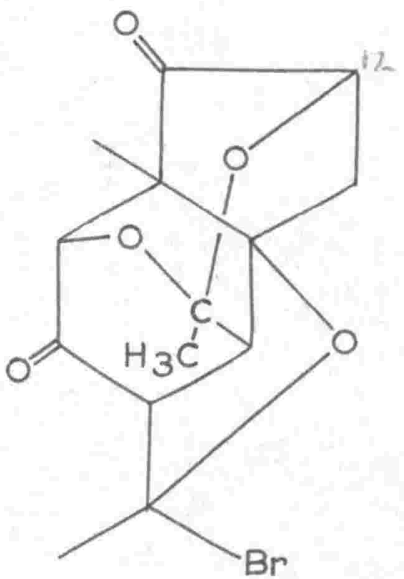

$\underline{\mathbf{L}}$

The chromic acid product I gave a mono 2:4-dinitrophenylhydrazone, $\mathrm{C}_{21} \mathrm{H}_{21} \mathrm{O}_{8} \mathrm{BrIN}_{4}$, m.p. $267^{\circ} \mathrm{C}$. Infra-red absorption analysis of this derivative showed the presence of a single carbonyl band at $1749 \mathrm{~cm}^{-1}$. As this same band was assigned to the six-membered cyclic ketone in the parent compound, it is apparent that the five-membered ketone is the one which has formed the hydrazone and this compound is hence formulated as II. The ultra-violet absorption spectrum of the hydrazone gave mexima at 3550,2580 , and 2220 \&. 


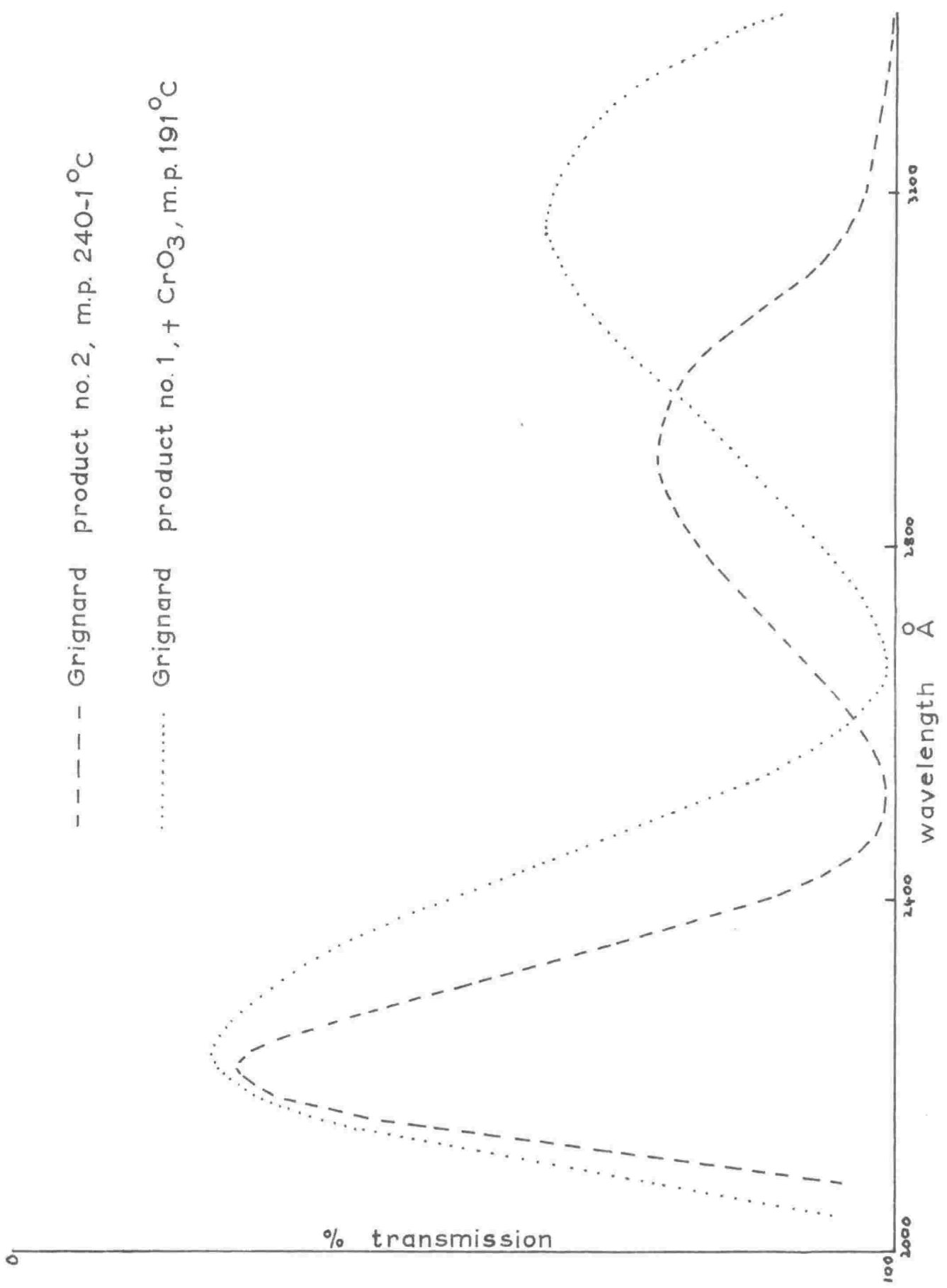

GRAPH II 


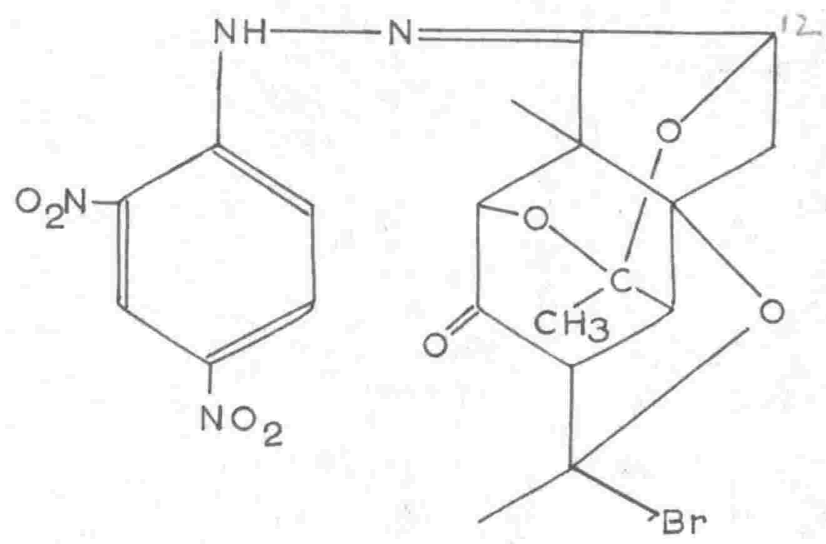

LI

The range of absorption of the longest wavelength band of the 2:4-dinitropheyihydrazones of normal ketones is from $3620-710 \AA 73,99$. 2:4-dinitrophenylhydrazones absorbing below $3620 \AA$ have all been found to have an $\alpha$-carbon substituted with an oxggen atom, either as a free hydroxyl or as an ester or ether linkage. 100 The 2:4-dinitrophenylhydrazones of both the periodate and chromic acid oxidation products absorb at a lower wave length than normal, thus verifying the presence of an oxygen atom on the $\alpha$-carbon atom, i.e. $c_{12}$, in

99. Braude \& Jones. J.C.S. 1945498 100. Fleisher \& Kendall. Jo Org. Ghem. 16556 (1951) 
both compounds XIIX and $\mathrm{L}$.

The reaction of the chromic acid product with dilute hydrochloric acid at $100^{\circ} \mathrm{C}$ was followed spectrophotometrically as only a dark brown oil could be obtained by ordinary methods. The original maximum at $3160 \AA$ was retained throughout the reaction, and a new peak at $2620 \AA$ was developed after a reaction time of seven hours. This latter maximum indicated that same degradation of the molecule was occurring, but the fact that absorption at the longer wave-length did not diminish, suggested that the cyclohexanone ring system was still being held in a strained position. It was unfortunate that such vigorous acid conditions were necessary to degrade the molecule, but this stability is almost certainly due to the compacted structure of the ring systems. Once again it was hoped that debromination of the compound might yield a product which could be degraded under mild conditions, but debromination experiments produced only intractable brown oils. An attempt to open the ketal linkage with warm acid in the presence of periodate, conditions which should cause any glycal formed to be immediately oxidized, again produced only a brown oil together with copious amounts of iodine.

A second compound could be obtained fram chromic acid oxidation of the grignard product, this being isolated from the mother-liquors in low yield. The compound melted at $209^{\circ} \mathrm{C}$ and analysed best as a $\mathrm{C}_{17} 7_{23}{ }^{\mathrm{O}} 7^{\mathrm{Br}}$ compound. 
It did not give an iodoform reaction. Both the ultra-violet (3150 \&, $\varepsilon$-23) and infra-red $\left(1741 \mathrm{~cm}^{-1}\right)$ spectra suggested that the compound was a cyclic six-membered ketone, but insuffict ient material could be obtained for further study and it is impossible to postulate a satisfactory structure.

A third compound was also isolated from the chromic acid oxidation of the grignard product in very low yield, m.p. $230^{\circ} \mathrm{C}$. The compound analysed best for the expected product, $\mathrm{C}_{18} \mathrm{H}_{25}{ }_{6} \mathrm{Br}$, but instead of showing the infra-red. absorption normal for a cyclic six-memb ered ketone at around 1740 - $50 \mathrm{~cm}^{-1}$, the compound gave three carbonyl peaks at $1755 \mathrm{~cm}^{-1}, 1732 \mathrm{~cm}^{-1}$, and $1701 \mathrm{~cm}^{-1}$. The peak at $1755 \mathrm{~cm}^{-1}$, together with the ultra-violet maximum at $2990 \AA$, is assigned to a cyclic five-membered ketcone, the peak at $1732 \mathrm{~cm}^{-1}$ is probably due to a six-membered cyclic ketone in a less-strained enviromment to those previously mentioned in this discussion, while the peak at $1701 \mathrm{~cm}^{-1}$ is due to a simple unstrained ketone. The relatively high $\&$ value of the ultra-violet maximum ( $\varepsilon=52$ ) is almost certainly due to the cumulative effect of these three keto-groups. The compound absorbed in the infrared hydroxyl region at $3363 \mathrm{~cm}^{-1}$.

In order that this oxidation product might contain three ketcne groups as well as at least one hydroxyl group, it is essential to postulate the degradation of the ketal function present in the starting material (XIVIII). The oxdation 
product is therefore pictured to be of the type LII. However, this structure requires the formula $\mathrm{C}_{18} \mathrm{H}_{25} \mathrm{O} \mathrm{Br}$, and it may be necessary to amend structure III slightly before a satisf actory formulation is obtained. Additional material for further study could not be obtained.

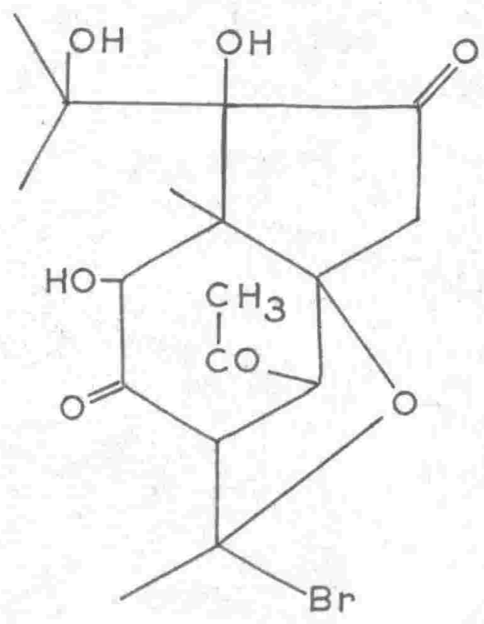

\section{III}

The product $\mathrm{C}_{18} \mathrm{H}_{27}{ }_{6} \mathrm{Br}$, XIVIII, was normally the only material obtained from the grignard reaction on methyl $\beta$-bromopicrotoxinic ester. However, in one reaction a minor product of higher melting point was also formed. On this occasion ammonium chloride had been us ed to hydrolyse the grignard complex but the higher melting product could not be obtained again when the reaction was repeated under similar conditions. The compound could be separated only with difficulty from the mother-liquors after the major product had been crystallized out, and it was badly contaminated with the latter compound. Multiple liquid-liquid extraction of the mother liquors using water as the stationary phase and ethyl acetate - ether 1:1 
as the moving phase, gave a good separation into a fraction mop. $220-5^{\circ} \mathrm{C}$ (major product), and a fraction $\mathrm{m}_{\bullet} \mathrm{p}_{\text {. circa }} 240^{\circ} \mathrm{C}$ (minor product). Recrystallization of the minor product from ethanol gave glistening white crystals, m.p. $241-2^{\circ} \mathrm{C}$, which analysed as $\mathrm{C}_{17} \mathrm{H}_{23} \mathrm{O}_{6} \mathrm{Br}$. The compound gave a 2:4-dinitwophenylhydrazone derivative, a positive iodoform reaction, an altra-violet maximum at $2900 \&$ (Graph II) and an infra-red maximum at $1696 \mathrm{~cm}^{-1}$, and was therefore formulated as a methyl ketane. The maximum at $1696 \mathrm{~cm}^{-1}$ is lower than that normally associated with methyl ketones (1706-7 $\mathrm{cm}^{-1}$ in steriods ${ }^{101}$ ) and is more normal for $\alpha$-hydroxy ketones of the structure IIII where hydrogen bonding lowers the wavelenth of the carbonyl absorption. 102,103 The ultra-violet peak at $2900 \AA$ is also normal for an $\mathcal{L}$-hydroxy ketone while being a little high for a simple methyl ketane. 73,104

$$
\mathrm{CH}_{3}-\mathrm{CO}-\stackrel{\mathrm{OH}}{\mathrm{c}}-
$$

\section{IIII}

The 2:4-dinitrophenylhydrazone of the minor product, $\mathrm{C}_{23} \mathrm{H}_{27} \mathrm{O}^{\mathrm{BrNN}}{ }_{4}, \mathrm{~m}_{\bullet} \mathrm{p}_{0} 258^{\circ} \mathrm{C}$, gave maxima at 3640 and $2300 \AA$, and a strong inflexion at $2520 \AA$, Whilst this absorption is normal for simple ketones, $99,105-7$ the peak at $3640 \AA$ is also in the region

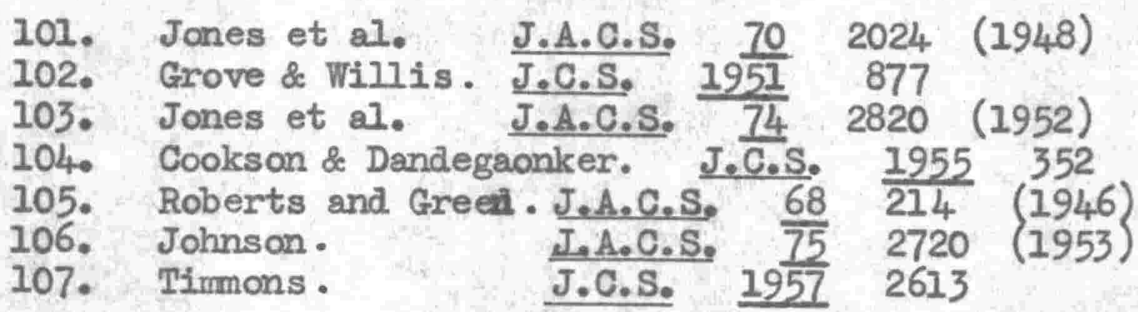




\section{EXPEERTMENTAI}

Unless stated otherwise ultra-violet absorption spectra were measured in $95 \%$ ethanol with a Unicam spectrophotometer, and infra-red spectra in nujol mull with a Perkin-Mlmer doublebeam spectrophotometer.

Methyl $\quad \beta$-bromopicrotoxinate. 59. $\quad \beta$-Bromopicrotoxinin (5.01g.) suspended in methanol (25 ml.) was treated with three drops of sodium methoxide solution ( $1 \mathrm{~g}$ of sodium in $25 \mathrm{ml}$ methanol). The mixture was magnetically stirred for four hours at room temperature and allowed to stand overnight. White crystals were deposited $(4.90 \mathrm{~g})$ and were recrystallized from ethanol-water, m.p. $225^{\circ} \mathrm{C}$ (1i terature ${ }^{59} \mathrm{~m} \cdot \mathrm{p} \cdot 225^{\circ} \mathrm{C}$ ).

Infra-red spectrum : $3548 \mathrm{w}, 1744 \mathrm{sbr}, 1390 \mathrm{w}, 1340 \mathrm{w}$, $1321 \mathrm{w}, 1305 \mathrm{~m}, 1286 \mathrm{w}, 1275 \mathrm{w}, 1262 \mathrm{~m}, 1229 \mathrm{w}, 1214 \mathrm{~m}, 1163 \mathrm{w}$, $1150 \mathrm{w}, 1134 \mathrm{w}, 1113 \mathrm{w}, 1098 \mathrm{w}, 1080 \mathrm{w}, 1056 \mathrm{~m}, 1041 \mathrm{~s}, 1028 \mathrm{~s}$, 989 w, 973 w, 954 w, 944 w, 921 ․, 912 w, 903 w, 882 w, 860 w, $826 \mathrm{~m}, 792 \mathrm{w}, 767 \mathrm{w}, 749 \mathrm{w}, 735 \mathrm{w}, 715 \mathrm{w}, 687 \mathrm{w} \mathrm{cm}^{-1}$. Reaction of Methyl B-bromopicrotoxinate with methyl ma gresium iodide - (a) In toluene :-

Methyl $\beta$-bromopicrotoxinate $(4.5 \mathrm{~g}, .011 \mathrm{~mole})$ in anhydrous toluene $(200 \mathrm{ml})$ was added aropwise during two hours to a stirred fefluxing solution of magnesium $(2.74 \mathrm{~g} ., .11 \mathrm{~mole}$ ) and methyl iodide $(15.97 \mathrm{~g} . .11$ mole $)$ in anhydrous ether $(100 \mathrm{ml})$. The sesultant white suspension was further refluxed for thirty minutes and then cooled and acidified (sulphuric acid $4 \mathrm{~N}, 50 \mathrm{ml}$, 
and ice 50g). The organic layer was decanted off, and the aqueous solution extracted with ether $(4 \mathrm{x}, 50 \mathrm{ml})$. The combined organic solution was dried $\left(\mathrm{Na}_{2} \mathrm{CO}_{3}\right)$ and taken to dryness under reduced pressure. The resul tant gum was chromatographed on alumina and washed with ether ( $6 \mathrm{x}, 10 \mathrm{ml})$, to give an oil which deposited crystals (3.5g) from chloroform, m. $\mathrm{p}_{0} 223^{\circ} \mathrm{C}$. Recrystallization from ethanol (3X) and sublimation (2x, $165^{\circ} \mathrm{C}, .02 \mathrm{~mm}$ ) gave white crystals, m.p. $228-9^{\circ} \mathrm{C}$. (Found: C, $5.22 ; \mathrm{H}, 5.46 \%$ ). A further sample was recrystallized from water, m.p. $227^{\circ} \mathrm{C}$. (Found: C, 50.70, 50.99; H, 6.00, 6.39; $\mathrm{Br}, 18.84 \cdot \mathrm{C}_{18} 8_{27}{ }^{\circ} 6^{\mathrm{Br}}$ requires $\left.\mathrm{C}, 51.54 ; \mathrm{H}, 6.48 ; \mathrm{Br}, 19.08 \%\right)$. $\lambda \max _{0} 2220 \&(\varepsilon=275)$. Infra-red absorption: 3543 w, 32.27 m, br, 1390 m, 1342 w, 1313 w, 1293 vw, 1276 w, 1257 w, 1230 w, 1198 w inflex, 1190 w, 1158 m, 1130 w, 1097 m, 1075 w, 1063 w, 1049 w, 1034 w, 1016 m, 993 m, 982 m, 963 w, 951 w, 944 w, 912 w, 903 w, 892 w, 868 w, 854 w, 840 w, 826 vw, 810 w, $780 \mathrm{ww} \mathrm{br}, 755 \mathrm{ww}, 748 \mathrm{w}, 721 \mathrm{w}, 703 \mathrm{~m}, 680 \mathrm{w} \mathrm{cm}^{-1}$. The compound gave negative unsaturation tests, a negative test with ammoniacal silver nitrate and with Fehling's solution, and a negative iodoform reaction. It gave white material, $m_{\bullet}$ p. $200-36^{\circ} \mathrm{C}, \lambda \max 2180 \AA$, with silver oxide and methyl iodide, and material, m.p. circa $192^{\circ} \mathrm{C}$, with dimethyl sulphate. These compounds were not purified further. Attempted debromination with zinc and anmonium chloride gave an intractable oil. (b) In ether - acidic hydrolysis 
Methyl $\beta$-bromopicrotoxinate $(.025$ mole) was extracted from a Bolton extractor into a refluxing ethereal solution of methyl magnesium iodide (.20 mole). Reflux was continued for one hour after extraction was completed, and the complex then hydrolysed with ice $(50 \mathrm{~g})$ and excess acid (4N sulphuric acid). Sodium bicarbonate was added until the solution was neutral to litmus, and the ether layer then separated off. Bxtraction of the aqueous phase with ether $(4 \mathrm{X}, 50 \mathrm{ml})$ and ethyl acetate $(5 \mathrm{X}, 100 \mathrm{ml})$ gave, after drying $\left(\mathrm{Na}_{2} \mathrm{CO}_{3}\right)$ and evaporation of the combined organic fraction, a brown solid ( $85 \%$ yield), which was crystallized (ethyl acetate) to give prisms, m•p. and mixed m•p. $227^{\circ} \mathrm{C}$, identical with the compound ob tained in (a) above. (c) In ether - neutral hyarolysis

The reaction was carried out as in (b) above, except that hydrolysis was carried out with saturated aqueous ammonium chloride solution, (100 ml). Work up in the normal mamer gave a brown gum which was separated by multiple liquid-liquid extraction (20 tubes each containing ethyl acetate-ether $1: 1$ (30 ml) and water $(30 \mathrm{ml}))$ into the compound, m.p. $227^{\circ} \mathrm{C}$, obtained in $(\mathrm{a})$ and (b) above, and into a compound, m.p. $241-2^{\circ} \mathrm{C}$. (needles from ethanol). (Found: C, 51.20; H, 5.71; $\mathrm{Br}, 20.21 . \mathrm{C}_{17} \mathrm{H}_{23} \mathrm{O}^{\mathrm{Br}}$ requires C, $50.62 ; \mathrm{H}, 5.74 ; \mathrm{Br}, 19.82 \%)$. $\lambda \max .2205,2900 \AA, \lambda \min 2505 \&$. Infra-red absorption: $3462 \mathrm{~s}, 2650 \mathrm{w}$ br, $2320 \mathrm{w}$ br, $1699 \mathrm{~s}, 1439 \mathrm{~s}$, $1347 \mathrm{~s}, 1314 \mathrm{~s}, 1282 \mathrm{~m}, 1266 \mathrm{~m}, 1254 \mathrm{~m}, 1229 \mathrm{~s}, 1200 \mathrm{w}, 1190 \mathrm{~m}$, 1158 s, 1136 ww, 1120 w, 1100 s, 1086 w, 1076 w, 1052 s, 1030 m inflex, 1016 s, 1003 s, 975 w, 968 w, 953 m, 942 m, 892 m, 870 m, $858 \mathrm{~m}, 830 \mathrm{~s}, 813 \mathrm{~s}, \ldots$. 
$807 \mathrm{~m}, 732 \mathrm{~m}, 714 \mathrm{~m}, 680 \mathrm{~m}, 657 \mathrm{w} \mathrm{cm}^{-1}$. The compound gave a positive iodoform test. Reducing and unsaturation tests were negative. The 2:4-dinitrophenylhydrazone, m.p. $258^{\circ} \mathrm{C}$ (from ethanol-water), was prepared by chromatographing on bentonitekiesulguhr the oil formed by heating the ketone $(30 \mathrm{mg})$ and 2:4-dinitrophenylhydrazine $(30 \mathrm{mg}$ ) in ethanal $(10 \mathrm{ml}$ ) with concen trated sulphuric acid ( $1 \mathrm{ml}$ ). (Found: C, 47.48; $\mathrm{H}, 4.69 ; \mathrm{N}, 9.70 . \mathrm{C}_{23} \mathrm{H}_{27} \mathrm{O}_{9} \mathrm{Br} \mathrm{N} \mathrm{N}_{4}$ requires $\mathrm{C}, 47.34 ; \mathrm{H}, 4.67$; $N, 9.60 \%$.). $\lambda \max 2300,3640 \AA, \lambda \min 2950 \AA, \lambda$ inflex 2520 \&.

Acetylation of compound XIVIII The alcohol XIVIII (.097 g) in pyridine $(1 \mathrm{ml})$ was treated with acetic anhydride $(2 \mathrm{ml})$ for twenty-four hours at $20^{\circ} \mathrm{C}$. Addition of water and evaporation to dryness gave a gum which on repeated distillation $\left(160^{\circ} \mathrm{C}\right.$, $.01 \mathrm{~mm}$ ) gave a colourless glass, m.p. $82^{\circ} \mathrm{C}$. (Found: C, 51.58; $\mathrm{H}, 6.19 ; \mathrm{Br}, 17.28 ; \quad \mathrm{C}_{20} \mathrm{H}_{29} \mathrm{O}_{7} \mathrm{Br}$ requires $\mathrm{C}, 52.05 ; \mathrm{H}, 6,33$; $\mathrm{Br}, 17.34 \%)$. $\lambda_{\max } 2200 \AA(\varepsilon=260)$. Infra-red absorption: 3438 wbr, $1740 \mathrm{mbr}, 1700 \mathrm{vw}$ inflex, $1314 \mathrm{vw}$, 1304 w br, 1277 w, 1236 sbr, 1200 w, 1175 w, 1156 m, 1094 w, $1050 \mathrm{w} \mathrm{br}, 1017, \mathrm{~m} \mathrm{br}, 954 \mathrm{w}, 903 \mathrm{w}, 880 \mathrm{ww}, 854 \mathrm{w}, 825 \mathrm{w}, 800 \mathrm{ww}$, $720 \mathrm{w}, 667 \mathrm{w} \mathrm{cm}^{-1}$. This acetate was stable to oxidation by chromic acid in acetone. Reaction of compound XIVIII with periodic acid Compound XIVIII $(.145 \mathrm{~g})$ in periodic acid $(10 \mathrm{ml}, .4698 \mathrm{~N})$ was stirred for twenty-four hours at $20^{\circ} \mathrm{C}$. Seven aliquots ( $1 \mathrm{ml}$ each) were 
removed as the reaction progressed and the excess periodate determined with standard arsenite and iodine solutions. In a further experiment, air was bubbled through compound XIVIII $(.975 \mathrm{~g})$ in periodic acid $(20 \mathrm{ml}, .4698 \mathrm{~N})$, and passed into a saturated solution of 2:4-dinitrophenylhydrazine in N sulphuric acid. The precipitated hydrazone, $m_{\bullet} p_{\bullet}$ and mixed $m_{\bullet} p_{0}$ with acetone 2:4-dini trophenylhydrazme, $125^{\circ} \mathrm{C}$, had $\lambda \max 3650 \AA$. Vield 65\%. The reaction mother liquors were extracted with ether $(5 \mathrm{X}, 100 \mathrm{ml})$ and ethyl acetate $(4 \mathrm{x}, 100 \mathrm{ml})$, and the combined organic extracts distilled into a 2:4-dinitrophenylhydrazine solution to give further acetone 2:4-dinitrophenylhydrazine (16\%) and a white solid $(.85 \mathrm{~g})$. Recrystallization gave the ketone $\mathrm{X} I \mathrm{IX}, \mathrm{m} \cdot \mathrm{p} \cdot 223^{\circ} \mathrm{C}$ (nnedles from ethyl acetate), mixed m.p. $204^{\circ} \mathrm{C}$ with compound XIVII. (Found: C, 50.24, $50.60,50.77$; H, 5.21, 5.71. $\mathrm{C}_{15} \mathrm{H}_{19} \mathrm{O}_{5} \mathrm{Br}$ requires C, 50.14; $H, 5.33 \%)$. $\lambda \max 2230(\varepsilon=227), 3010 \AA(\varepsilon=33)$. Infra-red spectrum: $3488 \mathrm{~m}, 1767 \mathrm{~s}, 1468 \mathrm{w}, 1390 \mathrm{~m}, 1366 \mathrm{w}$ 1350 w, 1331 w, 1324 w, 1313 w, 1306 w, 1286 w, 1278 w, 1267 m, 1234 w, 1222 m, 1195 w, 1185 w, 1162 vw, 1146 w, 1133 w, 1115 m, 1095 m, 1065 m, 1053 s, 1038 s, 995 m, 974 w inflex, 955 m, 935 w, 932 ww, 906 w, 892 w, 882 w, 873 w, 860 w, 832 m, 819 m,

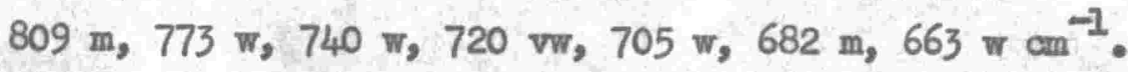
Sodrum periodate or lead tetraacetate oxidation of compound. XIVIII gave the same compound. The ketone would not react wi th slenium dioxide, nor with benzaldehyde and sodium ethoxide. It was stable to treatment with .2N sulphuric acid at $100^{\circ} \mathrm{C}$, and gave an intractable brown gum with 레 acid at the same temperature. 
It formed a 2:4-dinitrophenylhydrazone, m.p. $230-40^{\circ} \mathrm{C}, \lambda \max$ $3600 \AA$, and an acetate with acetic anhydride in pyridine, m.p. $144^{\circ} \mathrm{C}$ (needles from water) (Found: C, 51.40; H, 4.96. $\mathrm{C}_{17} \mathrm{H}_{21} \mathrm{O}_{6} \mathrm{Br}$ requires $\left.\mathrm{C}, 50.87 ; \mathrm{H}, 5.31 \%\right) . \lambda \max 2230(\varepsilon=210)$, $3000 \&(\varepsilon=30)$. Infra-red spectrum: $1762 \mathrm{~s}, 1729 \mathrm{~s}, 1427 \mathrm{~m}$, $1341 \mathrm{w}, 1296 \mathrm{w}, 1246 \mathrm{~s}, 1215 \mathrm{~s}, 1126 \mathrm{~m}, 1061 \mathrm{~m}, 1050 \mathrm{~m}, 1030$ w, 1017 w, 989 m, 950 m, 929 m, 898 w, 876 w, 835 m, 815 w, 794 w, $740 \mathrm{w} \mathrm{br}, 655 \mathrm{w} \mathrm{cm}^{-1}$.

Reaction of acidified hydrogen peroxide with compound XIVII6 The grignard product XIVIII ( .I g) was warmed on a water bath for four hours with dilute sulphuric acid (.4N, $5 \mathrm{ml})$ and hydrogen peroxide solution ( $3 \%, .5 \mathrm{ml}$ ). Formic acid, recognised by its reactions with litmus, ammoniacal silver nitrate, and barium-bydroxide - bromine water, was liberated. Ether extraction of the reaction mixture gave an intractable gum. Periodate oxidation of the acetate of cormound XIVIIS The acetate $(.01 \mathrm{~g})$ and periodic acid ( $2 \mathrm{~N}, 2 \mathrm{ml}$ ) were shaken together for 15 hours at room temperature. Water (10 ml) was added and the solution extracted with ether. The ether was distilled into a 2:4-dinitrophenylhydrazine solution, the mixture shaken well and evaporated to half volume, and the solution extracted with petroleum ether $(5 \mathrm{X}, 20 \mathrm{ml})$. This extract was chromatographed with an authentic specimen of acetone 2:4dini trophenylhydrazone on a paper column (solvent - diethyl ether - petroleum ether 1:19, spray - potassium hydroxide 10\% aq.) to give identical spots, Rf value .90. 
(literature ${ }^{1079} \mathrm{Rf}$. value for acetone 2:4-dini trophenylhydrazone in this solvent system is .85).

Chromate oxidation of compound XIVIII Compound XIVIII (.97 g) in acetone $(10 \mathrm{ml})$ was treated overnight with chromic anhydride $(.5 \mathrm{~g})$ in sulphuric acid (4N, $5 \mathrm{ml})$. Excess sodium sulphide in water $(50 \mathrm{ml})$ was added, and the whole ether extracted. The extract was chromatographed on alumina and recrystallized from ethanol-water to give compound I (.42 g), m.p. $191^{\circ} \mathrm{C}$ (plates from ethanol). (Found: C, 50.25; $\mathrm{H}, 4097 ; \mathrm{Br}, 22.46 . \mathrm{C}_{15} \mathrm{H}_{17} \mathrm{O}_{5} \mathrm{Br}$ requires $\mathrm{C}, 50.43 ; \mathrm{H}, 4080 ; \mathrm{Br}, 22.38 \%) . \lambda \max 3160(\varepsilon=79)$, $\lambda \min 2700 \AA$. Infra-red absorption: $1769 \mathrm{~m}, 1749 \mathrm{~m}, .1399 \mathrm{w}$, $1373 \mathrm{w}$ inflex, 1358 w, 1316 ww, 1307 w, 1285 w inflex, 1276 w, $1264 \mathrm{ww}, 1234 \mathrm{w}$ inflex, $1226 \mathrm{~m}, 1194 \mathrm{~m}, 1160 \mathrm{w}, 1145 \mathrm{ww}, 1142 \mathrm{w}$, $1114 \mathrm{vw}, 1102 \mathrm{vw}, 1076 \mathrm{~m}, 1050 \mathrm{~m}, 1034 \mathrm{~s}, 1015 \mathrm{w}, 993 \mathrm{w}, 977 \mathrm{vw}$, $961 \mathrm{w}, 9.56$ w, $939 \mathrm{w}, 903 \mathrm{~m}, 880 \mathrm{w}, 862 \mathrm{w}, 847 \mathrm{~m}, 822 \mathrm{~m}, 814 \mathrm{~m}$, $788 \mathrm{vw}, 770 \mathrm{w}, 733 \mathrm{w}, 720 \mathrm{vw}, 707$ w, 682 vw, 670 vw, $663 \mathrm{w}$, $652 \mathrm{w} \mathrm{cm}^{-1}$. The compound was stable to further chromic acid oxidation, gave an intractable gum ( $\lambda \max .3160,2620 \AA)$ with hydrochloric acid ( $\underline{\text { NN }}$ ) at $100^{\circ} \mathrm{C}$, and gave an intractable oil with zinc and ammonium chloride. The compound was stable to periodate oxidation. The ketone gave the 2:4-dinitrophenylhydrazone II by the normal procedure, m.p. $267^{\circ} \mathrm{C}$ (needles from chloroform-ethanol). (Found: C, 45.97; H, 3.36; Br, 14.86,

107A Rice et al. Anal. Chem, $23 \quad 194$ (1951) 
14.97: $\mathrm{N}, 10.13 . \mathrm{C}_{21} \mathrm{H}_{21} \mathrm{O}_{8} \mathrm{Br} \mathrm{N} \mathrm{N}_{4}$ requires $\mathrm{C}, 46.92$; $\mathrm{H}, 3.94 ;$ $\mathrm{Br}$. 14.87; N, 10.42\%). $\lambda \max 3550,2580,2220 \AA . \quad$ Infra-red spectrum: $3360 \mathrm{w}, 2735 \mathrm{ww}, 2685 \mathrm{ww}, 1749 \mathrm{w}, 1628 \mathrm{w}, 1601$ w, 1539 w, 1521 w, 1506 w, 1370 w, 1343 w, 1317 w, 1312 w, 1285 w, 1225 w, 1193 w, 1153 vw, 1136 w, 1115 ww, 1093 w, $1068_{\text {w, }}^{1041} 1031$ w inflex, 1014 w, 989 w, 951 w, 925 ww, 912 w, 901 w, 885 w inflex, 862 w, 845 w, 841 w, 834 w, 828 vw, 814 w, 790 w, 764 w, 742 w, $721 \mathrm{w}, 706 \mathrm{w} \mathrm{cm}^{-1}$.

Two further ketones were obtained from the motherliquors after the crystallization of compound $L$. The first, ob tained in about $10 \%$ yield by recrystallization, had m.p. $209^{\circ} \mathrm{C}$ (needles from ethanol-water). (Found: C, 48.47; H, 5.14; $\mathrm{Br}, 18.79 ; \mathrm{C}_{17} \mathrm{H}_{21} \mathrm{O}_{7} \mathrm{Br}$ requires $\mathrm{C}, 48.94 ; \mathrm{H}, 5.07 ; \mathrm{Br}, 19.15$. $\mathrm{C}_{17} \mathrm{H}_{23} \mathrm{O}_{7} \mathrm{Br}$ requires $\left.\mathrm{C}, 48.70 ; \mathrm{H}, 5.53 ; \mathrm{Br}, 19.06 \%\right) . \lambda \max$ $3150(\varepsilon=23), \quad \lambda \min 2670 \AA$. Infra-red absorption: $3608 \mathrm{w}$, 3518 w, 3408 w, 3318 w, 1741 s, 1632 w, 1440 ww, 1398 w, 1367 w, $1344 \mathrm{w}, 1330 \mathrm{w}, 1314 \mathrm{w}, 1294 \mathrm{~m}, 1259 \mathrm{w}, 1242 \mathrm{w}, 1234 \mathrm{w}$ inflex, 1196 m, 1186 w inflex, 1169 w, 1155 w, 1140 w, 1125 w, 1105 w, 1085 w, 1072 w, 1051 m, 1035 w, 1025 s, 1016 w, 994 vw, 955 w, $941 \mathrm{ww}, 901 \mathrm{ww}$ inflex, $895 \mathrm{w}, 880 \mathrm{w}, 866 \mathrm{w}, 843$ w, 829 w, $816 \mathrm{ww}$, 801 w, 786 ww, 759 w, 725 w, 712 w, 689 w, $686 \mathrm{ww}, 680$ vw, $668 \mathrm{w} \mathrm{cm}^{-1}$. This compound gave a negative iodoform reaction. The second compound, obtained by repeated sublimation $\left(150^{\circ} \mathrm{C}, .02 \mathrm{~mm}\right.$ ) in about $10 \%$ yield, had m.p. $230^{\circ} \mathrm{C}$. (Found: C, 51.37; H, 5.70; $\mathrm{Br}$, 19.66. $\quad \mathrm{C}_{18} \mathrm{H}_{25}{ }^{\mathrm{O}} 6^{\mathrm{Br}}$ requires $\left.\mathrm{C}, 51.78 ; \mathrm{H}, 6.03 ; \mathrm{Br}, 19.15 \%\right)$. $\lambda \max 2990(\varepsilon=52), \lambda \min 2620 \AA$. Infra-red absorption: 
3363 m, 1755 m, 1732 s, 1701 s, 1391 m, 1358 m, 1327 w, 1310 w, 1302 vw, 1272 vw, 1262 w, 1234 vw, 1222 w, 1192 w, 1177 m, 1153 w, $1135 \mathrm{ww}, 1125$ w, 1088 w, 1073 w, 1044 m, 1026 w, 1011 s, 1000 w, 973 w, 949 w, 936 w, 900 ww, 888 w, 880 vw, 842 m, 823 s, 811 w, $797 \mathrm{w}, 777 \mathrm{vw}, 729 \mathrm{w}, 718 \mathrm{vw}, 689 \mathrm{w}, 670 \mathrm{w}, 649 \mathrm{w} \mathrm{cm}^{-1}$.

Chromate oxidation of the compound XIIX. - The ketane XIIX $(50 \mathrm{mg})$ in acetone $(2 \mathrm{ml})$ was treated overnight with chromic anhydride $(20 \mathrm{mg})$ in sulphuric acid ( $4 \mathrm{~N}, 1 \mathrm{ml})$. Addition of excess sodium sulphite solution and ether extraction gave the diketone I (30 mg), m.p. and mixed m.p. $191^{\circ} \mathrm{C}$, identical with the compound obtained by chromate oxidation of compound XVVIII. 
B-Bromopicrotoxinic Acia 


\section{Discussion}

Methyl magnesium iodide should give an $\alpha$-hydroxy acid with $\beta$-bromopicrotoxinic acid if rearrangement of the ether link occurs in a manner analogous to that which takes pleice with methyl $\beta$-bramopicrotoxinate. Treatment of this acid with lead tetraacetate would then give a compound identical to that formed by periodate oxidation of the ester grignard compound (XIIX).

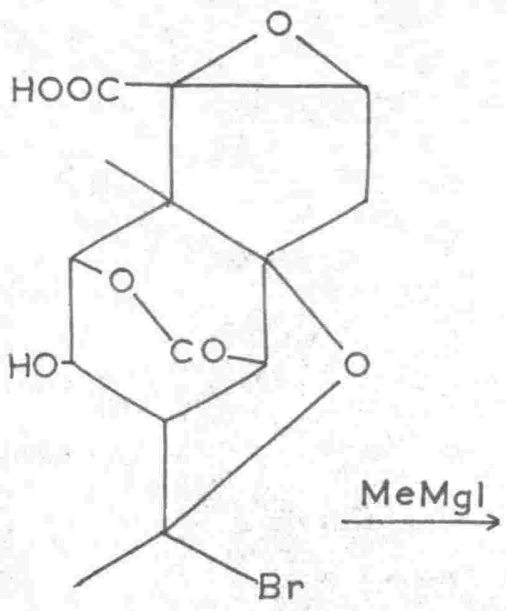

XXIV
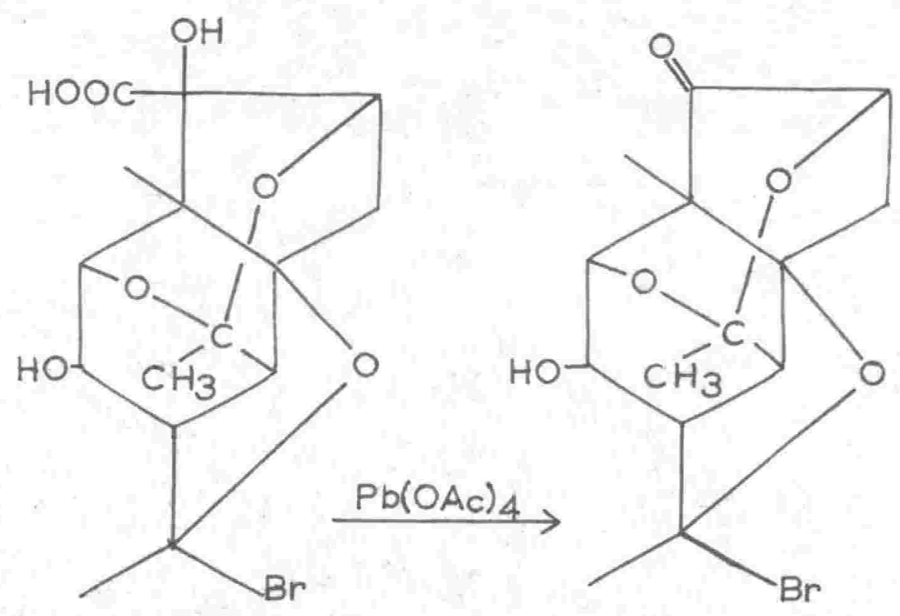

The reaction between $\quad \beta$-bromopicrotoxinic acid and methyl magnesium iodida in ethereal solution produced a small amount of an acidic material, m.p. $215^{\circ} \mathrm{C}$. This compound analysed as $\mathrm{C}_{16} \mathrm{H}_{21} \mathrm{O}_{7} \mathrm{Br}$ and absorbed in the ultra-violet at 2100 \&. It was stable to periodate oxidation, but underwent reaction with lead tetraacetate in glacial acetic acid to give 
two compounds which wefe separated by sublimation, m.p. $141^{\circ} \mathrm{C}$ and $218^{\circ} \mathrm{C}$ respectively. The compound $\mathrm{m}_{\bullet} \mathrm{p}_{\bullet} 218^{\circ} \mathrm{C}$ was shown by mixed melting point determinations and by its ultra-violet absorption spectrum to be identical to compound XIIX, the periodate oxidation product fram methyl $\beta$-bromopicrotoxinate plus methyl magnesium iodide. Sufficient compound m•p. $141^{\circ} \mathrm{C}$ was not available for satisfactory characterisation, but it is possible that it is identical to the monoacetate of XIIX, m.p. $144^{\circ} \mathrm{C}$, (page 47 ).

Thus it has now been shown that both methyl

$\beta$-bromopicrotoxinic ester and $\beta$-bromopicrotoxinic acid undergo rearrangement of the ether link when treated with either lithium aluminium hydride or methyl magnesium iodide.

Debromination of reduced $\beta$-bromopicrotoxinin has given interesting results ${ }^{65}$, but no successful debromination of either grignard or hydride treated $\beta$-bromopicrotoxinic ester has been recorded. Attempted debromination of the grignard product XIVIII, of this product after periodate oxidation XIIX, and of the chromic acid oxidised grignard product I, gave intractable brown gums. This was almost certainly due to reactions which were additional to the simple debromination, and it was considered likely that, when the browine atom and associated oxide ring were removed, the ketal function was readily hydrolysed under the mild acid conditions. (XIIX $\rightarrow$ LVI). The stability of the ketal before debromination is probably due to steric considerations. 


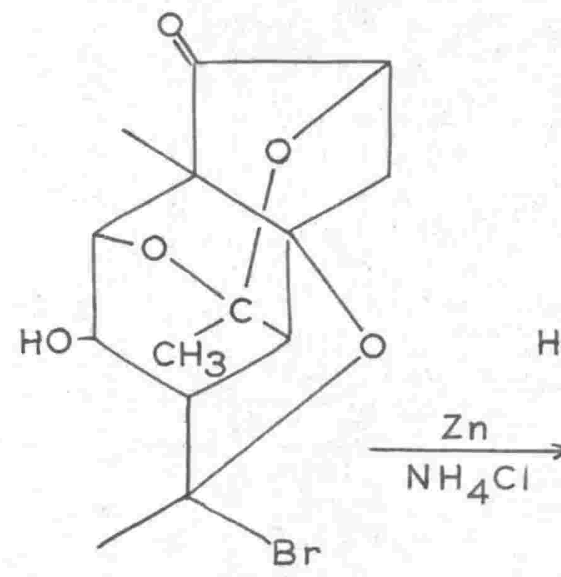

XIIX
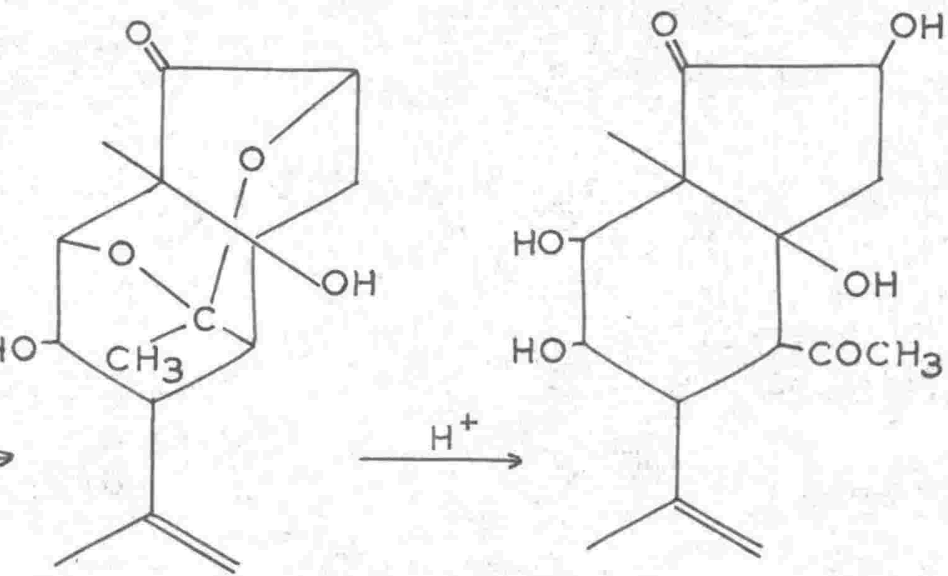

IV
LVI

The periodate oxidation product of methyl $\beta-$ bromopicrotoxinate reduced with Iithium aluminium hydride, XXVI, was prepared and debrominated under very mild conditions. It was hoped that the reaction would follow the scheme XXVI $\rightarrow$ IVIII whence it should be easy to detect the aldehyde in the end product.

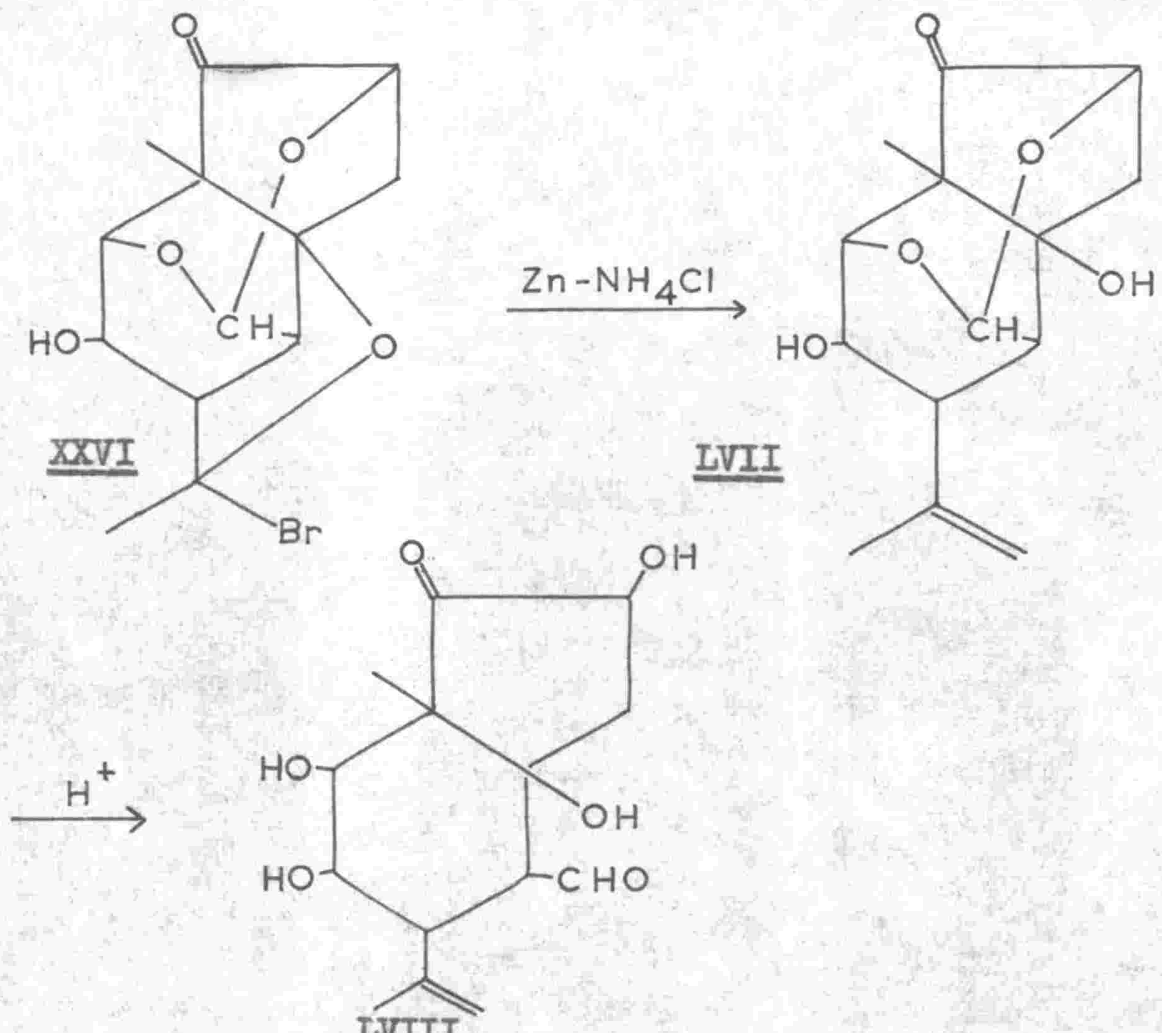


The product formed, m.p. $215-8^{\circ} \mathrm{C}$, analysed as $\mathrm{C}_{14^{\mathrm{H}}} 18^{\circ} 5^{\circ}$ As the starting material was a $\mathrm{C}_{14^{\mathrm{H}}} \mathrm{H}^{\mathrm{O}} 5^{\mathrm{Br}}$ compound, this change represented a simple debromination. The compound was unsaturated to bromine water, but showed no dauble bond absorption in the infra-red. It was thus cansidered likely that the dauble bond had shifted into a tetra-substituted position. The compound reacted with .45 mole of periodic acid during 24 hours, indicating the possible presence of the ketal system present in formula IVII. A compound of formulation LVIII would be expected to react rapidly with two moles of periodate, but the formulation IVII should only be attacked slowly as the ketal function is hydrolysed by acid. The presence of the five-membered cyclic ketane was shown in both the ultra-violet $\left(\lambda \lambda_{\max } 3010-20 \AA\right)$ and infra-red $\left(1753 \mathrm{~cm}^{-1}\right)$ spectra, and the debrominated product is therefore formulated as IIX.

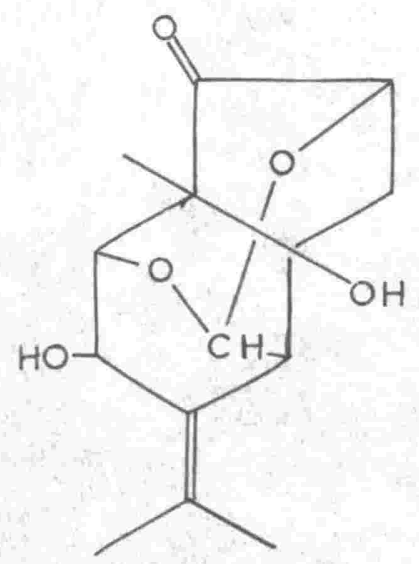


It has been shown by the reaction with periodate that mild hydrolysis of the ketal system of this compound is possible, and the product should give profitable results if its properties and reactions are studied further. 
Bxperimental

Reaction of $\quad$-bromopicrotoxinic acid with methyl magnesium iodide. $\quad \beta$-Bromopicrotoxinic acid, $(2.12 \mathrm{~g}, .005$ mole)

was ether extracted from a Bolton into a refluxing ethereal solution of methyl magnesium iodide (.05 mole). After further reflux ( $\mathrm{l} \mathrm{hr})$ ), the complex was hydrolysed with acid ( $\mathrm{N} \mathrm{H}_{2} \mathrm{SO}_{4}$, $100 \mathrm{ml}$ ), and the ether layer decan ted off. Fther ( $3 \mathrm{X}, 100 \mathrm{ml})$ and ethyl acetate ( $3 \mathrm{X}, 100 \mathrm{ml}$ ) extraction of the aqueous phase gave, after combination of the organic extracts and evaporation to drymess, much iodine together with the acid XXIVa $(.05 \mathrm{~g})$, m.p. $215^{\circ} \mathrm{C}$ (needles from water). (Found: C, 47.05; H, 4.40; $\mathrm{C}_{16} 6_{21} \mathrm{H}_{7} \mathrm{Br}$ requires $\left.\mathrm{C}, 47 \cdot 42 ; \mathrm{H}, 5.22 \%\right) . \quad \lambda \max$ below $2150 \AA$. The acid did not react with periodic acid.

Reaction of compound XXIVa with lead tetraacetate.

Compound XXIVa $(.02 \mathrm{~g})$ and lead tetraacetate $(.05 \mathrm{~g})$ were warmed together in glacial acetic acid ( $2 \mathrm{ml}$ ) at $50^{\circ} \mathrm{C}$ for one hour, and allowed to stand at room temperature overnight. Addition of water $(30 \mathrm{ml})$ and ether extraction gave a yellow oil which on sublimation $\left(130^{\circ} \mathrm{C}, .02 \mathrm{~mm}\right)$ gave a compound m.p. $141^{\circ} \mathrm{C}$ (trace), together with a product $(.01 \mathrm{~g})$ identical with compound XIIX, m.p. and mixed m.p. $218^{\circ} \mathrm{C}$. Preparation of Compound XXVI

Methyl $\beta$-bromopicrotoxinate $(4 \mathrm{~g})$ was reduced with lithium aluminium hydride and the product oxidised with periodic acid in the manner previously described ${ }^{65}$ to give campound XXVI (1.5g), m.p. $200^{\circ} \mathrm{C}, \quad \lambda_{\max } 3020$ \&. (li terature ${ }^{65} \mathrm{~m} \cdot \mathrm{p} \cdot 200-1^{\circ} \mathrm{C}$, 
Debromination of compound XXVI. Compound XXVI $(.5 \mathrm{~g})$ in water (10 ml) was debrominated in the normal manner for ten minutes using zinc $(.3 \mathrm{~g})$ and ammonium chloride $(.3 \mathrm{~g})$. The colourless liquid was filtered, acidified ( $\left.2 \mathrm{~N} \mathrm{H}_{2} \mathrm{SO}_{4}\right)$, and continuously ether extracted. The debrominated compound obtained ( .2 g) had a m.p. $202-15^{\circ} \mathrm{C}$, raised to $215-8^{\circ} \mathrm{C}$ by sublimation ( $4 \mathrm{X}, 150^{\circ} \mathrm{C}, .02 \mathrm{~mm}$ ) and recrystallization (water). (Found: C, 63.36; H, 6.74. $\mathrm{C}_{14} \mathrm{H}_{15}{ }^{\circ}{ }_{5}$ requires C, 63.14; H 6.81\%). $\lambda \max 3010-20 \&(\varepsilon=30), \lambda \min 2580-620 \AA$. Infra-red spectrum; $3426 \mathrm{~s}, 1753 \mathrm{~s}, 1415 \mathrm{~m}, 1341 \mathrm{w}, 1332 \mathrm{w}$ 1324 w, 1299 w, 1279 m, 1271 m, 1260 w, 1243 m, 1220 m, 1201 w, 1158 m, 1139 w, 1118 m, 1111 m, 1094 w, 1075 w, 1049 s, 1032 w, 1004 s, 989 m, 960 w, 948 w, 938 m, 902 m, 879 w, 869 w, 845 w, $825 \mathrm{~s}, 805 \mathrm{w}, 790 \mathrm{~m}, 770 \mathrm{w}$ inflex, $719 \mathrm{vw}, 709$ ww, $698 \mathrm{~m}$, $663 \mathrm{vw}^{-1}$. The compound did not reduce ammoniacal silver nitrate or Fehling's solution, but decolourised a solution of bromine water. The compound reacted with .45 mole of perialate after 24 hours at $18^{\circ} \mathrm{C}$. 


$$
\beta \text { - Chloropicrotoxinin }
$$


Discussion

The product obtained by lithium aluminium hydride reduction of $\beta$-bromopicrotoxinin has been shown to undergo an anomalous reaction with periodic acid. 65 During oxidation bromine was liberated and up to $3.5 \mathrm{~mol}$ es of periodate were consumed. The material formed in this reaction was lactonic in nature and contained no other detectable carbonyl group. No satisfactory explanation has been presented for the expulsion of the bromine, and it was therefore considered desirable to study the reduction and subsequent oxidation of $\beta$-chloropicrotoxinin in order to ascertain whether canditions due to the size and reactivity of the chlorine atom, as compared with the bromine atom, would affect the course of the reactions. $\beta$-Chloropicrotoxinin was reduced with lithium aluminium hydride in the normal manner, using a mixture of dioxan and ether as the solvent. When an attempt was made to work up the product in the mamer used for reduced $\beta$-bromopicrotoxinin, 1.e. by extracting the dried reaction products with absolute alcohol and chromatographing the extract, a sticky brown viscous solution was formed from which crystals could not be obtained. Therefore, in further reductions the reaction products were reduced to dryness and continously extracted with ether from 2 Bolton extractor, giving white solid material which could then be recrystallized from ethanol, m.p. $217^{\circ} \mathrm{C}$. The yield of $40 \%$ compared favourably with that obtained in the reduction of $B$-bromopicrotoxinin. (31\%). 
The alcollinol analysed as $\mathrm{C}_{15} \mathrm{H}_{23} \mathrm{O}_{6} \mathrm{Cl}$, indicating that right hydrogen atoms had been added during reduction. No absorption due to lactone or carbonyl groups was present in the ultra-violet or infra-red absorption spectra of the molecule, and it was considered likely that both lactones had been completely reduced as in the bromo-series.

Complete reduction of both lactones should give four hydroxyl groups. ( $\beta$-Chloropicrotoxinin does not contain any hydroxyls). Two of these will necessarily be primary, while the other two may be either primary, secord ary, or tertiary. Infra-red absorption showed two hydroxyl peaks at 3353 and $3278 \mathrm{~cm}^{-1}$. The alcohol on acetylation with acetic anhydride in pyridine gave a triacetate, $\mathrm{C}_{22} \mathrm{H}_{29} \mathrm{O}_{9} \mathrm{Cl}, \mathrm{m}_{\mathrm{p}} \mathrm{p} .74-78^{\circ} \mathrm{C}$. This derivative had infra-red absorption in the hydroxyl region due to a remaining unacylable hydroxyl group which must either be sterically hindered or tertiary. The former possibility appears more likely fram the position of a strong peak at $1024 \mathrm{~cm}^{-1}$ and ${ }^{108}$ will be discussed more fully later under reduced $\beta$-bromopicrotoxinin.

A striking similarity was noted between the infrared absorption spectra of the triacetates of reduced $\beta$-bromoand reduced $\beta$-chloropicrotoxinin. The two spectra are so similar (Graph III) that the triacetates involved, and hence the parent compounds, must have practically identical structures. 


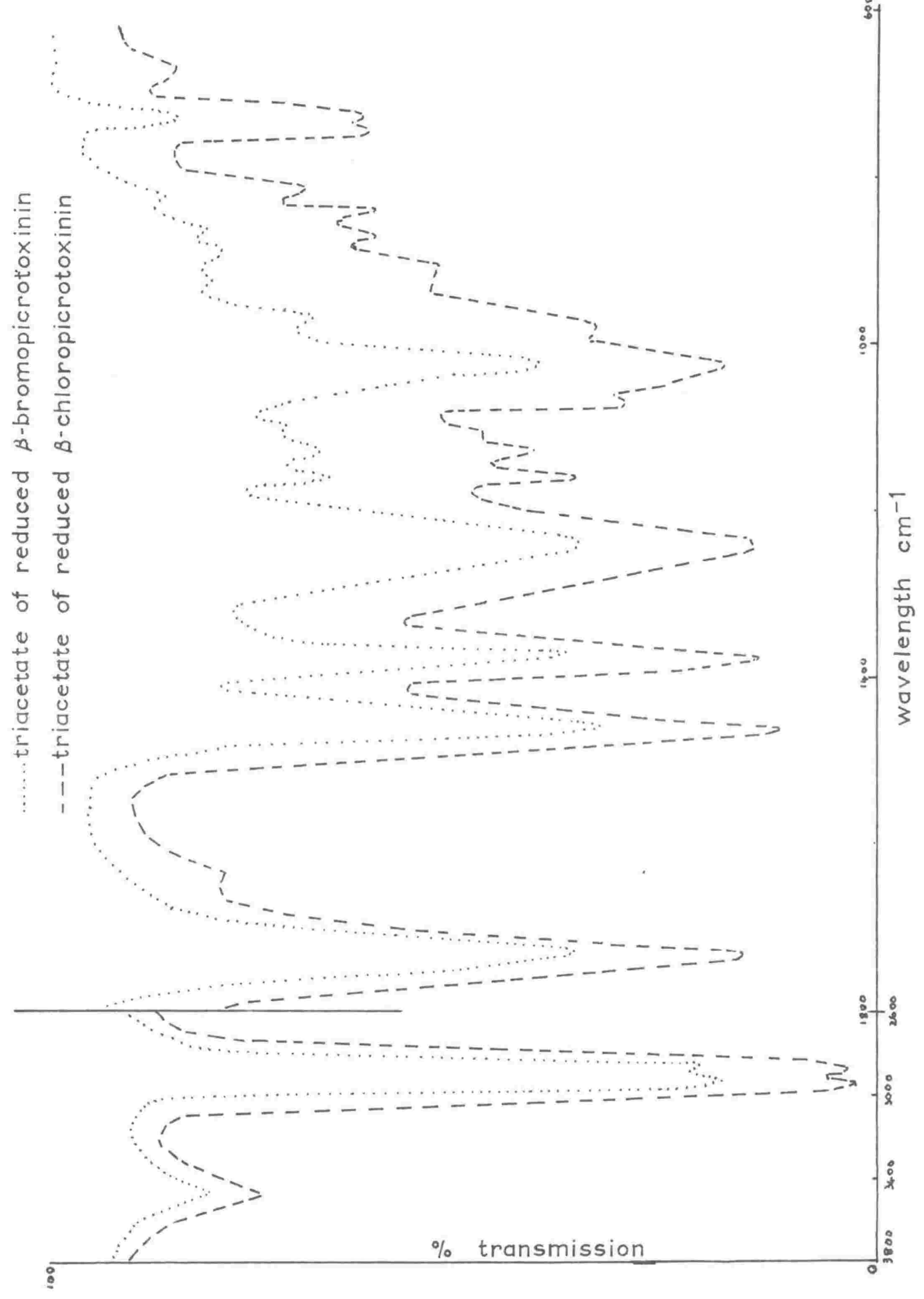

GRAPH III 
The peaks at 1639 and $990 \mathrm{~cm}^{-1}$ in the chloro-compound are probably due to a trace of double bond impurity which may he arisen while the compound was being distilled for analysis.

Reduced $\beta$-chloropicrotoxinin did not react with boiling dilute alkali, but it gave with boiling mineral acid a yellow solution fram which no product other than starting material could be obtained. The alcohol was boiled with acidified hydrogen peroxide solution, but again no solid product could be isolated and no 2:4-dinitrophenylhydrazone derivative could be prepared from the dark brown oil which formed.

An attempt was made to oxidise reduced $\beta$-chloropicrotoxinin with chromic anhydride in pyridine. 109 The yellow oil formed could not be crystallized before or after chromatography. It appeared to form a 2:4-dinitrophenylhydrazone, but this compound could not be eluted from a bentonite-kieselguhr column with solutions containing up to $10 \%$ ethanol ${ }^{70}$, and was therefore probably unchanged 2:4-dinitrophenylhydrazine. The yellow oil gave a dull purple spot with the polyol spray reagent vanillin/perchloric acid which was very similar to the purple coloration given by reduced $\beta$-chloropicrotoxinin under the same conditions, and it was concluded that no oxidation had occurred.

109. Poos et al. J.A.C.S. $\frac{75}{13} \quad 422$ (1953)

110. Godin. Nature. $174 \quad \frac{75}{134}$ (1954) 
Reduced $\beta$-chloropicrotoxinin was oxidised with chromic anhydride in acetone 95,97 . Reaction was indicated by the formation of the green chromic coloration, but the yellow oil which was isolated could not be crystallized nor further purified by chromatography.

The reaction of reduced $\beta$-chloropicrotoxinin with periodic acid was followed by titrating aliquots of the excess oxidatant present with standard arsenite and iodine solutions. Analyses were carried out at reaction times varying between one and forty hours, and the amount of periodate consumed approximated in each case to one mole per mole of alcohol. No chlorine was detected from any reaction carried out at toom temperature, and solutions of the alcohol in periodate were left at $20^{\circ} \mathrm{C}$ for periods of up to 165 hours without the formation of any free chlorine.

This result was not unexpected as any chlorine liberated from the alcohol in a manner analogous to the liberation of bromine from the reduced $\quad \beta$-bromopicrotoxinin molecule must initially be present in solution as chloride ions. That these ions would not be expected to be oxidised to chlorine molecules by excess periodate is shown by the well-known preparation of periodate.

$$
\mathrm{H}_{2} \mathrm{O}+\mathrm{O}_{2}+\mathrm{IO}_{3}^{\prime} \longrightarrow \mathrm{IO}_{4}^{\prime}+2 \mathrm{Cl}^{\prime}+2 \mathrm{H}^{+}
$$

in which the equilibrium lies strongly toward the right hand 
side. 11 However it has also been shown that the reaction can 112

proceed in a small degree toward the left, and this was further demonstrated when reduced $\beta$-chloropicrotoxinin was warmed with periodic acid at $35^{\circ} \mathrm{C}$ for 72 hours. Chlorine, recognized by its smell, its action on starch/iodide paper, and its reaction with concentrated ammonia, was evolved, and could still be detected above the solution after 160 hours. The reaction was not followed analytically, but it was apparent that the reaction was proceeding in a manner similar to the reaction of periodate upon reduced $\quad \beta$-bromopicrotoxinin with .....

(a) Rapid uptake of one mole of periodate, almost certainly due to the oxidation of an $\mathcal{L}$-glycol system.

(b) Slower reaction requiring a temperature slightly above $20^{\circ} \mathrm{C}$ and due to the oxidation of chloride ions to chlorine. This reaction involves at the most a further half mole of periodate.

Reduced $\beta$-chloropicrotoxinin gave no indication of consuming an abnormally large amount of periodate as occurred in the bromo-series. No mechanism can be produced, on the basis of experimental results available at present, to satisfactorily account for the liberation of chlorine from the molecule.

111. Hill. J.A.C.S. $50 \quad 2678$ (1928)

112. Willard \& Greathouse. J.A.C.S. 602869 (1938) 
The product formed by periodate oxidation was removed from inorganic material by ether extraction of the aqueous reaction mixture. In some instances extended. continuous extraction was necessary in order to isolate a reasonable amount of product and yields of $30-40 \%$ were obtained. Precipitation of the excess iodate and periodate with barium hydroxide did not assist in giving a cleaner product or a larger yield.

The pale yellow product melted with decomposition over the range $120-80^{\circ} \mathrm{C}$. It could not be purified by recrystallization from a wide range of solvents, but either precipitated as a chalky powder or as an oil. Solid material was generally white or pale yellow in colour, and of ten formed dark brown solutions in organic solvents. No difference in properties could be detected between material extracted after a reaction time of one hour and material extracted after 168 hours. Material extracted from the solution from which chlorine was evolved did not differ from that extracted from non-chlorine producing solutions.

The material was run on a series of alumina columns and a large number of fractions collected. The melting point of these fractions varied between $160-220^{\circ} \mathrm{C}$. Fractions containing material melting between $200-20^{\circ} \mathrm{C}$. were combined and run on another alumina colum giving a midale fraction melting at $212-20^{\circ} \mathrm{C}$. This material could not be crystallized, and an attempt was made to purify it by precipitation. The product 
was dissolved in chloroform and precipitated out by the rapid addition of petroleum ether. The melting point of material obtained by this method varied considerably but tended to rise as the process was repeated. However, the actual melting point remained very indistinct and the compound of ten decomposed without melting over a range of $10-20^{\circ} \mathrm{C}$.

The ultra-violet absorption spectrum of the crude material was examined with a view to using the curve as a test of purity. It showed end absorption below $2200 \&$ together with a small subsidiary peak at 2560 \&. Repeated precipitation of the material as described above reduced the intensity of this latter peak to a point on a smooth curve extending from 3600 to $2200 \AA$, and the material was therefore judged to be pure. This sample softened at $202^{\circ} \mathrm{C}$ and decomposed at $218^{\circ} \mathrm{C}$. Flementary analysis gave the values ..

$$
\text { C, } 59^{2} 94 \% \quad \mathrm{H}, 6 \cdot 38 \% \quad \mathrm{Cl}, 2 \cdot 91 \% \text {. }
$$

A $\mathrm{C}_{15}$ compound containing one chlorine atom would require approximately $10 \%$ chlorine. It therefore appears that the analysed material must have contained a compound which had lost its halogen atom, together with about $30 \%$ of a chlorine-containing compound. In an attempt to separate these compounds, paper chromatograms were run using a butanol/ ethanol/water (4:1:5) system as a solvent. It was difficult to detect the position of any spots on the chromatogram as the compounds did not give positive reactions with reagents such as benzidine, ammoniacal silver nitrate, vanillin/ 
perchloric acid ${ }^{110}$, or permanganate/benzidine $e^{113}$. However pale brown spots were detectable with both acid ${ }^{114}$ and alkaline ${ }^{115}$ potassium permanganate spray. The position of these spots indicated that the material had moved as a single substance of $\mathrm{Rf}$ value 0.95 , and this result was confirmed by the detection of very weak spots at the same place under ultra-violet light. Further chromatograms using different solvent systems were not run as the method used to detect the spots was considered to be oversensitive and thus unreliable. The infrasred spectrum of the periodate product of reduced $\beta$-chloropicrotoxinin showed peaks at 3408 and $1102 \mathrm{~cm}^{-1}$ (hydroxyl), a band at $828 \mathrm{~cm}^{-1}$ which together with a weak peak at $1635 \mathrm{~cm}^{-1}$ could be due to a trisubstituted double bond, and a weak peak at $1715 \mathrm{~cm}^{-1}$ probably due to carbonyl absorption. The chemical evidence in favour of the presence of a carbonyl gooup was conflicting. The material did not react 2:4-dinitrophenylhydrazine or with Fehling's solution. It did however react slowly with sensitized anmoniacal silver nitrate, gave a positive test with cold alkaline permanganate and with anmoniacal roseaniline ${ }^{116}$, and gave a doubtful positive test with Schiff's reagent. The presence of the ultra-violet

113. Wolfram \& Miller. Anal. Chem. 281037

114. Prochazka. Chem, Listy. $\frac{44}{45} 4 \overline{3}$ (1950)

(1956)

115. Pacsu, Mora, and Kent. Science 110446 (1949) 116. Feigel. "Spot Tests" p. 346 교 sevier (1947) 
maximum at $2560 \AA$ may have been due to a carbonyl group, but this was present only as an impurity, and was removed by purification.

The presence of a double bond is also in doubt as the material did not react with bromine water or with bromine in carbon tetrachloride, but reacted with cold $1 \%$ neutral permanganate.

Since the treatment of reduced $\beta$-chloropicrotoxinin with periodic acid did not result in the liberation of fomaldehyde, neither of the primary hydroxyl groups could have taken part in the glycol fission. This should leave the oxidation product wi th two primary hydraxyls, both of which should be acetylatable. An attempted acetylation was carried out in the normal manner using acetic anhydride in pyridine. The material ob tained, m.p. $208-13^{\circ} \mathrm{C}$, could not be crystallized, and chromatography on alumina did not improve the purity. A paper chromatogram containing both the suspected acetate and storting material was run using the organic phase of butanol-water (1:1) as a solvent. Material fran the two campounds reached an Rf position of 0.85 in each $c$ ase (permanganate spray), and the two spots appeared to be identical. No other detectable spots were present on the chromatogram, and it was considered that no acetate had formed. An attempt to form a 3:5-dinitrobenzoate also failed. A compound isolated in the periodate oxidation of reduced $\beta$-bromopicrotoxinin has been shown to be a lactone. 65 However, the analogous material from reduced $\beta$-chloropicrotoxinin was as equally insoluble in alkali as in water. Titration 
of this coupound with standard acid and alkali using phenolphthalein as an indicator gave an anomalous value of 0.2 lactone groups per molecule. No titrations were carried out conductometrically as sufficiently pure starting material could not be obtained. The weak infra-red peak at $1715 \mathrm{~cm}^{-1}$ could have been due to lactone absorption, 117 but was more probably due to a simple carbonyl group. Thus the presence of any lactone in the mixture is very doubteul.

Reduced $\beta$-chloropicrotoxinin reacts on many occasions in a marmer similar to reduced $\beta$-bromopicrotoxinin. They both give low melting triacetates which from infra-red data are of nearly identical structure, and they both give unsatisfactory products with periodate. In order to show that the two compounds were completely analogous, it was proposed to compare the respective dehalogenated products, which should of course be identical.

Debromination of reduced $\beta$-bromopicrotoxinin has been shown to give at least two compounds, a crystalline substance m.p. $126-44^{\circ} \mathrm{C}$, and an ammorphous powder m.p. $226^{\circ} \mathrm{C} .65$ Dechlor? ination of reduced $\beta$-chloropicrotoxinin with zinc and ammonium chloride gave an intractable pale yellow oil. These compounds were therefore compared by paper chromatography using butanol saturated with water as a solvent. (Table IV). The spots were detected with the vanillin-perchloric acid spray reagent. 110

117. Rasmussen \& Brattain J.A.C.S. 711073 (1949) 


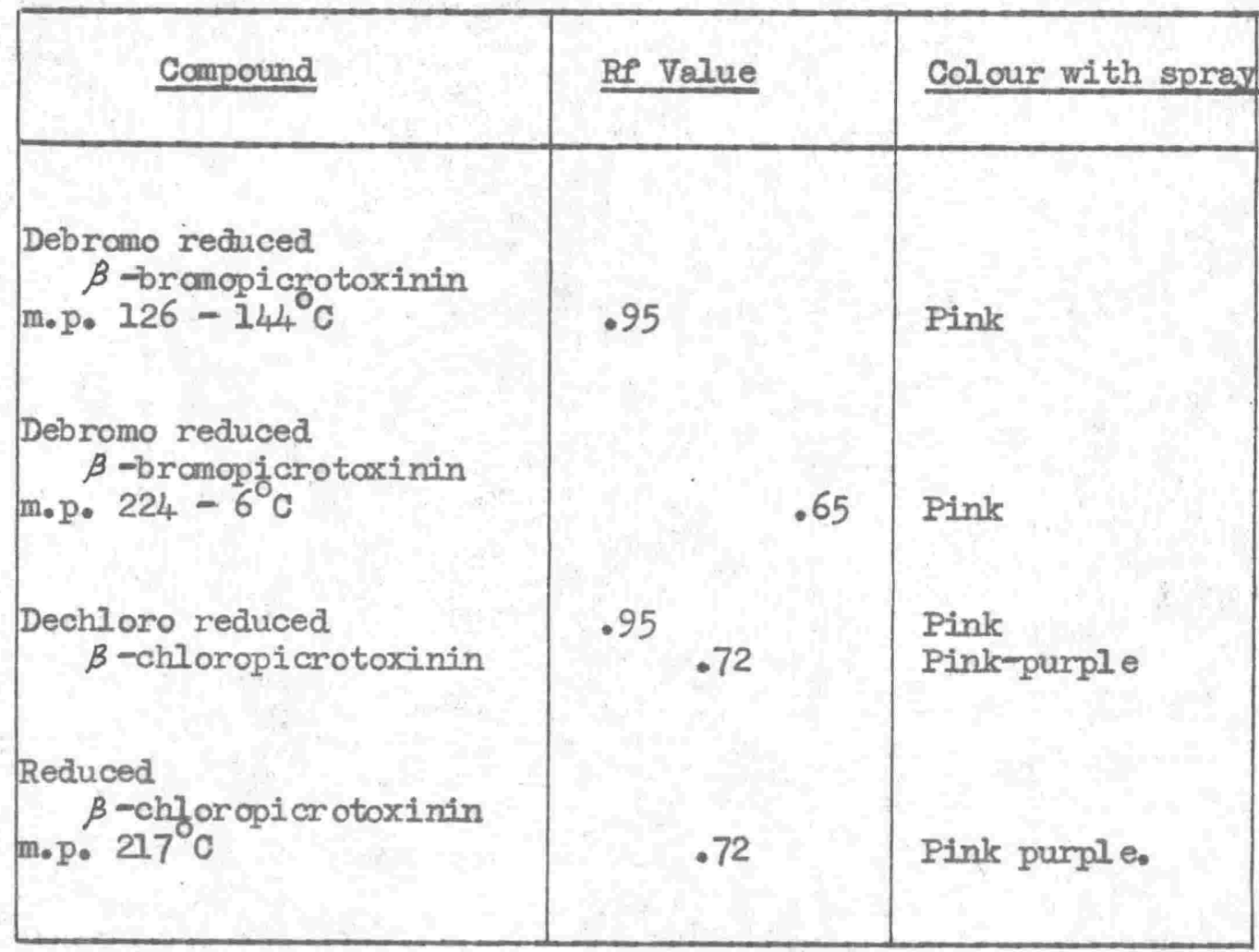

\section{Table IV}

This chromatogram indicated that the oil obtained by dechlorination of the reduced $\beta$-chloropicrotoxinin contained material identical with the debrominated material, m.p. $126-144^{\circ} \mathrm{C}$, together with some unchanged reduced $\beta$-chloropicrotoxinin. A further chromatogram using petroleum ether / butanol / water $(2: 2: 1)$ as a solvent gave the same result. (Table V) 


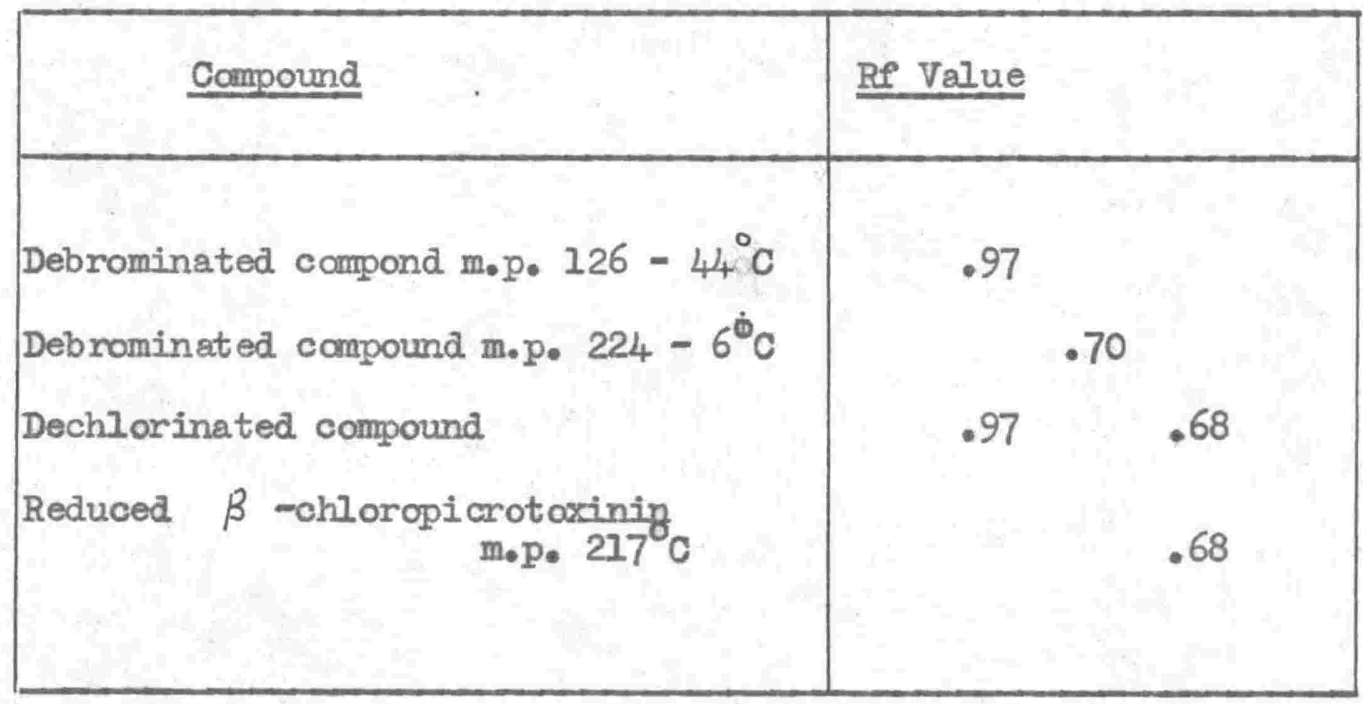

\section{Table V}

No compound m.p. $224-6^{\circ} \mathrm{C}$ was obtained by dechlorination of reduced $\beta$-chloropicrotoxinin. This compound is too high melting to be a simple dehalogenation product, and its relationship to the halogen-containing compound is obscure.

The dehalogenation products of both the bromo- and. -chloro- reduction compounds are identical, and it can thus be assumed that the reduced compounds themselves are completely analogous. The structure of reduced $B$-chloropic rotoxinin will therefore be discussed together with the structure of reduced $\beta$-bromopicrotoxinin in the next section. 


\section{Experimental}

\section{$\beta$-Chloropicrotoxinin}

Excess chlorine gas was passed into picrotoxin (5g) in boiling water (150 ml). The solution was filtered hot and the precipitate $(2.35 \mathrm{~g})$ extracted with ethanol from a Bolton to give $\beta$-chloropicrotoxinin, m.p. $270^{\circ} \mathrm{C}$ (Meyer and Bruger ${ }^{22}$ give $\left.272^{\circ} \mathrm{C}\right)$.

Reduction of $\beta$-Chloropicrotoxinin - $\beta$-Chloropicrotoxinin (5g) in anhydrous dioxan (50 ml) was added dropwise to lithium aluminium hydride $(2 \mathrm{~g})$ in dry ether $(80 \mathrm{ml})$. The solution was stirred during the addition and during the reflux period ( 45 min.). Ethyl acetate $(5 \mathrm{ml})$ was added dropwi se, and then sodium sulphate (20 ml saturated aqueous solution). The whole was taken to dryness mder reduced pressure and the residue extracted with boiling absolute ethanol ( $5 \mathrm{x}, 100 \mathrm{ml}$ ). The combined extracts were taken to dryness to give a brown solid which was extracted from a Bolton with dry ether to give needles $(2 \mathrm{~g}), \mathrm{m} \cdot \mathrm{p} \cdot 277^{\circ} \mathrm{C}$ (from ethanol). (Found: C, 54.79, 54.72; H, 6.98, 6.87; Cl, 10.76\%). A sample after sublimation $\left(165^{\circ} \mathrm{C}, .02 \mathrm{~mm}\right)$ melted at $218^{\circ} \mathrm{C}$. (Found: C, 54.20; $\mathrm{H}, 6.59 . \mathrm{C}_{15} \mathrm{H}_{23} \mathrm{O}_{6} \mathrm{Cl}$ requires C, 53.84; H, 6.93; Cl, 10.59\%). Infra-red spectrum: $3353 \mathrm{~m}$, $3278 \mathrm{~m}, 1415 \mathrm{ww}, 1300 \mathrm{ww}, 1285 \mathrm{w}, 1258 \mathrm{vw}, 1196 \mathrm{w}, 1173 \mathrm{w}, 1153 \mathrm{w}$, 1137 w, 1120 w, 1113 w, 1090 w, 1082 w, 1041 m, 1019 m, 999 w, 984 w inflex, $965 \mathrm{vw}, 945 \mathrm{w}, 910 \mathrm{w}, 892 \mathrm{vw}, 879 \mathrm{ww}, 855 \mathrm{vw}$, $838 \mathrm{w}, 813 \mathrm{w}, 755 \mathrm{w}, 722 \mathrm{w}, 695 \mathrm{w}, 660 \mathrm{w} \mathrm{cm}^{-1}$. The compound did not react with chromic anhydride in pyridine at rocm temperature, and gave an intractable oil with chromic acid in acetone. 
The triacetate, prepared from acetic anhydride and pyridine, formed a glass, m.p. $74-8^{\circ} \mathrm{C}$, on distillation $\left(150^{\circ} \mathrm{C}, .05 \mathrm{~mm}\right)$. (Found: C, 54.4I; H, 625; CI, 6.54; $\mathrm{CH}_{3} \mathrm{CO}, 30.2 . \mathrm{C}_{21} \mathrm{H}_{29} \mathrm{O}_{9} \mathrm{Cl}$ requires $\left.\mathrm{C}, 54.71 ; \mathrm{H}, 6.34 ; \mathrm{Cl}, 7.69 ; \mathrm{CH}_{3} \mathrm{CO}, 28.01 \%\right)$. Inf ra-red spectrum: $3620 \mathrm{w}, 3490 \mathrm{w}$ br; $1742 \mathrm{vs}$ br, $1639 \mathrm{w}$, $1230 \mathrm{~s} \mathrm{br}, 1165 \mathrm{~m}, 1132 \mathrm{w} ; 1060 \mathrm{w}$ inflex, 1024 s, 990 w, 972 w, $925 \mathrm{ww}, 905 \mathrm{ww}, 868 \mathrm{w}, 842 \mathrm{w}, 815 \mathrm{w}, 744 \mathrm{~m}, 726 \mathrm{~m}, 677 \mathrm{w} \mathrm{cm}^{-1}$. Reaction of reduced $\beta$-chloropicrotoxinin with periodic acid. Reduced $\beta$-chloropicrotoxinin $(.92 \mathrm{~g})$ in periodic acid $(20 \mathrm{ml}$, $.307 \mathrm{~N})$ was kept at room temperature for 40 hours. Five aliquots ( $1 \mathrm{ml}$ each) were removed during this time and analysed in the normal manner ${ }^{129}$ for periodate. The remaining solution was continuously ether extracted to give a yellow powder $(.24 \mathrm{~g})$ m.p. $120-80^{\circ} \mathrm{C}$. Chromatography on alumina gave a midale fraction, m.p. $212-20^{\circ} \mathrm{C}$. This was taken up in chloroform and precipitated out with petroleum ether $\left(\mathrm{b} \cdot \mathrm{p} .80^{\circ} \mathrm{C}\right)$ to give a white powder, m.p. $218^{\circ} \mathrm{C}$. (Found: C, 59.94; H, 6.38; $\mathrm{Cl}$, 2.91. $\mathrm{C}_{15} \mathrm{H}_{21}{ }^{\mathrm{O}}{ }^{\mathrm{Cl}}$ requires $\mathrm{C}, 54.16 ; \mathrm{H}, 6.38 ; \mathrm{Cl}, 10.65$; $\mathrm{C}_{15} \mathrm{H}_{22} \mathrm{O}_{7}$ requires $\mathrm{C}, 57.31 ; \mathrm{H}, 7.06 ; \mathrm{Cl}, 0.0 \%$ ). Infra-red spectrum: 3408s $1715 \mathrm{w}, 1635 \mathrm{w}, 1302 \mathrm{w}, 1270 \mathrm{w}, 1208 \mathrm{vw}$, $1160 \mathrm{vw}, 1102 \mathrm{~m}, 1070 \mathrm{w}, 1044 \mathrm{w}, 1005$ w, 950 w, 915 w, $828 \mathrm{~m}$, $734 \mathrm{vw}, 718 \mathrm{vw}, 695 \mathrm{w}_{\mathrm{cm}} \mathrm{cm}^{-1}$. The compound gave negative tests with Brady's reagent, with Fehling's solution, with bromine water, and with bromine in carbon tetrachloride. It gave positive tests with sensitized ammoniacal silver nitrate, with ammoniacal roseaniline, and with cold $1 \%$ neutral permanganate. Titration 
with standard acid and alkali gave 0.2 lactone groups per molecule. An attempt to form an acetate and a 3:5 dinitrobenzoate failed. Repetition of the reaction at $35^{\circ} \mathrm{C}$ gave chlorine, (recognized by its action on starch-iodide paper and its reaction with concentrated ammonia), after a reaction time of 72 hours. Dechlorination of reduced $\beta$-chloropicrotoxinin - Reduced $\beta$-chloropicrotoxinin $(.2 \mathrm{~g})$ in ethanol (10 ml) and water $(3 \mathrm{ml}$ ) was debrominated in the normal mamer during $30 \mathrm{~min}$ using zinc $(.15 \mathrm{~g})$ and amnonium chloride $(.15 \mathrm{~g})$. Removal of the ethanol under reduced pressure and ether extraction of aqueous solution gave a brown oil. Paper chromatography of this oil showed a compound identical wi th material m.p. 126 $44^{\circ} \mathrm{C}$ obtained from debromination of reduced $\beta$-bromopicrotoxinin. 118 (Rf value in butanol saturated with water, .95. Rf value in petroleum ether - butanol - water, 2:2:1, .97). Vanillin ( $1 \%$ in ethanol) mixed with perchloric acid (3\% in water) was used as a spray reagent. 110 
$\beta$ - Bromopicrotoxinin with $\mathrm{IiAlH}_{4}$ 


\section{Discussion}

Both the expected formulation IX, and Conroy's formulation XXIX, for lithium aluminium hydride reduced $\beta$ bromopicrotoxinin are unsatisfactory.

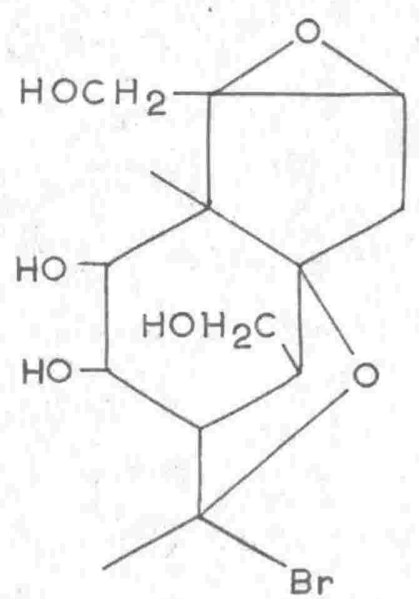

$\underline{\text { IXx }}$

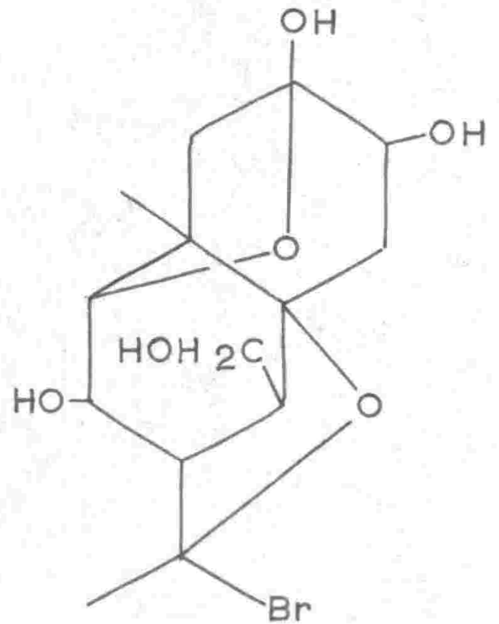

$\underline{\mathrm{xxIx}}$

Each of these structures should give a tetraacetate on acetylation whereas the only known acetate of reduced $\beta-$ bromopicrotoxinin is a triacetate. ${ }^{118}$ This derivative, which was originally prepared by treatment with acetic anhydride in pyridine, has now been found to be stable to further acetylation by an acetic anhydride - s.odium acetate mixture, despite the fact that infra-red absorption was present in the hydroxyl region $\left(3488 \mathrm{~cm}^{-1}\right)$. Thus the remaining hydroxyl in the 
triacetate must be either tertiery or sterically hindered. The position of an infra-red maximum at $1024 \mathrm{~cm}^{-1}$ suggested the presence of a primary hydroxyl ${ }^{108}$, and an attempt was made to oxidise the triacetate with chromic acid in acetone conditions under which a primary or second ary hydroxyl normally react. No oxidation occurred and the material could be recovered unchanged. More vigorous reaction with chromic in acetic acid however gave definite signs of oxidation and produced a brown intractable gum. This gum was non-acidic, and it reduced Fehling's and Tollen's reagents readily. It absorbed at $2550 \AA$ in the ultra-violet and may have thus been an aldehyde. All attempts at purification failed.

While definite evidence is still lacking, it is possible that the triacetate, and hence reduced $\beta$-bromopicrotoxinin itself, may contain a highly hindered primary hydroxyl which camot be acetylated, and which is stable to mild oxidation. No trityl derivative could be isolated when reduced $\beta$-bromopicrotoxinin was treated with triphenyl chloromethane, the only compound which was obtained being triphenyl carbinol.

Conroy $^{68}$ has suggested that the reduced compound XXIX, forrned by a simple pinacolic ring expension of LX, is produced when the reaction product is worked up in the presence of 2N sulphuric acid. The reduction with lithium al uminium hydride was therefore repeated under neutral conditions using sodium sulphate to hydrolyse the reaction complex. The product obtained was identical to that formed when acid was used in the 
workup. It was thus considered unlikely that a pinacol rearrangement had occurred as acid conditions are normally essential for this type of rearrangement. 119

Pyrolysis of the acetate of XXIX should yield a naphthalene derivative. An attempted pyrolysis of the triacetate was carried out at $170^{\circ} \mathrm{C}$ for 24 hours. Distillation of the resultant liquid at low pressure yielded a compound, (m.p. $82^{\circ} \mathrm{C}$ ), which did not depress the melting point of the starting material.

The oxidation of reduced $\beta$-bromopicrotoxinin with periodic acid has been previously examined, and has been found to be complex and involve the evolution of bromine together with the consumption of 3.5 moles of periodate. ${ }^{65}$ Formaldehyde was detected onee amongst the oxidation products, but no volatile aldehyde or ketone could be obtained regularly. An attempt has now been made to isolate formaldehyde more consistently fram the oxidation.

Three methods were available for the determination of formaldehyde - by precipitation with 2:4-dinitrophenylhydrazine, by precipitation with dimedone ${ }^{120}$, and colorimetrically with phenylhydrazine and potassium ferricyanide. ${ }^{121}$ The presence of periodate ions interfered with each of these methods, and it was thus necessary to remove the periodate before determination.

119. Gilman. "Organic Chemistry" Vol. I, p. 968, Wiley and 120. Bell. Sons, N.Y. (1953)

121. Hough. J.C.S. $\overline{1956} 4799$ 
Eight determinations were carried out and the following results obtained. In all cases bromine was evolved during the reaction.

(1) The cold reaction mixture was stirred by bubbling air through it and into a solution of 2:4-dinitrophenylhydrazine. No formaldehyde was detected.

(2) The excess periodate was reduced with arsenite, and the resultant solution distilled into dimedone solution. No formaldehyde was detected.

(3) The solution containing unreduced periodate was distilled into 2:4-dinitrophenylhydrazine solution. A $21 \%$ yield of formaldehyde was obtained.

(4) The solution containing periodate was distilled and the formaldehyde in the distillate was determined colorimetrically. A 23\% yield was obtained.

(5) The periodate was precipitated with barium chloride and sodium bicarbonate and the filtrate examined colorimetrically. No formaldehyde was ob tained.

(6) The periodate was precipitated with barium chloride and sodium bicarbonate, the filtrate refluxed, and then examined colorimetrically. No formaldehyde was detected.

(7) The solution was refluxed, distilled, and examined colorimetrically. A yield of $7 \%$ formaldehyde was obtained. (8) Reduced $\beta$-bromopicrotoxinin was refluxed with hydrochloric acid, the resultant solution cooled and treated with periodate, and the formaldehyde determined as in (5) 
above. A yield of $36 \%$ was obtained.

These results showed that formaldehyde was obtained only when the reduced $\beta$-bromopicrotoxinin was treated with periodate after having been boiled with acid. This suggests the presence of the grouping IXXI in the reduced compound where the bond $0-x$ is rupturable with boiling acid.<smiles>[X]OC1(CO)CCC1</smiles>

\section{$\underline{\text { LXI }}$}

The above partial structure is not present in Conroy's formulation XXIX of reduced $\beta$-bromopicrotoxinin. The reaction of reduced $\beta$-bromopicrotoxinin with concentrated hydrochloric acid was investigated further with a view to obtaining a solid product. The treatment of $\beta$-bromopicrotoxinic acid with concentrated boiling hydrochloric acid has been examined previously ${ }^{64,} 122$ when a

122. Sielisch. Ber 452563 (1912) 
chlorobromopicrotoxinic acid $\mathrm{C}_{15} \mathrm{H}_{1} 8^{0} 7^{\mathrm{BrCl}}$ was obtained. Conroy sugges ted that this acid may be a simple chlorohydrin formed by cleavage of an oxirane ring, and it was hoped that a similar compound might be obtained on acid treatment of reduced $\beta$-bromopicrotoxinin. This latter compound has been reported to be stable to boiling NN sulphuric acid ${ }^{118}$, and was therefore treated wi th boiling concentrated hydrochloric acid when the only product obtained was a dark brown intractable gum. This gum, when treated wi th periodate, yielded formaldehyde in approximately $35 \%$ yield, together with considerable quantities of chlorine.

For formaldehyde to be formed on cold periodate treatment it is necessary for the adjacent carbon to contain a free hydroxy, or possibly a free chloro-, group, and thus the ether link present in reduced $\beta$-bromopicrotoxinin must be ruptured by the concentrated acid treatment. The chlorine is formed either by hydrolysis of the activated halogen atom or by direct oxidation of an $\mathcal{L}$-hydroxy halogen with periodate. A possible scheme is indicated below.

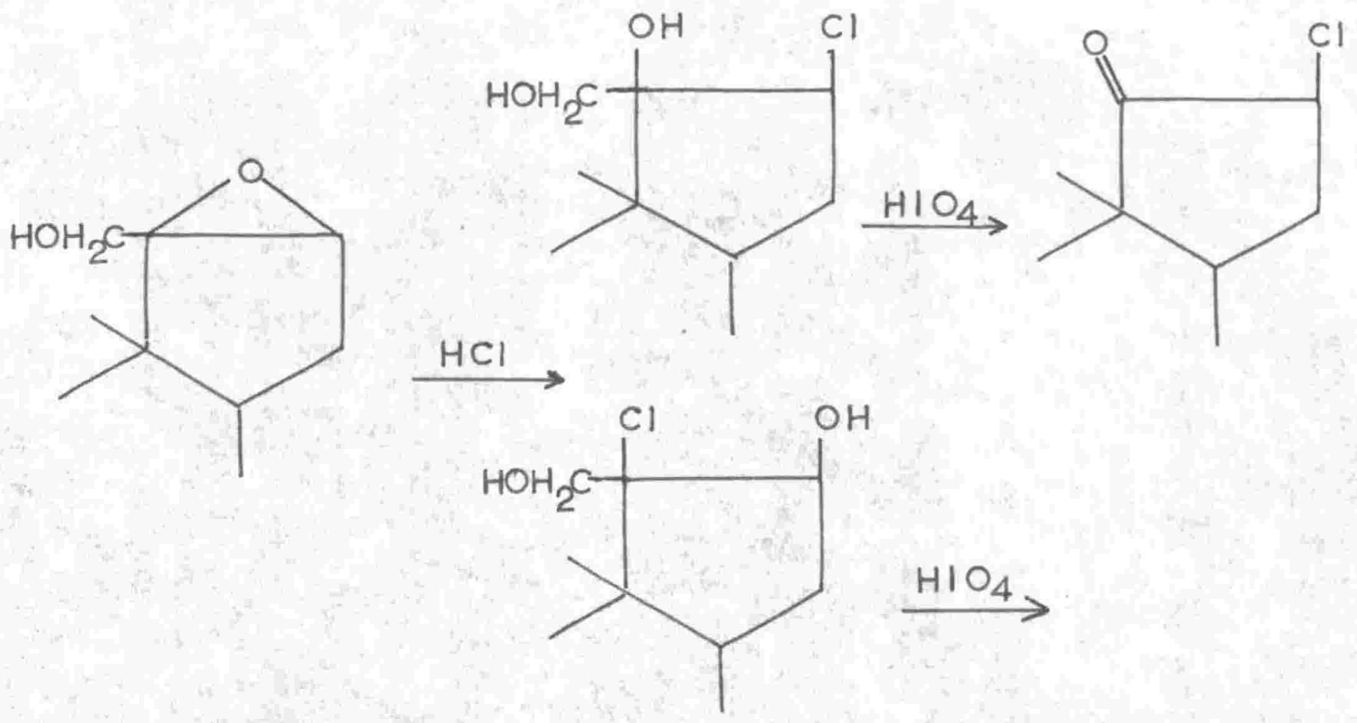



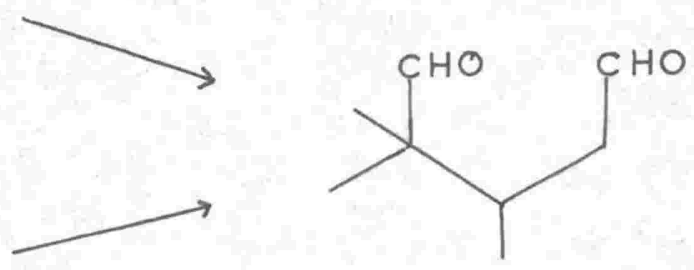

$+\mathrm{Cl}^{\prime}$

112

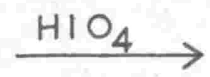

$\mathrm{Cl}_{2}$

Direct oxidation of the $-\begin{aligned} & \mathrm{CI} \\ & \mathbf{C}\end{aligned}$ with periodate, which has recently been shown to oxidise not only $\alpha$-glycol systems, but also active methylene groups ${ }^{123}$ and double bonds. 124

Treatment of the triacetate of reduced $\beta$-bromopicrotoxinin with boiling concentrated hydrochloric anid yielded a brown oil. This oil could not be sublimed and was thus not unchanged material. Treatment of the oil with periodate gave no detectable formaldehyde. While this absence of formaldehyde may be explained by assuming that the ether linkage had not been broken by acid hydrolysis, a more logical explanation is that the primary hydroxyl responsible for formaldehyde in the parent compound is no longer present as such in the acetate - LXII.

123. Huebner, Ames \& Bubl. J.A.C.S. 681621 (1946) 124. Chatter jee \& Majumdar. Anal. Chem. 28 878 (1956) 

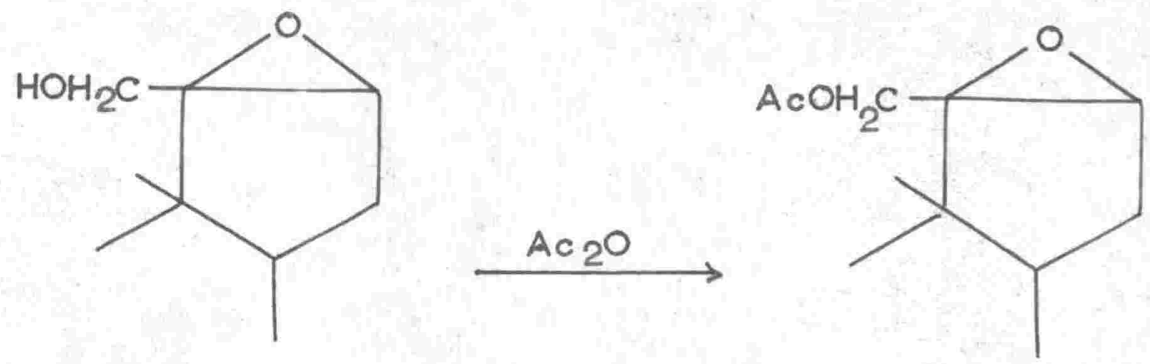

\section{IXII}

Debromination of lithium aluminium hydride reduced

$\beta$-bromopicrotoxinin has been shown to give an unsaturated. compound, m.p. $153^{\circ} \mathrm{C}$, which analysed as a $\mathrm{C}_{15} \mathrm{H}_{22} \mathrm{O}_{6}$ derivative. 65 This debromination reaction has now been repeated and a compound melting at $115-39^{\circ} \mathrm{C}$ was obtained from the resultant brown oil. This compound was continually resublimed until the melting point was constant $\left(156^{\circ} \mathrm{C}\right)$ when it then analysed as $\mathrm{C}_{15} \mathrm{H}_{22} \mathrm{O}_{5^{\circ}}$

This formula can be obtained from the parent compound $\mathrm{C}_{15^{\mathrm{H}}}{ }_{23}{ }^{\mathrm{O}} 6^{\mathrm{Br}}$ by two formal operations:
(a) $\mathrm{C}_{15} \mathrm{H}_{23} \mathrm{O}^{\mathrm{Br}}$ $\stackrel{\mathrm{Br}}{\longrightarrow} \mathrm{C}_{15^{\mathrm{H}}} 4_{4}{ }^{\circ}$
(b) $\mathrm{C}_{15} \mathrm{H}_{24}{ }^{\mathrm{O}} 6$ $=\mathrm{H}_{2} \mathrm{O} \rightarrow$ $\mathrm{C}_{15^{\mathrm{H}}} \mathrm{H}_{22} \mathrm{O}_{5}$

However the compound gave no double band absorption in the infra-red $>\mathrm{C}=\mathrm{c}-$ stretching region $\left(1620-80 \mathrm{~cm}^{-1}\right)$. This may have been due to isomerization of the double bond into a tetra-substituted position, but since the compound did not decolourise bromine water it was very doubtful whether a double bond was present, and it appeared likely that the compound may 
have rearranged. This fact became more obvious when it was found that the compound gave no infra-red hydroxyl absorption and hence contained no hydraxyl groups.

The parent reduced compound contains six oxygen atoms, four of which are present as hydroxyl groups. Simple debromination should regenerate a further hydroxyl, and it is difficult to see how these five hydroxyl groups could be lost without the occurrence of considerable rearrangement. Further work on this product is necessary.

The debromination compolund m.p. $126^{\circ} \mathrm{C}$ was originally thought to be simply an impure form of the material m. p. $156^{\circ} \mathrm{C}$. However the compound m.p. $120^{\circ} \mathrm{C}$ was found to be unsaturated to bromine water, and it was hydrogenated to give a compound m.p. $133^{\circ} \mathrm{C}$ which analysed for $\mathrm{C}_{15} \mathrm{H}_{22-24^{\circ}}{ }_{4}^{\circ}$. As the starting material m.p. $126^{\circ} \mathrm{C}$ had previously been analysed as a 118

$\mathrm{C}_{15} \mathrm{H}_{22} \mathrm{O}_{4}$ compound it was thought that simple hydrogenetion of a double bond had occurred. The product gave no characteristic infra-red double bond absorption, but absorbed at $3403 \mathrm{~cm}^{-1}$ in the hydroxyl region. At present no satisfactory formulation can be presented for this compound.

Reduced $\beta$-bromopicrotoxinin $\mathrm{C}_{15} \mathrm{H}_{23} \mathrm{O}_{6} \mathrm{Br}$ is campletely saturated and therefore must contain four ring systems. Two of these are present in the carbo-cyclic skeleton and one in the oxide ring associated with the biromine atom. The forth ring must also involve an ether link unless considerable change to the carbon skeleton has occurred during reduction.

Conroy's formulation XXIX for reduced $\beta$-bromopicrotoxinin camot be correct as this structure would not give 
formaldehyde on treatment with acid and periodate. Two other possible formulations exist, LXIII and LX. Formula LXIII would be expected to give a triacetate, but should give formic acid rather than formaldehyde on treatment with periodate, and should be reactive to $\underline{2 N}$ sulphuric acid.

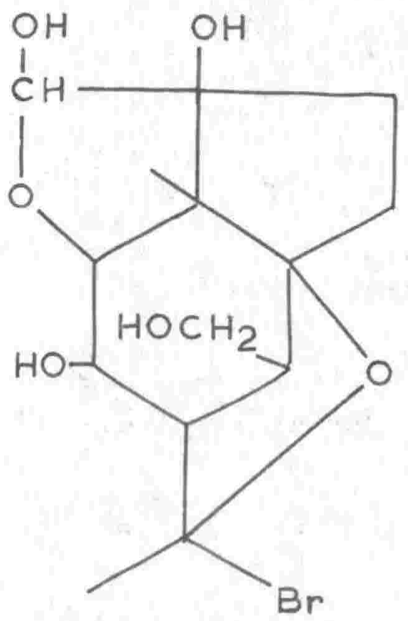

LXIII

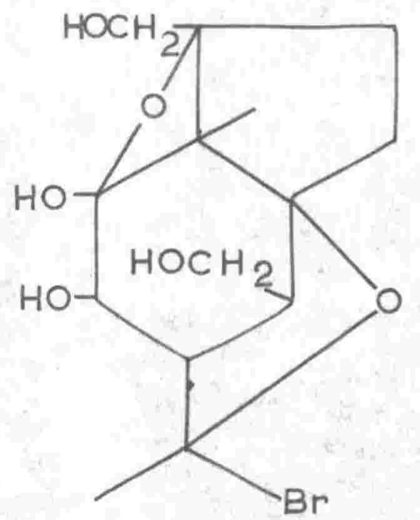

LXIV

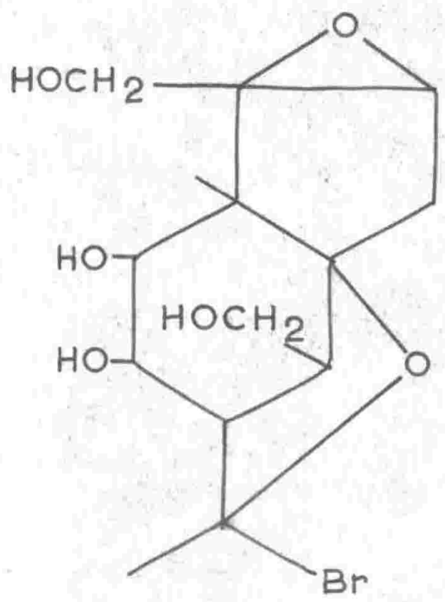

LX

Therefore LX is suggested as the correct formula, and this structure fulfills all requirements other than those implied by the formation of a triacetate, Other possible formulations (e.g. IXIV) also suffer from the disadvantage that they should give a tetracetate and should react readily with dilute acid, and hence the formula containing the epoxide IX is preferred.

Further work is necessary to justify more fully the acceptance of this structure. 
Experimental

Reduction of B -bromopicrotoxinin -

$\beta$-Bromopicrotoxinin $(10 \mathrm{~g})$ was reduced with lithium aluminium hydride as described in the literature ${ }^{65}$, except that the reaction complex was hydrolysed with sodium sulphate (200 ml saturated aqueous solution) instead of with sulphuric acid. The product, m.p. $210-213^{\circ} \mathrm{C}(3 \mathrm{~g})$ was crystallized from ethanol to give the compound $\mathrm{m}_{\bullet} \mathrm{p} \cdot 218^{\circ} \mathrm{C}$ identical with that previously described. 65 Treatment of this alcohol with triphenyl chloromethane in anhydrous pyridine failed to give a trityl derivative. Acetylation of reduced $\beta$-bromopicrotoxinin Acetylation of reduced $\beta$-bromopicrotoxinin $(.6 \mathrm{~g})$ with acetic anhydride $(5 \mathrm{ml})$ in pyridine $(2 \mathrm{ml})$ at room temperature $(15 \mathrm{hr}$.$) gave a gum which on distillation \left(110^{\circ} \mathrm{C}, .02 \mathrm{~mm}\right)$ gave a triacetate, m.p. $80-2^{\circ} \mathrm{C}$, identical to that previously obtrined. 118 Infra-red spectrum: $3488 \mathrm{w}, 1742 \mathrm{~s}$, $1238 \mathrm{~s} \mathrm{br}, \quad 1163 \mathrm{w}, \quad 1134 \mathrm{w}$ br. 
1115 w, 1024 m, 971 w, 925 w, 895 w, 865 w, 838 w, 814 w, 732 w, $722 \mathrm{w} \mathrm{cm}^{-1}$. The acetate was stable to pyrolysis at $170^{\circ} \mathrm{C}$. and to oxidation by chromic in acetone, but gave with chromic in acetic acid a non-acidic intractable gum which reduced Fehling's and Tollen's reagents and which had $\lambda \max 2550 \AA$. Attemoted acetylation of the triacetate of reduced B -Bramopicrotoxinin.

The triacetate $(.01 \mathrm{~g})$ was heated $(1 \mathrm{hr})$ on a water bath with sodium acetate $(.0 \mathrm{lg})$ and acetic anhydride $(1 \mathrm{ml})$. Unchanged triacetate, m.p. and mixed $m_{\bullet} p_{\bullet} 80-3^{\circ} \mathrm{C}$, was obtained upon the addition of water.

Reaction of reduced $\beta$-bromopicrotoxinin with periodic acid.

(A) A solution of reduced $\beta$-bromopicrotoxinin (.Ig) in periodic acid (.5M, $3 \mathrm{ml}$ ) was allowed to stand overnight at room temperature. Addition of water $(20 \mathrm{ml})$ and distillation into a solution of 2:4-dini trophenylhydrazine (20 ml, saturated solution in $\mathrm{N} \mathrm{H}_{2} \mathrm{SO}_{4}$ ) gave formaldehyde 2:4-dihitrophenylhydrazone (.2l mole), m•p. and mixed m•p. $158-60^{\circ} \mathrm{C}$.

(B) The reaction was carried out as in (A) above except that the formaldehyde was determined colorimetrically by the method of Hough ${ }^{121}$. A yield of .23 moles of formaldehyde was ob tained.

(a) Reduced $\beta$-Bromopicrotoxinin $(.026 \mathrm{~g})$ in water $(5 \mathrm{ml})$ was refluxed with periodic acid (.5M, $2 \mathrm{ml}$ ) for four hours. Distillation of the resulting solution and colorimetric determination of the distillate gave formaldehyde $(.07 \mathrm{~mole})$. 
(D) Reduced $\beta$-bromopicrotoxinin $(.3 \mathrm{~g})$ was refluxed with concentrated hydrochloric acid $(4 \mathrm{ml})$ for 30 minutes. Water was added and all acid azeotroped off. Evaporation to dryness gave a brown intractable gum. Addition of periodic acid (.5M, $5 \mathrm{ml}$ ) gave chlorine (starch-iodide paper) after 30 minutes, and colorimetric determira tion after seven hours gave a $36 \%$ yield of formaldehyde. An intractable gum was formed when the mother liquors were worked up in the normal mamer. Reaction of hydrochloric acid with the triacetate of reduced. $\beta$-bromopicrotoxinin. The acetate $(.08 \mathrm{~g})$ was refluxed with concentrated hydrochloric acid $(4 \mathrm{ml})$ for 30 minutes. The acid was azeotroped off with water to give an intractable brown oil which gave no formaldehyde when treated with periodic acid (.5‥ $2 \mathrm{ml})$.

Debromination of reduced $\beta$-bromopicrotoxinin - Reduced $\beta$-bromopicrotoxinin $(.5 \mathrm{~g})$ was debrominated with zinc $(.3 \mathrm{~g})$ and ammonium chloride $(.3 \mathrm{~g})$ in the normal mamer. The material isolated by recrystallization, m.p. $115-139^{\circ} \mathrm{C}$ (from ethanol), was resublimed $\left(5 \mathrm{X}, 100^{\circ} \mathrm{C}, .02 \mathrm{~mm}\right.$ ) to give needles, m.p. $156^{\circ} \mathrm{C}$. (Found: $0,64.23 ; \mathrm{H}, 7.97 . \quad \mathrm{C}_{15} \mathrm{H}_{22} \mathrm{O}_{5}$ requires $\mathrm{C}, 63.81 ; \mathrm{H}, 7.85 \%$ ). Infra-red spectrum: $1402 \mathrm{ww}$, $1348 \mathrm{vw}, 1315 \mathrm{w}, 1299 \mathrm{w}, 1283 \mathrm{w}, 1263 \mathrm{~m}, 1233 \mathrm{w}, 1223 \mathrm{~m}, 1210 \mathrm{~m}$, 1170 w, 1162 w, 1144 ww, 1127 w, 1108 m, 1087 w, 1077 w, 1052 s, $1037 \mathrm{~s}, 1013 \mathrm{~m}, 984 \mathrm{w}, 968 \mathrm{vw}, 898 \mathrm{vw}, 893 \mathrm{w}, 877 \mathrm{w}, 858 \mathrm{vw}$ inflex, 851 w, $842 \mathrm{~m}, 820 \mathrm{w}, 798 \mathrm{w}, 762 \mathrm{ww}, 748 \mathrm{w}, 730 \mathrm{w}$, $698 \mathrm{w}, 655 \mathrm{w} \mathrm{cm}^{-1}$. The debrominated material did not decolorise 
bromine water.

Hydrogenation of debrominated reduced $\beta$-bromopicrotoxinin, m.p. $126^{\circ} \mathrm{C}$.

Hydrogenation of debrominated compound $\mathrm{m}_{0} \mathrm{p} .126^{\circ} \mathrm{C}(.228 \mathrm{~g})$ with hydrogen $(50 \mathrm{ml})$ and Adam's catalyst $(.046 \mathrm{~g})$ gave a crude compound m.p. $110-20^{\circ} \mathrm{C} .118$ Repeated sublimation of this product $\left(7 \mathrm{X}, 100^{\circ} \mathrm{C}, .02 \mathrm{~mm}\right)$ gave needles, m.p. $133^{\circ} \mathrm{C}$. (Found: C, 67.15; H, 8.33. $\mathrm{C}_{15} \mathrm{H}_{22} \mathrm{O}_{4}$ requires $\mathrm{C}, 67.64 ; \mathrm{H}, 8.33$. $\mathrm{C}_{15} \mathrm{H}_{24} \mathrm{O}_{4}$ requires $\left.\mathrm{C}, 67.13 ; \mathrm{H}, 9.09 \%\right) . \lambda \max 2340 \AA$ Infrared spectrum (KBr disc): $3403 \mathrm{~m}, 2960 \mathrm{~m}, 2910 \mathrm{~m}, 1630 \mathrm{w}$ br, $1430 \mathrm{w} b r, 1418 \mathrm{w}, 1376 \mathrm{~m}, 1316 \mathrm{w}, 1285 \mathrm{w}, 1265 \mathrm{~m}, 1224 \mathrm{~m}$, $1210 \mathrm{~m}, 1172 \mathrm{~m}, 1163 \mathrm{w}, 1145 \mathrm{ww}, 1126 \mathrm{ww}, 1108 \mathrm{~m}, 1089 \mathrm{w}, 1078 \mathrm{w}$, $1058 \mathrm{w}, 1053 \mathrm{~s}, 1040 \mathrm{~m}, 1015 \mathrm{w}, 986 \mathrm{w}, 900 \mathrm{w}, 894 \mathrm{w}, 878$ w, $860 \mathrm{w}$, $852 \mathrm{vw}, 842 \mathrm{w}, 820 \mathrm{w}, 800 \mathrm{w}, 750 \mathrm{w}, 731 \mathrm{vw}, 701 \mathrm{vw} \mathrm{cm}^{-1}$. 
B - Bromopicrotoxinin with MeligI 


\section{Discussion}

Whilst treatment of $\beta$-bromopicrotoxinic acid with lithium al uminium hydride has led to a rearrangement of the ether link, $\beta$-bromopicrotoxinin itself yields as the chief product a compound in which the epoxide is apparently unchanged. It was therefore considered desirable to study the reaction of $\beta$-bromopicrotoxinin with a grignard reagent, and to see if a product analogous to the hydride reduced compound could be obtained.

$\beta$-Bromopicrotoxinin was insoluble in dry ether, and so pyridine and dioxan were tried as solvents for the girignard reaction. Reaction in pyridine gave only unchanged material together with a small quantity of a brown sludge and large amounts of iodine. Dioxan, when added to methyl magnesi um iodide in ether, gave the normal precipitate of complexes, 125,126 but after three hours reflux at the temperature of boiling ether, $\beta$-bromopicrotoxinin had reacted with the soluble dimethyl 127

magnesium in $10 \%$ yield. ( $85 \%$ of the $\beta$-bromopicrotoxinin was recovered unchanged). The resultant product, m.p. $198-9^{\circ} \mathrm{C}$, analysed as $\mathrm{C}_{17} \mathrm{H}_{23} \mathrm{O}^{\mathrm{Br}}$, and was thus formed by the addition of two methyl groups to $\beta$-bromopicrotoxinin. The compound had no absorption in the ultra-violet range $2200-3600 \AA$. Infrared showed a $\gamma$-lactane 117 at $1764 \mathrm{~cm}^{-1}$, and at least two

125. Shoragin et al. Ber $642584 \quad$ (1931)

126. Kullmann. Compt. Rend. 231 866 (1950)

127. Gilman. "Organic Chemistry" Vol I, p.498 Wiley \& Sons, 
hydroxyl groups, probably one secondary and one tertiary, at 3545, 3318, 1190, and $1112 \mathrm{~cm}^{-1}$. The compound did not react with periodic acid, and was stable to oxidation by chromic acid in acetone at room temperature.

The material did not appear to be more soluble in 2lkali than in water, but infra-red data indicated the presence of a $Y$-lactone. This function suggests that at least one of the original $\beta$-bromopicrotoxinin lactones was unaffected by the grignard reagent, and also that no rearrangement to a $\beta$ bromopicrotoxinic acid type compound had occurred during reaction.

Two structures for the compound $\mathrm{C}_{17} \mathrm{H}_{23} \mathrm{O}_{6}^{\mathrm{Br}}$ are possible - LXVV and LXVI.

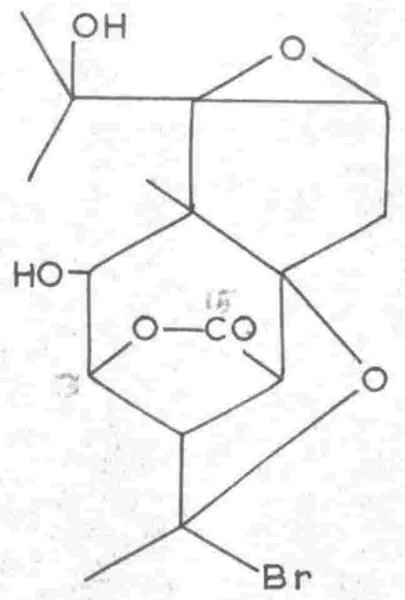

$\underline{\text { LXV }}$

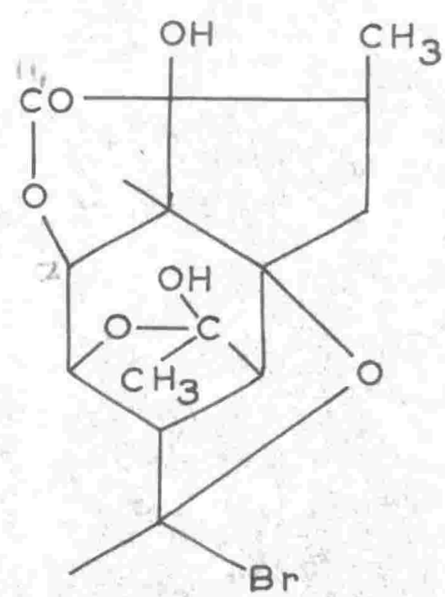

LXVI

Admittedly LXV contains a secondary hydroxyl which would be expected to undergo chromate oxidation, but picrotoxinin dimethyl dicarboxylate also apparently contains a secondary hydroxyl in the same position which is stable to oxidation, (page 128), and so formula LXV cannot be excluded for thet 
reason alone.

Structure LXVI should undergo mild acid hydrolysis to give a methyl ketone, whilst structure IXV should be stable to acid as the epoxide would be sufficiently protected from rearward attack. The compound $\mathrm{C}_{17} \mathrm{H}_{23} \mathrm{O}_{6} \mathrm{Br}$ was ther ef ore warmed with dilute (.IN) hydrochloric acid, and the reaction followed spectroscopically. A strong peak was formed at $2560 \AA$ $(\varepsilon=1800)$, but only a weak inflexion was present in the ketonic region $(2700-900 \AA)$. The origin of the peak at $2560 \AA$ was obscure, but its intensity indicated the formation of a conjugated system, and it was apparent that deep-seated changes were occurring in the molecule. No useful solid product could be ob tained from this reaction.

Structure LXV is possibly the more likely of the two formulations of the grignard product, as the lactone $\mathrm{C}_{15}-\mathrm{C}_{3}$ is the more hindered steric ally and hence would be more stable than the lactone $\mathrm{C}_{14}-\mathrm{C}_{2}$ to grignard reagent. 
Experimental

Reaction of $\beta$-bramopicrotoxinin with methyl magnesium iodide

$\beta$-Bromopicrotoxinin $(5 \mathrm{~g})$ in dioxan $(50 \mathrm{ml}$ ) was added dropwise to a stirred refluxing ethereal solution of magnesium $(2.2 \mathrm{~g})$ and methyl iodide $(12.9 \mathrm{~g})$. The milky white suspension was refluxed for three hours, ammonium chloride solution (100 ml, 15\% aq.) added dropwise, and the whole reduced to low volume under vacuum. Acidification and ether extraction of the resultant aqueous solution gave $\beta$-bromopicrotoxinin unchanged $(4.1 \mathrm{~g})$, together with a product $(.5 \mathrm{~g}) \mathrm{m}_{\bullet} \mathrm{p} \cdot 214_{-}$ $9^{\circ} \mathrm{C}$, separated from the unchanged material by recrystallization from ethanol-water to give needles (from ethanol), m.p. 198$9^{\circ} \mathrm{C}$. (Found: C, 50.45; H, 5.54; Br, 20.81. $\mathrm{C}_{\square} \mathrm{H}_{23} \mathrm{O}_{6} \mathrm{Br}$ requires $\mathrm{C}, 50.62 ; \mathrm{H}, 5.74 ; \mathrm{Br}, 19.82 \%)$. Infra-red spectrum: 3545 s, 3318 s, 1764 s, 1366 s, 1335 m, 1317 m, 1298 m, 1287 w, $1275 \mathrm{~m}, 1250 \mathrm{w}, 1237 \mathrm{w}, 1220 \mathrm{w}, 1200 \mathrm{~m}$ inflex, $1190 \mathrm{~s}, 1162 \mathrm{~m}$, $1134 \mathrm{~m}, 1112 \mathrm{~s}, 1102 \mathrm{~m}, 1087 \mathrm{ww}$ inflex, $1078 \mathrm{~m}, 1058 \mathrm{ww}$, 1043 w inflex, 1037 m, 1022 s, 1005 w, 980 m, 966 s, 931 m inflex, 923 s, 910 m, 900 w inflex, 874 w, 839 m, 820 w, 782 w, 759 m, $739 \mathrm{~m}, 716 \mathrm{w}, 705 \mathrm{~m}, 655 \mathrm{~m} \mathrm{~cm}^{-1}$. The compound did not react with periodic acid, or with chromic acid in acetone. Reaction of the grignard product with dilute acid. The grignard product $(.02 \mathrm{~g})$ was warmed with aquoous hydrochloric acid (.25N, $3 \mathrm{ml}$ ) and ethanol ( $5 \mathrm{ml}$ ) on a water bath. Aliquots ( $1 \mathrm{ml}$ ) were removed at intervals and the ultra-violet absorption measured against a blank. Reduction of the reaction mixture 
to low volume gave an intractable gum which had $\lambda \max 2560$ ( $\varepsilon=1800$ ). This gum gave a positive test with Brady's reagent. 
Picrotoxinin Dicarboxylic Acid 


\section{Discussion}

Conroy has suggested that the structure of picrotoxinin dicarboxylic acid, formed by mild alkaline hydrolysis of picrotoxinin, was simply LXVII. ${ }^{66}$

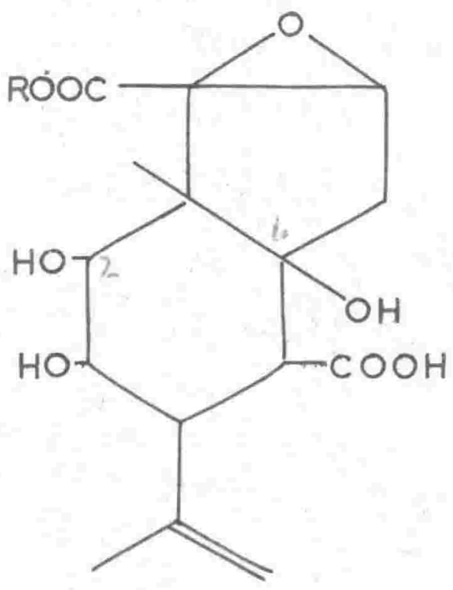

$$
\begin{array}{ll}
\text { IXVII } & \mathrm{R}=\mathrm{H} \\
\text { IXVIIII } & \mathrm{R}=\mathrm{CH}_{3}
\end{array}
$$

He postulated that a change in conformation had occurred, thus explaining why the compound could not be brominated or relactonised, IXVIIa. The dicarboxylic acid has been found to react with one mole of periodate ${ }^{60}$, but no crystalline product has been obtained. ${ }^{66}$ A diacetate has been prepared 57 , but otherwise little is known about the compound which absorbs at $1724 \mathrm{~cm}^{-1}$ in the infra-red. 


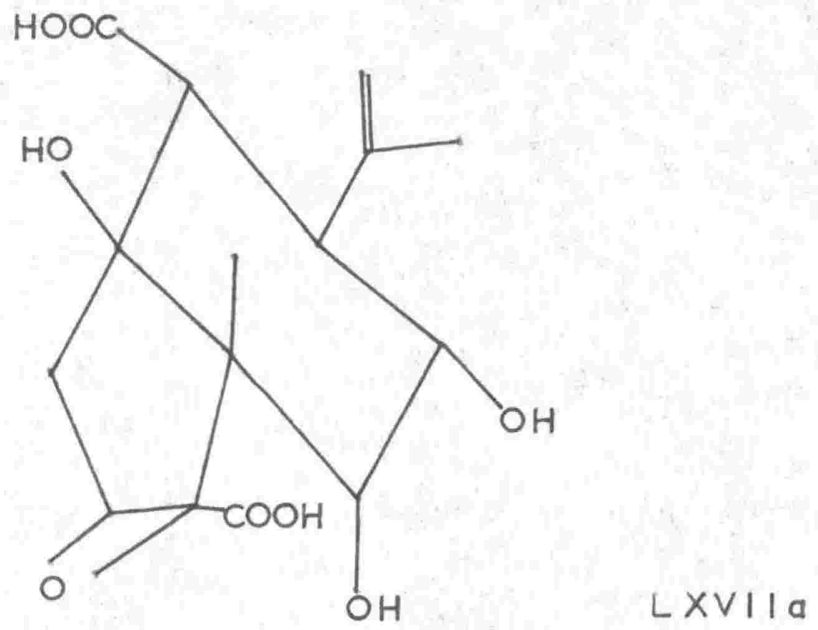

Picrotoxinin in the presence of alkali, (true picrotoxinin dicarboxylic acid), undergoes the Schlittler degradation and is thas unstable to ammoniacal silver nitrate 57 , and it would be expected that picrotoxinin dicarboxylic acid would be equally susceptible to degradation. However, it has now been found that the latter compound is stable to alkali, and that it does not give reducing tests.

Alkaline degradation can apparently occur in the picrotoxinin series unless -

(a) Compounds have no free hydroxyl at $\mathrm{C}_{6}-\mathrm{e.g}$. $\beta$-bromopicrotoxinin, $\beta$-bromopicrotoxinic acid.

(b) Compounds have no free hydroxyl at $\mathrm{C}_{2}$.

(c) Compounds have no epoxide linkage. e.g.

Picrotoxic acid? Apopicrotoxinic dilactone?

It may thus be possible that some rearrangement has occurr ed during the formation of the dicarboxylic acid, so that it does 
not contain all the functional groups necessary for degradation. The dimethyl ester of picrotoxinin dicarboxylic acid was prepared by treating picrotoxinin in methanol with one drop of sodium methoxide solution ${ }^{59}$. When this preparation was repeated small quantities of the diester were obtained together with large amounts of methyl picrotoxate, m.p. $170^{\circ} \mathrm{C}$. The use of smaller amounts of sodium methoxide gave picrotoxinin unchanged and the use of dried absolute methanol did not increase the yield of diester. It was thus necessary in all preparations of the diester to separate it fram picrotoxic eater by recrystallization.

Picrotoxinin dimethyl dicarboxylate was treated with 1.I moles of periodic acid and the solution left for 24 hours. Ether extraction gave a pale yellow intractable oil. This oil was non-acidic and gave positive tests with sensitised ammoniacal silver nitrate and with Fehling's solution. It did not absorb strongly in the ultra-violet, but gave a positive test with 2:4-dinitrophenylhydrazine solution. The precipitate from this test gave a red oil after chromatography on a bentonitekieselguhry column.

The diester was treated with chromic acid in acetone, when it was expected from formula LXVIII that an $\mathcal{\alpha}$-diketone might be formed. Careful titration of the diester with the oxidising agent until an orange colour remained after three minutes standing gave a white crystall ine material, m•p. $162^{\circ} \mathrm{C}$. 
This compound absorbed at $2900 \&$ in the ultra-violet, and at $3476 / 1107 \mathrm{~cm}^{-1}$ (secondary alcohol), $1733 \mathrm{~cm}^{-1}$ (ester), $1699 \mathrm{~cm}^{-1}$ (ketone), and $1644 \mathrm{~cm}^{-1}$ (double bond), in the infra-red. Elementary analysis gave $\mathrm{C}_{17} \mathrm{H}_{22} \mathrm{O}_{8}$, indicating the loss of two hydrogen atoms during oxidation.

The ultra-violet spectrum suggested the presence of a keto-grouping and this was verified by infra-red absorption at $1699 \mathrm{~cm}^{-1}$. This latter peak is at a lower wavelength that is usual for a normal ketone, and is thus thought to be due to an $\alpha$-hydroxy ketone. ${ }^{102,103}$ The compound gave reducing tests with Fehling's solution and with amnoniacal silver nitrate, (the parent compound gave no reducing tests), which also suggested the presence of an $\mathcal{L}$-ketal.

If the formula LXVIII is assumed for dimethyl picrotoxinin dicarboxylate, the oxidation product can be formulated as LXIX.

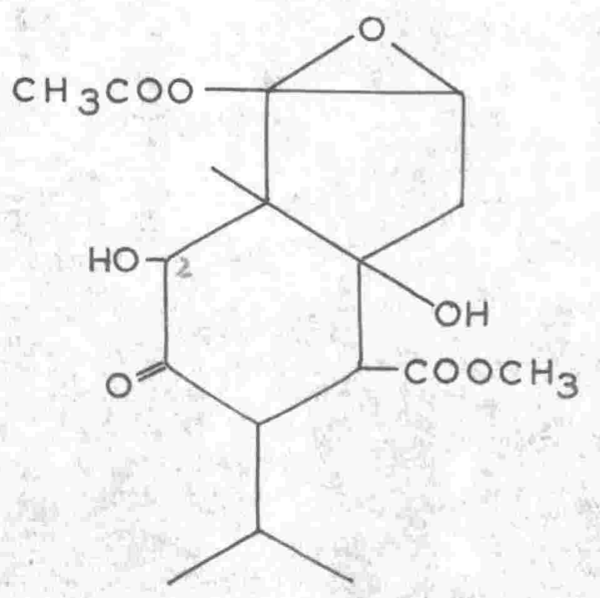

$\underline{\operatorname{LXIX}}$

No reasons can be given for the apparent stability of the 
secondary hydroxyl group to chromic acid oxidation. Infrarea absorption at $1107 \mathrm{~cm}^{-1}$ was almost certainly due to a secondary hydroxyl, but the stability to oxidation may be taken to indicate the presence of a tertiary hydroxyl. The $\alpha$-ketal was therefore treated with periodic acid whence a tertiary hydroxyl should give a keto-acid Lxx, and a secondary hydroxyl should give an aldehyde LXXXI.

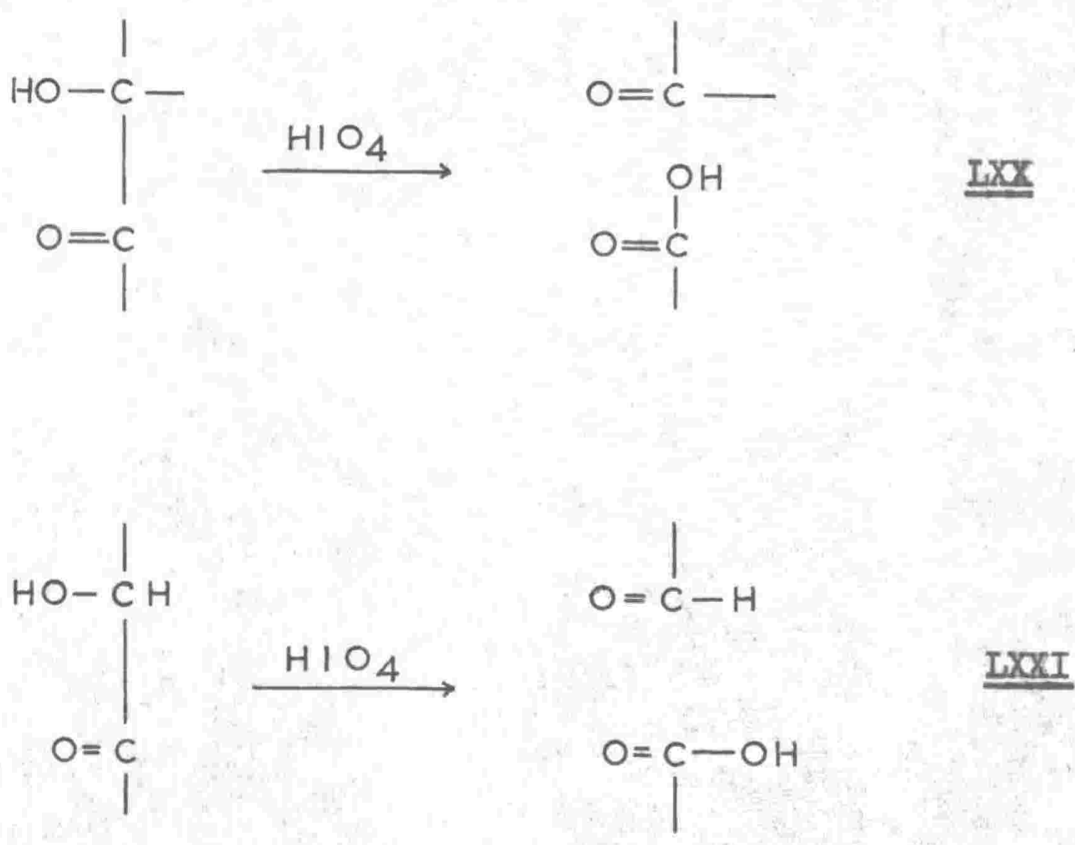

No solid product could be obtained from this reaction. However much iodine was evolved, indicating that a function which was strongly reducing under acid conditions was being generated. ${ }^{128-30}$

128. Salmon \& Powell. J.A.C.S. $61 \quad 3507 \quad$ (1939) 129. Adams, "Organic Reactions" VoI II, p. 360 Wiley \& Sons, N.I. (1944)

130. Dean \& Manunapichu. J.C.S. 19573123 
This was most probably an aldehyde and it appears that option LXXI above is the more likely, and that the $\mathcal{C}$-hydroxyl group is therefore a secondary one.

The diester of picrotoxinin dicarboxylic acid forms a diacetate. 59 The infra-red absorption spectrum of this derivative was recorded, and hydroxyl absorption noted at $3492 / 1170 \mathrm{~cm}^{-1}$ and double bond absorption at $1646 \mathrm{~cm}^{-1}$. Thus picrotoxinin dicarboxylic acid contains at least three hydroxyl groups.

The above evidence does not disprove the structure LXVII for the dicarboxylic acid. However two problems remain to be solved before this formulation can definitely be acdepted.

(a) The reason for the stability of the molecule to alkali.

(b) The reason for the stability of the hydroxyl at $\mathrm{C}_{2}$ to mild acid oxidation. 


\section{Experimental}

Preparation of dimethyl picrotoxinin dicarboxylate. The diester was prepared as described in the literature ${ }^{59}$ by treatment of a methanolic solution of picrotoxinin $(.75 \mathrm{~g}$ in $20 \mathrm{ml}$ ) with sodium methoxide ( $1 \mathrm{drop}, 1 \mathrm{~g}$ sodium in $20 \mathrm{ml}$ methanol). Addition of acetic acid ( 1 drop) and water gave a mixture from which was separated the diester $(.25 \mathrm{~g}), \mathrm{m}_{\bullet} \mathrm{p} .187^{\circ} \mathrm{C}$, and methyl

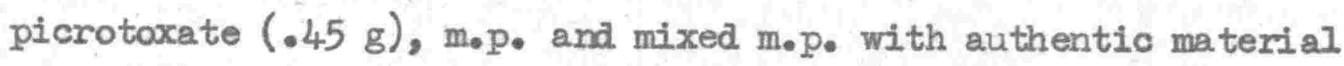
$170-1^{\circ} \mathrm{C}$. The diester did not reduce Fehling's or Tollen's reagents and did not undergo the Schlittler degradation with sodium hydroxide. The diacetate, m.p. $134^{\circ} \mathrm{C}, 59$ had inf ra-red absorption: $3492 \mathrm{~s}, 3421$ w, $1808 \mathrm{w}, 1730 \mathrm{~s}$ br, $1699 \mathrm{w}$ inflex, $1646 \mathrm{~m}, 1363 \mathrm{w}, 1350 \mathrm{w}, 1302 \mathrm{~m}, 1270 \mathrm{~m}, 1230 \mathrm{~s}$ vbr, $1170 \mathrm{~m}$, 1146 w, 1128 w, 1110 m, 1060 s, 1037 s, 1023 s, 1006 vw, 987 w, 967 m, 947 m, 927 m, 918 m, 903 s, 898 s, 856 w, 839 m, 806 w, $787 \mathrm{~s}, 750 \mathrm{w}, 725 \mathrm{w}, 717 \mathrm{vw}, 677 \mathrm{vw}, 670 \mathrm{~m} \mathrm{~cm}^{-1}$.

Periodate oxidation of dimethyl picrotoxinin dicarboxylate. The diester $(.182 \mathrm{~g})$ in ethanol $(2 \mathrm{ml})$ was treated $\left(24\right.$ hours, $\left.18^{\circ} \mathrm{C}\right)$ with a solution of periodic acid (.197 M, $3.83 \mathrm{ml}, 1.18 \mathrm{moles})$. Addition of water and ether extraction gave an intractable oil. This oil was neutral, and gave positive tests with Tollen's and Fehling's solutions. The precipitate obtained with Brady's reagent gave an intractable red oil af ter chromatography on bentonite-alumina.

Chromic acid oxidation of dimethyl picrotoxinin dicarbaxylate. The diester $(.05 \mathrm{~g})$ in acetone $(5 \mathrm{ml})$ was titrated dropwise with a solution of chromic anhydride in acid [chromic anhydride 
$(26.7 \mathrm{~g})$, conc. sulphuric acid $(23 \mathrm{ml})$, water $(70 \mathrm{ml})$, acetone $(100 \mathrm{ml})]$. When a definite orange colour remained after three minutes shaking at room temperature, the solution was diluted with water $(5 \mathrm{X})$ and extracted wi th ether. White product $(.042 \mathrm{~g}) \mathrm{m}_{\bullet} \mathrm{p} .137^{\circ} \mathrm{C}$ was obtained and was recrystallized (ethanol, ethanol-water) to give needles, m.p. $162^{\circ} \mathrm{C}$. (Found: C, 57.95; H, 6.01. $\mathrm{C}_{17} \mathrm{H}_{20} \mathrm{O}_{8}$ requires $\mathrm{C}$, 57.95; $\mathrm{H}$, 5.72. $\mathrm{C}_{17} \mathrm{H}_{22} \mathrm{O}_{8}$ requires $\mathrm{C}, 57.62 ; \mathrm{H}, 6.26 \%$ ). $\lambda \max$ $2900 \AA, \lambda \min 2500 \AA . \quad$ Infra-red spectrum: $3476 \mathrm{~m}, 1733 \mathrm{~s}$, $1699 \mathrm{~s}, 1644 \mathrm{w}, 1434 \mathrm{~s}, 1403 \mathrm{w}, 1356 \mathrm{~m}, 1307 \mathrm{~m}, 1276 \mathrm{~m}, 1251 \mathrm{w}$, $1230 \mathrm{~s}, 1207 \mathrm{w}, 1191 \mathrm{~m}, 1165 \mathrm{~m}, 1160 \mathrm{~m}, 1138 \mathrm{vw}, 1107 \mathrm{~s}, 1065 \mathrm{w}$, $1050 \mathrm{w}, 1044 \mathrm{vw}, 1023 \mathrm{w}, 1000 \mathrm{w}, 975 \mathrm{~m}, 951 \mathrm{~m}, 917 \mathrm{vw}, 899 \mathrm{~s}$, 889 w, 840 w, 806 m, 750 s, 718 w, 706 vw, 688 w, 674 w, $667 \mathrm{ww} \mathrm{cm}^{-1}$. The compound gave reducing tests with sensitised anmoniacal silver nitrate and with Fehling's solution. Oxidation with periodic acid gave an intractable oil together with much iodine. 


\section{ABSTRACT}


ABSTRACT.

The reaction between methyl $\beta$-bromopicrotoxinate and methyl magnesium iodide has been studied and a compound formulated a.s XIVII has been obtained. It is suggested that this compound is formed by rearrangement of the postulated ether link in a manner analogous to the rearrangement which occurs in the hydride reduction series.

Treatment of lithium aluminium hydride reduced $\beta$-chloropicrotoxinin with periodic acid results in the evolution of chlorine. Dehalogenation studies have shown that reduced $\beta$-chloropicrotoxinin and reduced $\beta$-bromopicrotoxinin are completely analogous. The formation of formaldehyde when reduced $\beta$-bromopicrotoxinin is treated with warm periodic acid shows that Conroy's (a) formula (XXIX) for the reduced compound cannot be correct. The structure LX is preferred. Oxidation of dimethyl picrotoxinin dicarboxylate with chromic in acetone gives an $\alpha$-ketol.

No evidence has been produced to disprove the Conroy (b) formula for picrotoxinin (XXI). 


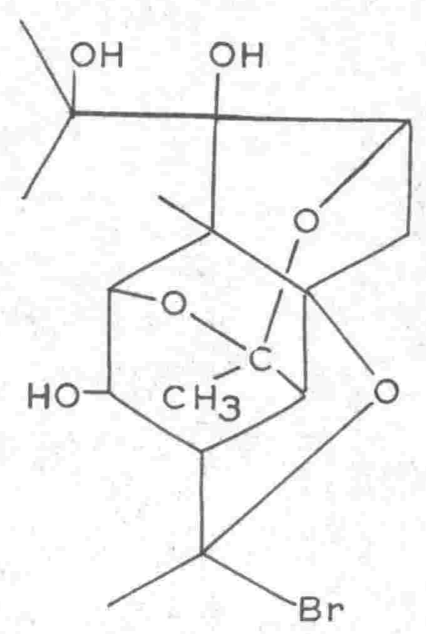

$\underline{X I V I I}$

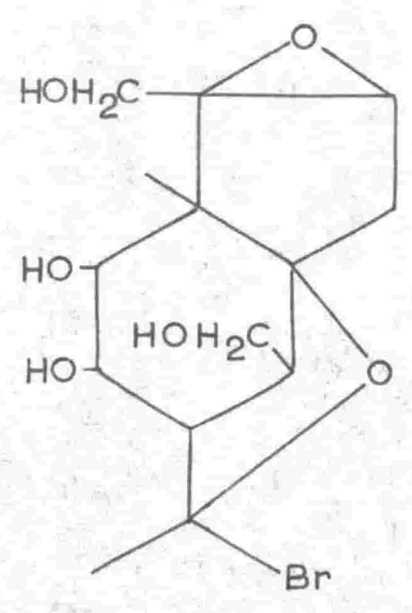

IX

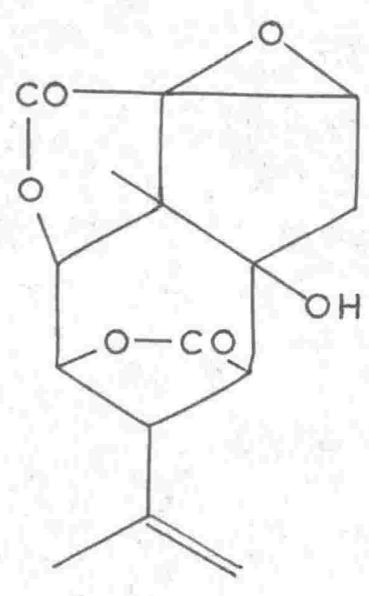

XXXI

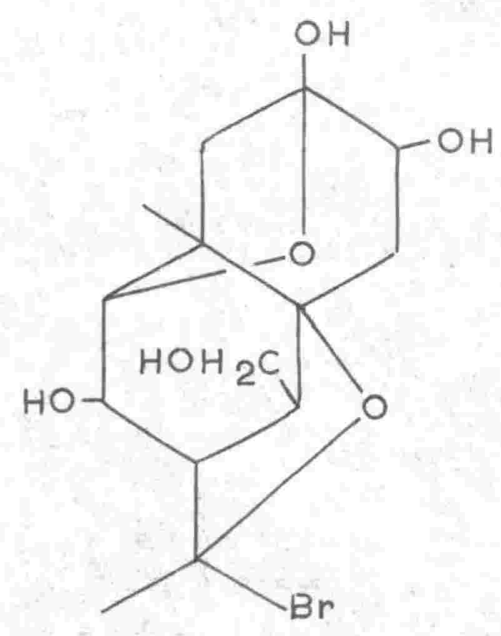

XXIX

(a) Conroy Chem. and Ind. 1957704.

(b) Conroy J.A.C.S. $73 \quad 1889$ (1951) 


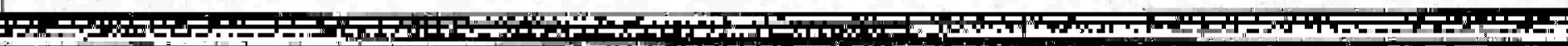

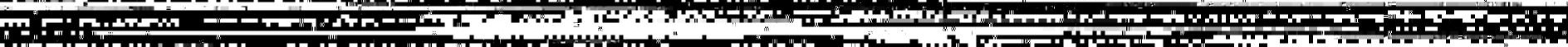

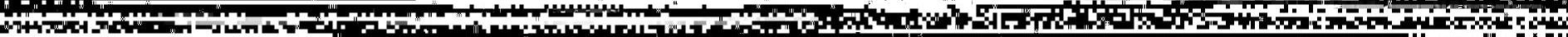
管 r.

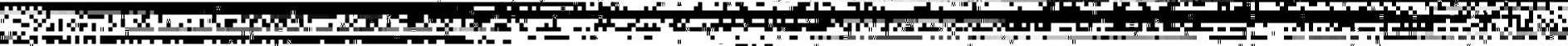

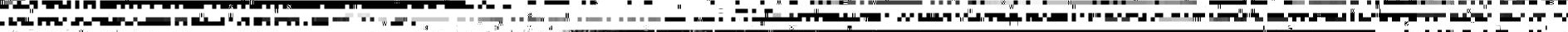

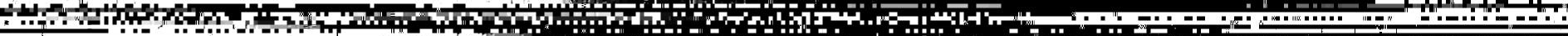
\%or 20

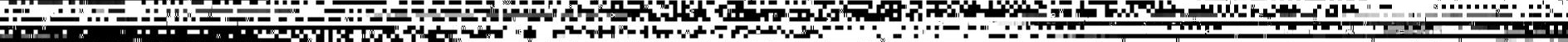

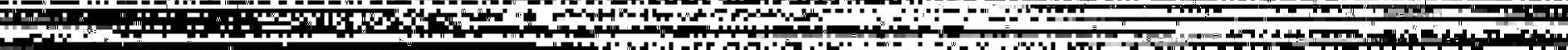

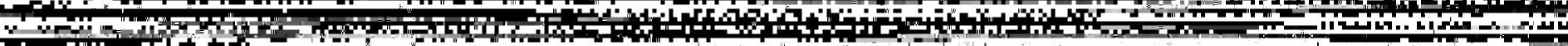
Fing

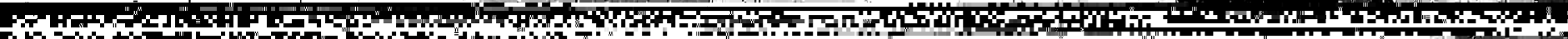
Q r. F

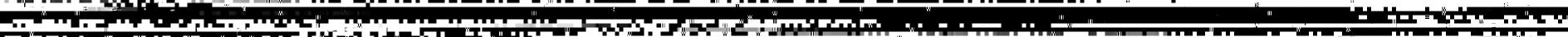

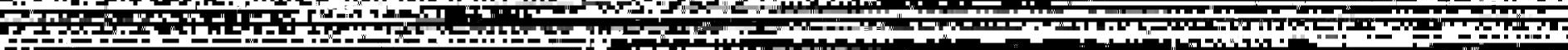

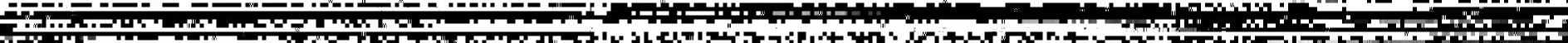

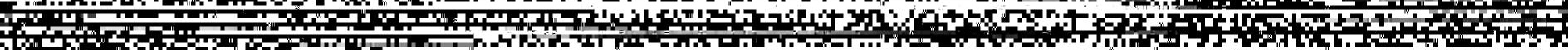

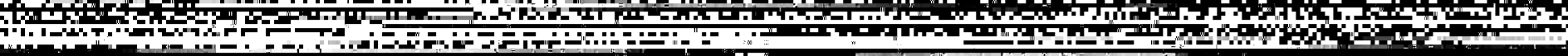
- 
ACKNOWLEDGEMENTS.

The author would like to thank the following:

Dr A.D. Campbell, University of Otago, for semimicro analytical determinations.

Mr I.R. MaDonala, Dominion Laboratory, Wellington, for infra-red determinations and assistance in their interpretation.

Dr R.B. Johns, for gifts of chemicals.

Mr R. Barbour, glassblower, Victoria University of

Wellington, for advice and technical assistance.

Professor S.N. Slater, for directing and supervising this work. Dr R.B. Johns, for valuable advice and for many helpful discussions during the course of the work. The author is also indebted to the Victoria

University of Wellington, and to the University of New Zealand who provided financial assistance in the form of a Victoria University College Research Scholarship, and a University of New Zealand Research Fellowship. 